INELEXT-97-00141

\title{
Performance Test Results of Noninvasive Characterization of Resource Conservation and Recovery Act Surrogate Waste by Prompt Gamma Neutron Activation Analysis
}

\author{
R. J. Gehrke \\ G. G. Streier
}

Published March 1997

Idaho National Engineering and Environmental Laboratory

Lockheed Martin Idaho Technologies Company

Idaho Falls, Idaho 83415

Prepared for the

U.S. Department of Energy

Assistant Secretary for Environmental Management

Under DOE Idaho Operations Office

Contract DE-AC07-941D13223 


\section{DISCLAIMER}

This report was prepared as an account of work sponsored by an agency of the United States Government. Neither the United States Government nor any agency thereof, nor any of their employees, makes any warranty, express or implied, or assumes any legal liability or responsibility for the accuracy, completeness, or usefulness of any information, apparatus, product, or process disclosed, or represents that its use would not infringe privately owned rights. Reference herein to any specific commercial product, process, or service by trade name, trademark, manufacturer, or otherwise does not necessarily constitute or imply its endorsement, recommendation, or favoring by the United States Government or any agency thereof. The views and opinions of authors expressed herein do not necessarily state or reflect those of the United States Government or any agency thereof. 


\section{DISCLAIMER}

Portions of this document may be illegible electronic image products. Images are produced from the best available original document. 


\section{EXECUTIVE SUMMARY}

During FY-96, a performance test was carried out with funding from the Mixed Waste Focus Area (MWFA) of the Department of Energy (DOE) to determine the noninvasive elemental assay capabilities of commercial companies for Resource Conservation and Recovery Act (RCRA) metals present in 8-gal drums containing surrogate waste. Commercial companies were required to be experienced in the use of prompt gamma neutron activation analysis (PGNAA) techniques and to have a prototype assay system with which to conduct the test assays. Potential participants were identified through responses to a call for proposals advertised in the Commerce Business Daily and through personal contacts. Six companies were originally identified. Two of these six were willing and able to participate in the performance test, as described in the test plan (see Part 1), with some subsidizing from the DOE MWFA.

The tests were conducted with surrogate sludge waste because (1) a large volume of this type of waste awaits final disposition and (2) sludge tends to be somewhat homogeneous. Further, because of its high density matrix, successful assay of this waste type implies that other high-density waste could be successfully assayed. Low-density waste low in high-neutron cross-section materials should be the easiest to assay. To minimize the expense of preparing and shipping the surrogate samples, the surrogates were prepared in 8-gal drums. To keep the assay expenses from becoming prohibitive, the surrogate waste was spiked with only three RCRA metals: cadmium, mercury, and lead. These elements have high, medium, and low thermal neutron cross sections, respectively. To reduce the potential for cross interference during analysis between the RCRA components in a waste matrix, mercury with a thermal neutron cross section of 375 barns, was not mixed with either lead or cadmium in the same drum. Because lead has a low thermal neutron cross section ( 0.180 barns) and cadmium has a high thermal neutron cross section ( 2,450 barns), concentrations of these two elements could be added to the same waste matrix with very small cross interference if the inelastic scatter peaks of lead are analyzed.

The surrogate concentrations of the above RCRA metals ranged from $\sim 300 \mathrm{ppm}$ to $\sim 20,000 \mathrm{ppm}$. The lower limit was chosen as an estimate of the expected sensitivity of detection required by noninvasive, pretreatment elemental assay systems to be of value for operational and compliance purposes and to still be achievable with state-of-the-art methods of analysis. The upper limit of $\sim 20,000 \mathrm{ppm}$ was chosen because it is the opinion of the author that assay above this concentration level is within current state-of-the-art methods for most RCRA constituents. The recipes for the surrogates are given in Appendix A of Part 1 of this report .

This report is organized into three parts: Part 1, "Test Plan to Evaluate the Technical Status of Noninvasive Elemental Assay Techniques for Hazardous Waste," Part 2, "Participants' Results," and Part 3, "Evaluation of and Comments on Participants' Results." Part 1, the test plan, has not been previously published as a report (the test plan, which was written before the performance test was performed, was provided, however, without the unknown surrogate elemental concentrations, to each participant). Part 2 consists of the participants' reports in their entirety. Part 3 provides an evaluation of each participant's report along with their scores, and also contains the conclusions and recommendations.

For the reader interested only in the conclusions derived from the performance test, only the Executive Summary need be read. 
If the reader is interested in the purpose of this project, organization of the test, personnel responsibilities, preparation of the surrogate samples, quality objectives, analytical methods, and management of residual waste, Part 1 should be read. Preparation of the surrogates including recipes are provided in Appendix A of Part 1. The reporting form to be used by the participants is given in Appendix B of Part 1. The instructions to the participants and the grading criteria are given in Appendix $C$ of Part 1 .

For readers interested in the participants' reports, information such as the contact person and phone numbrrs, experimental configuration, cost of equipment, assay methods, and specific results is in Part 2.

Part 3 is an evaluation of and comments on the participants results along with their score. It also provides discussion of the results, conclusions, and recommendations.

The Westinghouse Science and Technology Center scored the highest on the performance test with a score of 142.1 points out of a possible 184.9 points. They successfully identified the presence of RCRA elements cadmium, mercury, and lead in all of the blind samples. Further, they made no incorrect identification of elements that were not present (Drum 7 contains no lead). They also quantified these elements in all but one drum (Drum 5 for cadmium) to within $\pm 20 \%$ for a total percent score of $76.9 \%$.

The Special Technology Laboratory found that the use of a NaI(TI) detector with its poorer energy resolution relative to a Ge detector hampered its ability to identify, much less quantify, the RCRA elements at the concentrations provided in this test. The Special Technology Laboratory also claimed that the presence of the RCRA metals in the form of sulfides also hampered their ability to identify the RCRA elements of cadmium and lead. Sulfur has prompt gamma rays in the energy regions near several of the prompt gamma rays emitted from cadmium and lead. Because sulfur has a much lower thermal capture cross section than cadmium and no sulfur was present in the surrogate matrix above trace quantities, it is difficult to understand how the sulfide compounds of cadmium hampered their detection. Sulfides of cadmium, mercury, and lead were chosen because they are the best compounds of these elements to ensure passage of the toxicity characterization leaching procedure (TCLP) test for eventual land-fill disposal of the samples. For this reason, sulfides were used to prepare the surrogates. As a result, in part because of the above limitations and the much lower fluence of the Special Technology Laboratory source (i.e., $3 \times 10^{6}$ neutrons/second versus $1 \times 10^{7}$ neutrons/second), none of the reported results met the requirements for the awarding of points of less than 20\% deviation from the "known" concentration for any of the three elements. Even the identification of which RCRA elements were present was incorrect about as often as it was correct.

No attempt was made by the Special Technology Laboratory to measure the mercury concentrations because the associated particle imaging (API) technique that the laboratory used to image the waste was primarily designed to detect the presence of bulk quantities. The API technique also is severely limited in its present configuration to quantitatively assay for low concentrations of RCRA elements. This is because of the deliberate lack of moderating material surrounding the sample being irradiated with $14 \mathrm{MeV}$ neutrons and the very poor high-energy neutron cross section of mercury.

Grading the results using Table 1 of the Special Technology Laboratory report (see Part 2) and the comments in the text of its report is difficult because no provision was made for subtracting incorrect identifications and about half of the reported identifications were incorrect. Only correct positive identifications were awarded points. Correct identification of an etement not being present was not awarded 
points.) With this in mind, the total score for Special Technologies Laboratory is 10 points. A total of 48 points is possible for correctly identifying all RCRA elements present in the blind surrogates.

From these tests, the Westinghouse Science and Technology Center demonstrated that (1) for cadmium the lower limits of detection (LLDs) of 9 and $15 \mathrm{ppm}$ have been achieved for acquisition times of 2,000- and 600-second counts, respectively; (2) for mercury, LLDs of 115 and $170 \mathrm{ppm}$ have been achieved for 2,000and 600-second counts, respectively; and (3) for lead, LLDs of 4,400 and 8,600 ppm have been achieved for 2,000- and 600-second counts, respectively. The detection limits of other RCRA elements undergoing thermal capture can be estimated from a ratio of the macroscopic cross sections, $\Sigma$, of one of the above elements (e.g., mercury) times its respective prompt gamma-ray emission probability, $P_{\gamma}$, to that of the element in question. Quantitative measurements of mercury and cadmium were performed at $\sim 350 \mathrm{ppm}$ concentration level to an accuracy of less than $20 \%$. Quantitative measurements of lead were performed by the analysis of the 1,063-keV gamma-ray peak from the decay of the activated 810-millisecond isomer of ${ }^{207 \mathrm{~m}} \mathrm{~Pb}$. Elements identified by the participants in the blank surrogate drum by noninvasive PGNAA include hydrogen, iron, calcium, silicon, aluminum, oxygen, and possibly chromium. The concentrations of these matrix elements are reported in Part 1.

The LLDs reported by the Special Technology Laboratory are at or above $1 \%$ for cadmium and lead with no value reported for mercury.

From the performance test conducted, it is obvious that PGNAA holds great promise in the assay of RCRA elements present in bulk material and containerized waste. Though analyses at free release limits were not the objective of this test and have not been achieved, quantification of RCRA metals at concentration levels useful for the purpose of waste treatment, process control, and verification have been demonstrated by the Westinghouse Science and Technology Center at concentrations down to $\sim 350 \mathrm{ppm}$ with an accuracy of $20 \%$. With improvements to the present experimental configuration and analysis methodology, even lower concentrations of these elements may be measurable.

If PGNAA is to be used for waste assay during cleanup of the DOE complex, it is time for DOE to fund the building of a full-scale demonstration PGNAA facility for full-size 55-gal drums and for the assay of loose waste material. Further, the winning participant is interested in building or participating in a collaborative effort with a major manufacturer of ionizing radiation measurement instrumentation and systems to build such a facility. This facility would be used to further explore the ability to assay other waste forms, improve the sensitivity, and develop advanced methods including modeling for the assay of nonhomogeneous matrixes. Large sums of money could be saved with use of PGNAA by reducing or eliminating the need for sampling and laboratory analysis. The savings can be realized throughout waste handling, treatment, and disposal processes if PGNAA is developed to its full potential.

a. The macroscopic themal neutron capture cross section is $\Sigma=(\sigma) / A$ whereo is the microscopic thermal capture cross section, and $A$ is the atomic number. The ratio with which to scale the LLD of mercury to determine the LLD for silver, for example, is $\Sigma(A g)\left(P_{A g}\right) \sqrt{\Sigma}\left(H_{g}\right)\left(P_{H_{7 y}}\right)=0.0473$. Therefore, the LLD for silver for a 2,000-second count with the Westinghouse system is deduced to be $(115 \mathrm{ppm}) 0.0473=2,428 \mathrm{ppm}$. 


\section{ACKNOWLEDGMENTS}

The authors wish to acknowledge Mark Hollingbrook and Ronald Chessmore of Rust Geotech for developing the surrogate recipes and for the preparation of the blank, calibration, and blind surrogate waste. The authors thank Kliss McNeel, Dirk Gombert, M. J. Connolly, P. M. Castle, and S. J. Priebe for reviewing the test plan or the final report or both, and P. A. Tucker for her thorough technical edit of the final report. The reviewers' comments are greatly appreciated. Finally, we wish to thank the companies that participated in this test, the Westinghouse Science and Technology Center and its technical contact for the project, Abdul Dulloo, and the Special Technology Laboratory and its contact for the project, James Tinsley. This test could not have been conducted and the status of the technology could not have been evaluated without their participation.

This project was funded by the Department of Energy Office of the Mixed Waste Focus Area. 


\section{CONTENTS}

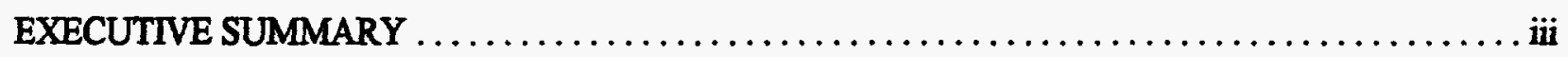

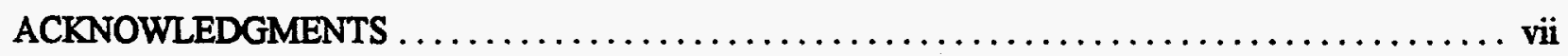

PART 1-Test Plan to Evaluate the Technical Status of Noninvasive Elemental Assay Techniques for Hazardous Waste

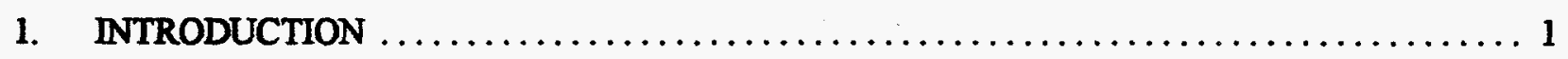

2. ORGANIZATION AND RESPONSIBIUTIES $\ldots \ldots \ldots \ldots \ldots \ldots \ldots \ldots \ldots \ldots \ldots \ldots \ldots \ldots$

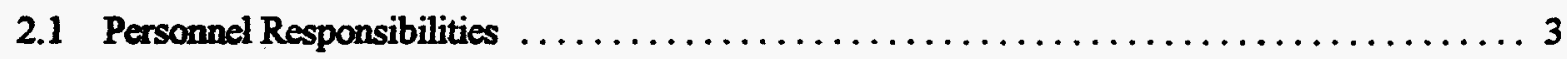

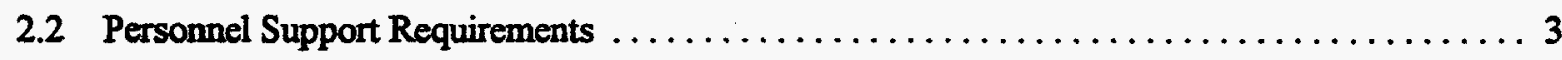

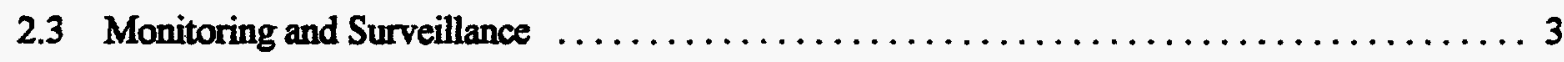

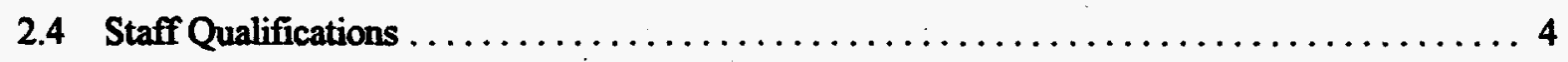

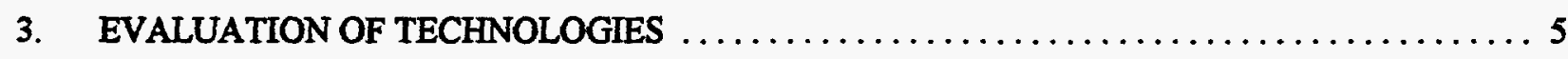

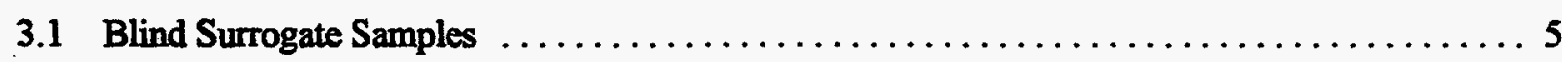

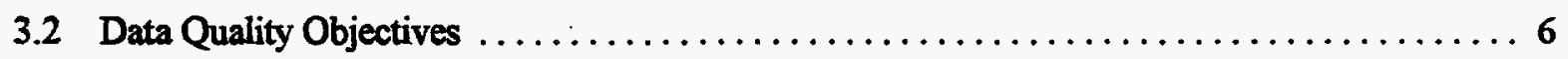

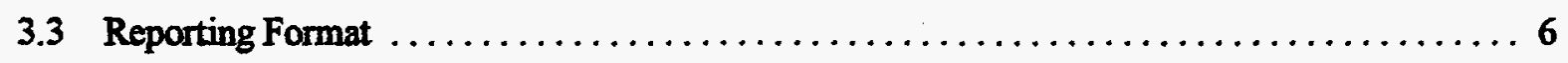

4. SEQUENCE OF ACTIVITIES $\ldots \ldots \ldots \ldots \ldots \ldots \ldots \ldots \ldots \ldots \ldots \ldots \ldots \ldots \ldots \ldots \ldots$

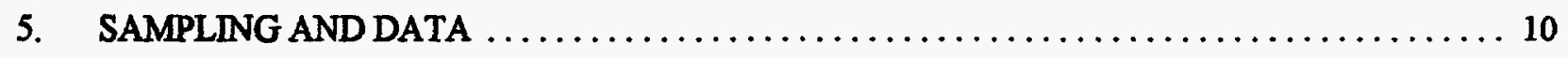

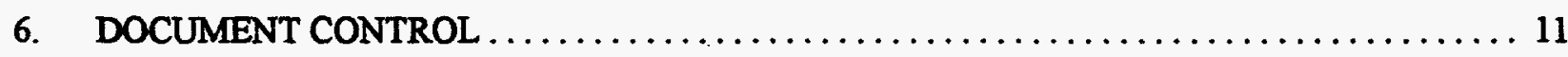

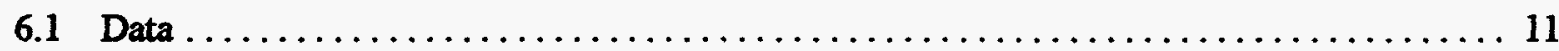

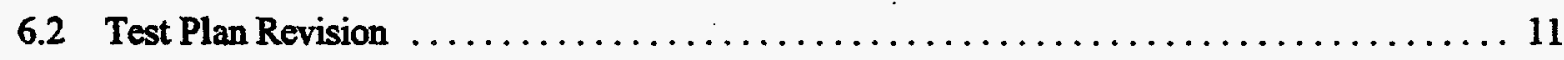

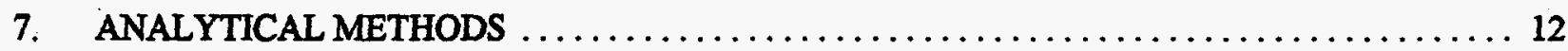

8. DATA REDUCTION, VALIDATION, AND VERIFICATION $\ldots \ldots \ldots \ldots \ldots \ldots \ldots \ldots$

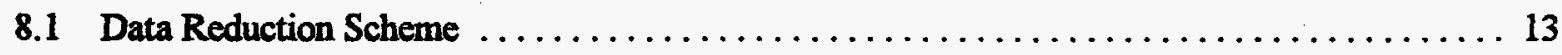

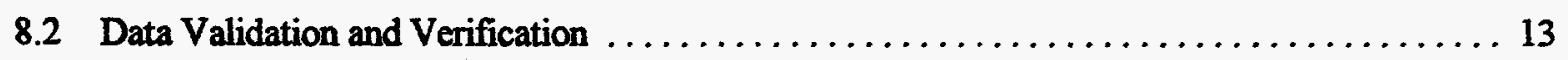


8.3 Data Reporting

9. QUALITY ASSURANCE AND QUALITY CONTROL METHODS 14

10. EQUIPMENT AND INSTRUMENTS 15

11. SUPPLIES, UTILITIES, AND FACILITIES 16

12. HEALTH AND SAFETY 17

13. RESIDUALS MANAGEMENT 18

14. REFERENCES 19 Appendix A-Preliminary Report on the Preparation of Simulated Waste Drums Appendix B-Reporting Form Appendix C-Instructions to Participants

PART 2-Participants' Reports

Report of Analytical Results-Westinghouse Science and Technology Center 39

Report of Analytical Results-Special Technologies Laboratory 96

PART 3-Evaluation of and Comments on Participants' Results

1. EVALUATION OF PARTICIPANT PERFORMANCE 113

2. SELECTION CRITERIA FOR "BEST" ASSAY SYSTEM 115

2.1 Westinghouse Science and Technology Score 115

2.2 Special Technology Laboratory Score 116

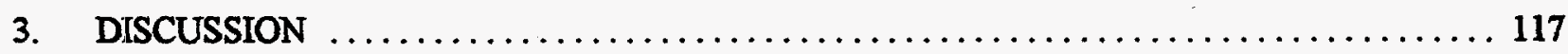

4. CONCLUSIONS AND RECOMMENDATIONS $\ldots \ldots \ldots \ldots \ldots \ldots \ldots \ldots \ldots \ldots \ldots \ldots$

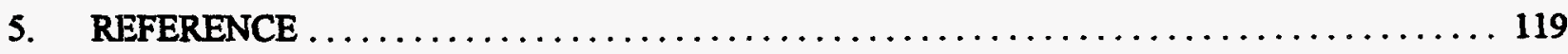




\section{Test Plan to Evaluate the Technical Status of Noninvasive Elemental Assay Techniques for Hazardous Waste}

\section{INTRODUCTION}

The U. S. Department of Energy (DOE) has accumulated a variety of mixed, hazardous, and radioactive waste." Thermal treatment is being considered for many types of mixed waste because of the ability of thermal treatment to destroy hazardous organic constituents, reduce the volume and mass of solid waste, and provide a durable solid waste form. Thermal treatment of mixed waste can be carried out in a safe manner that poses no threat or impact to workers, the public or the environment. Under the Federal Facilities Compliance Act, DOE mixed waste treatment facilities must meet all applicable regulations and permitting requirements imposed by the U. S. Environmental Protection Agency (EPA) and individual states. Hazardous constituents are regulated under the EPA Resource Conservation and Recovery Act (RCRA), whereas radioactive constituents at DOE sites are regulated by DOE.

In its regulation of hazardous waste, the EPA, under RCRA (40 CFR 264, Subpart B), requires that a facility conduct sufficient waste analysis of "representative" samples to verify that the waste feed to the incinerator is within the physical and chemical limits specified in the facility operating permit. These analyses shall be accurate and up to date. Of the various operating parameters, the feed rate limits for metals, chlorine and chlorides, and ash are key elements for which facilities must maintain records to demonstrate compliance. In addition, characterization of the waste for the heating value and the organics expected to be in the waste is encouraged or required. The waste characterization activities, as described above, shall be contained in a waste analysis plan (WAP).

To ensure proper thermal treatment of hazardous, mixed low-level, and mixed transuranic (TRU) waste, EPA regulations and individual facility operating permits establish limits on operating parameters and emissions including those for off-gas releases. Waste analysis requirements specifically for incinerators are contained in 40 CFR 264, Subpart O, and in the facility's operating permit. The limits ensure that the maximum levels of emissions of the constituents of concern from the thermal treatment units are below the maximum acceptable levels considered to be of public health concern. To demonstrate this, air dispersion modeling and emissions testing are used to establish operating limits for a facility to ensure that its emissions do not exceed regulatory levels. Emissions tests are conducted during the trial burn for thermal treatment

a. Waste is hazardous if it is "listed" by the U.S. Environmental Protection Agency or exhibits any of the characteristics of ignitability, corrosivity, reactivity, or toxicity. Waste is radioactive if it has smearable or fixed radioactive contamination as specified in the DOE Radiation Control Manual. Waste is mixed when it is hazardous and radiosetive.

b. "Representative" is defined as a sample of the universe or the whole that can be expected to exhibit the average properties of the waste universe. The waste analysis must be repeated as necessary to ensure that it is accurate and up to date. 
units attempting to obtain operating permits. Mass balances are calculated from the waste input, secondary waste streams, emissions, and solid product waste.

On-stream, noninvasive, elemental assay of feed stock for RCRA heavy metals and other key elements (e.g., chlorine) in hazardous, mixed low-level, and mixed TRU waste is proposed to supplement or replace the analysis of grab samples. Noninvasive assay has several advantages over batch sampling and analysis. The advantages of noninvasive assay include reducing hazards by avoiding the opening of sealed containers and eliminating the direct handling of waste. With bulk noninvasive elemental assay of 55-gal drums, sampling can be effected through drum rotation and scanning along the vertical axes of the drums. Other advantages of noninvasive assay over batch sampling include the performance in near real-time of elemental assays covering, in one assay, a significant portion or all of the container instead of individual sample assays covering only a small fraction of the container (when only a small fraction of the container is sampled). With sampling and laboratory analyses, special composite sampling techniques may be required. The sensitivity and potential accuracy of noninvasive elemental assay systems for waste streams being routed for thermal treatment have not been evaluated for either homogeneous or nonhomogeneous samples contained in 55-gal drums.

This RCRA waste characterization performance test project will focus on the identification, testing, and develojment of technologies for the characterization of RCRA metals. The work in the project is directed toward the Plasma Hearth Project (PHP) even though the intent is to provide characterization support for all treatment options. Though obtaining EPA acceptance (and approval for use) of noninvasive elemental assay techniques is beyond the scope of the project, data to verify calibration techniques, representative sampling, and accuracy will be required before acceptance by the EPA.

The purpose of the performance test project is to locate and evaluate characterization technologies that have been developed into prototype systems and can provide information noninvasively on RCRA constitutents in solid containerized waste as required for treatment and disposal. The initial portion of the project will be to establish the program, identify capable participants, develop blind sample drums containing selected RCRA metals with their concentrations unknown to the participants, and test suitable technologies for the assay of containerized waste for Resource Conservation and Recovery Act (RCRA) waste products. From an initial survey of noninvasive elemental assay techniques for the assay of solid and liquid containerized waste, prompt gamma analysis techniques show the greatest potential for success. Therefore, the performance test project will focus on prompt gamma analyses. The radioactive portion of the waste stream will be determined by technologies currently being funded by DOE for the assay of containerized TRU waste to be shipped to the Waste Isolation Pilot Plant (WIPP).

If no participants are identified, a report summarizing the activities of the performance test project will be submitted to the DOE Mixed Waste Focus Area (MWFA) 2 months after the solicitation of interest activities end. Reasons for lack of participation shall be reported to the extent possible. 


\section{ORGANIZATION AND RESPONSIBILITIES}

The purpose of the performance test project work, sponsored by the DOE Office of Technology Development (OTD), Mixed Waste Focus Area (MWFA), at the Idaho National Engineering and Environmental Laboratory (INEEL), is to develop a quantitative method for the assay of containerized mixed and hazardous waste for RCRA metals. The organizational affiliations and responsibilities of the key personnel involved are listed in Section 2.1. Personnel from the Radiation Physics Products Department of Lockheed Martin Idaho Technologies Company (LMTCO), the DOE contractor for the INEEL, will evaluate all measurements from the blind tests.

\subsection{Personnel Responsibilities}

R. J. Gehrke, the principal investigator (PI), is responsible for the overall scientific development of the evaluation of prompt gamma neutron activation analysis (PGNAA) technologies. He has 30 years of experience in basic and applied research in $\mathrm{X}$ - and gamma-ray spectrometry, and his reports have been published in more than 60 journal publications. He has more than 5 years of experience in the development and use of PGNAA.

G. G. Streier, the project manager (PM), is responsible for the overall management of the project including the budget, weekly and monthly reports, and the call for proposals. He also will assist the PI in the development of test plans, data quality objectives, performance criteria to be tested, and other additional reports or presentations that are requested.

Kliss McNeel is a resource for regulations governing the thermal treatment of mixed and low-level radioactive waste and the effluent created from such treatment. She also is responsible for reviewing those sections of test plans, reports, and presentations that specify the regulations to be followed.

Dirk Gombert is a resource for the operation of thermal treatment facilities. He also is responsible for reviewing those sections of test plans, reports, and presentations that refer to technical specifications related to the assay of RCRA metals in any thermal treatment of waste.

Ronald Chessmore, of Rust Geotech, Grand Junction, Colorado, is responsible for the preparation and spiking of the surrogates. Ronald has more than 20 years of experience in the preparation of samples spiked with various elements or radionuclides or both that can be used as calibration samples, working standards, or blind samples.

\subsection{Personnel Support Requirements}

All assay measurements including applicable compliance to regulations, setup, procedures, and calibration of the equipment are the responsibility of the participant. The INEEL staff will provide guidance so that useful information about preparation and disposal of the surrogate samples (exclusive of the RCRA metal content of the blind samples) and the applications being considered for noninvasive, elemental assay can be made available to the participants. A reporting form shall be provided to all participants so that all data can be reported in a consistent format for equitable evaluation by the PI, PM, and supporting staff. 


\subsection{Monitoring and Surveillance}

Monitoring of the participants' measurement activities will be provided by the INEEL staff overseeing the project. Overall oversight is the responsibility of the PI and PM with assistance from Kliss McNeel and Dirk Gombert.

\subsection{Staff Qualifications}

The qualifications of the INEEL PI are stated in Section 2.1 while the qualifications of the technical staff of the participating laboratories will be stated in the laboratory proposals and the participant reporting form. 


\section{EVALUATION OF TECHNOLOGIES}

To qualify for participation in the performance test project, an actual prototype instrument capable of performing noninvasive elemental assays shall be assembled. The instrument being evaluated for further development shall be at least capable of assaying the blind samples at the quoted lower limit of detection (LLD) with a 2,000-second real-time count. Systems that can achieve an LLD of $300 \mathrm{ppm}$ for the RCRA metals under test with a 600-second real-time count are ultimately preferred. If counts are for a given live time, they should be chosen to ensure that the selected real time (i.e., 600 -second or 2,000-second times) is not exceeded.

EPA, DOE, and state regulations, that provide waste analysis guidance for facilities that burn hazardous waste, are being used to provide guidance in addressing the work scope of the present project. The elemental analysis capabilities being addressed are to assist waste treatment and disposal activities in meeting DOE, EPA, and State of Idaho regulations.

\subsection{Blind Surrogate Samples}

To evaluate the capabilities of state-of-the-art PGNAA technologies for noninvasive elemental assay, it is necessary to develop a set of surrogate samples comprising waste matrices containing RCRA metals that will be encountered by thermal treatment units. Initial waste streams being targeted for PHP treatment are organic and inorganic sludges, combustible, and heterogeneous waste. These surrogate waste samples shall simulate actual hazardous and mixed low-level and TRU waste in all aspects with the exception of containing hazardous volatile organics or entrained radioactive material. Future surrogate waste drums will be designed to permit insertion of encapsulated radioactive sources in dry wells strategically placed in the surrogate. These sources would be removed for shipment or storage of the surrogate waste drums. The initial test will be without the addition of encapsulated radioactive sources and will not be constructed with dry wells. In developing the blind surrogate waste, the series of Mixed Waste Integrated Program reports on thermal treatment technologies (Bostick et al. 1994; Chang et al. 1994) have been referenced, as have certain industry reports (SAIC 1995). However, because of the special requirements of a surrogate waste drum for evaluating characterization technologies (e.g., long-term stability), the surrogates prepared for these tests differ significantly from those prepared for use in a trial burn.

The blind waste samples provided by LMITCO will consist of a surrogate waste matrix contained in an 8-gal drum with spikes of known quantities of RCRA metals that are unknown to the participant. The matrix components and recipes to prepare them, excluding RCRA metals, are given in Appendix A. Only homogeneously distributed amounts of the RCRA metals will be prepared. The homogeneously mixed samples will be distributed throughout the matrix and chemically or physically bound to prevent unintentional stratification of the RCRA metals. A key goal of each instrument being evaluated is that it be capable of assaying blind surrogates containing, individually or together, concentrations of the cadmium, mercury, and lead down to 300 ppm.

The surrogates will be prepared in accordance with the EPA toxicity characteristic leaching procedure (TCLP) and thereby qualify for disposal in a landfill. It is also the intention to develop surrogate waste samples, whenever possible that could qualify for use in trial test burns. Some modifications from trial test burn surrogates have been necessary to incorporate the considerations of importance for surrogates intended 
primarily for RCRA metals characterization before treatment (e.g., elemental assay of matrix materials, long-term stability, and homogeneity). The requirement for the surrogates to be prepared in accordance with the TCLP to permit landfill disposal will result in their being encased in cement. Unlike the surrogates prepared for trial burns, the concentrations of the RCRA metals will be allowed to vary from the $\sim$ 2,500-ppm level used for the trial test burn surrogates (Chang et al. 1994). The surrogates being prepared for RCRA metals characterization will contain spikes of one or more of the RCRA metals that will cover a range from $\sim 300 \mathrm{ppm}$ to $\sim 20,000 \mathrm{ppm}$. The lower limit was chosen as an estimate of the expected lower limit of detection needed by noninvasive, pretreatment elemental assay systems to be of value for operational and compliance purposes. The upper limit of $20,000 \mathrm{ppm}$ was chosen because it is the opinion of the PI that assay above this concentration level is within the current state-of-the-art for most RCRA constituents.

\subsection{Data Quality Objectives}

The following data quality objectives (DQOs) have been chosen for the performance test project.

- For an elemental concentration to be considered detected, the primary signal for a given element assay shall have an estimated standard deviation of less than $35 \%$ for the combined uncertainty in the "signal" (i.e., counting statistics and the peak fitting uncertainty), which should be equivalent to an LLD as defined by L.A. Currie (1968). The goal is the detection of all RCRA metals added to the samples down to the lowest concentration level in a blind sample when real-time counting periods are for 600 seconds or for 2,000 seconds.

- For an elemental concentration to be considered quantified, the primary signal shall have an estimated standard deviation of less than $20 \%$. The total uncertainty for a quantified measurement should be less than $25 \%$ with the estimated standard deviations combined in the normal statistical manner (i.e., in quadrature). All quantified RCRA metal concentrations shall be known to be less than $25 \%$.

- The experimental geometry shall be reproducible and recorded with the help of a sketch showing the locations of the source, sample, any detectors, and shielding or moderating material. The uncertainty component because of the nonreproducibility in the experimental geometry should not be greater than $5 \%$. (Verification can be demonstrated through sequential assays of the blind sample by removing and reinserting it in the same orientation into the assay configuration.) This information shall be provided in the participant reporting form.

\subsection{Reporting Format}

To perform an equitable evaluation of the performance of all participants in the performance test project, it is important that the same information and reporting format be received from the participants of the performance test. This will be done by providing the participants with a reporting form (see Appendix B).

c. For the definition of total uncertainty and how it is propagated (see Part 1, Section 14, ANSIN42.14-1991 and Taylor and Kuyatt 1993.) 
A completed reporting form will contain information about the type of instrumentation, type of control and analysis computer, utilities required, footprint dimensions, cost of equipment, sensitivity, accuracy, analysis time per sample (i.e., count plus spectrum analysis), calibration method, analysis methodology, data results, and an estimate of robustness of the instrumentation.

The reporting form requires participants to document all pertinent information from calibration data, background data, sample analysis data, replicate analyses, a listing of the analysis equations or reference to the modeling method employed. The reporting form also requires an estimate of the uncertainty components, systematic errors, the method used to combine the uncertainty and error components, and the total uncertainty for each result. This information should help INEEL staff validate the results. Participants should be prepared to furnish spectral plots of the acquired data, including background counts, of sufficient resolution to allow visual verification of detected peaks associated with the RCRA constituents. 


\section{SEQUENCE OF ACTIVITIES}

The outlined activities for the performance test project work scope follow.

1. Obtain approval of the environmental checklist.

2. Develop the formulations for a set of waste surrogates for testing noninvasive elemental assay technologies for RCRA metals. Several surrogates will be prepared to cover a range of concentrations ( $\sim 300$ to $\sim 20,000 \mathrm{ppm})$ for cadmium, mercury, and lead. Recipes for the surrogate matrixes are given in Appendix A.

3. Develop the DQOs, and reporting requirements for evaluating specific assay systems participating in the tests (see Section 3 for list of DQOs).

4. Place a call for proposals advertisment in the Commerce Business Daily. Locate potentially applicable technologies through this call to industry.

5. Publish the test plan. The test plan includes recipes for preparing surrogate samples (Appendix A), the reporting form (Appendix B), and instructions for all participants (Appendix C). The test plan incorporates the basic purpose, minimum requirements for participation in the test, DQOs, performance requirements, and reporting requirements.

6. Respondents to the call for proposals will be evaluated through the assay of a set of blind surrogate samples (prepared above). Interested participants from the DOE laboratory complex and universities may participate in follow-on measurements. The assays will be performed at the participant's facility.

7. Based upon the selection criteria listed in Appendix C, "Instructions to Participants," one or two participants will be selected, contingent upon continuing need for noninvasive RCRA materials assay, available funding, and the results of the performance test to further develop their technology for on-stream, near-real-time, noninvasive, elemental assay of containerized waste for RCRA metals prior to thermal treatment. These criteria will address speed of analysis, turnaround time for results, accuracy, sensitivity, and equipment cost and will be quantitatively rated by priority and capability.

8. If no participants are identified from the call for proposals in the Commerce Business Daily, the PI will contact commercial companies known to be developing PGNAA systems for elemental assay to learn why the companies did not participate. If lack of funding is the reason, potential funding for participation will be discussed with the MWFA. If the present technology is unable to achieve the sensitivity required to successfully assay the blind samples, discussions with experts in PGNAA within the DOE and contractor arena and within the commercial sphere will be held to determine whether the sensitivity is achievable with further development. 
9. Noninvasive elemental assay systems at DOE and university laboratories may be evaluated in future performance tests based on the results of this first test. This activity will be pursued only if the results of the commercial tests are discouraging, or a DOE or university laboratory has demonstrated significant advancement of the state-of-the-art relative to the commercial laboratories.

10. Ultimately, the selected noninvasive elemental assay technology will need to be made commercially viable with demonstrated capability to assay the RCRA metals at the concentrations required for process control or to meet the release limits of the facility permit. These concentrations will vary from facility to facility and from state to state. Further development of the selected technology is planned to proceed under MWFA funding.

11. A progress report of each year's annual activities will be published. 


\section{SAMPLING AND DATA}

The MWFA is pursuing the development of noninvasive elemental assay technologies for containerized waste prior to thermal treatment. Sampling for this data is not planned. 


\section{DOCUMENT CONTROL}

\subsection{Data}

Participants in the noninvasive elemental assay performance test carried out on surrogate waste samples in 8-gal drums shall complete the reporting form (Appendix B) and be willing to make available the entire data package to allow the PI to validate the data. All information (including raw data, analysis methods, and results) provided by the participants shall be treated as LMITCO proprietary material unless permission is granted by the participants for general release to the technical community and public. The reporting form also requests information that demonstrates that a quality program incorporating all of the essential ingredients (e.g., procedures, calibration of instrumentation, quality control checks, training, and document control) was implemented and followed during the measurement of the blind samples.

\subsection{Test Plan Revision}

This test plan, including the appendices, will be revised as required and controlled by the PI responsible for the performance test. Only the PI can authorize deviations from the test plan. When a deviation has been authorized, the deviation must be communicated to all of the participants. When the same circumstances exist for other participants, they also will be allowed to take advantage of authorized deviations.

A deviation from the test plan will be documented by a memorandum from the PI to the PM and the participants. Further, concurrence by the PM will be required prior to implementing any changes in this test plan. 


\section{ANALYTICAL METHODS}

Each participant will be responsible for the calibration of his/her own assay instrumentation. Four drums containing known amounts of mercury and three drums containing known amounts of cadmium or lead will be furnished to each participant for calibration. A blank surrogate for each sample type, composed of the same matrix but not containing any added RCRA elements, also will be provided to the participants. Recipes for the surrogate matrixes, exclusive of specific quantities of RCRA metals, are given in Appendix A. An assay of residual RCRA mercury, cadmium, and lead metals present in the blank surrogate will be provided to all participants receiving blank surrogates. The concentrations of any high cross-section metals or halogens present in the surrogates also will be provided to the participants. All analytical methods used in the analysis of samples shall be detailed on the participant reporting form. 


\section{DATA REDUCTION, VALIDATION, AND VERIFICATION}

\subsection{Data Reduction Scheme}

Participants shall incorporate into procedures all analytical and data reduction methods, along with any calibration methods, used to assay the surrogate samples and shall describe such methods on the participant reporting form. Participants should report samples with RCRA element concentrations that fall below estimated detection limits, or the measured result and its uncertainty, in the participant reporting form. For the surrogate assay, any element concentration for which the statistical uncertainty, in the primary signal (in a respective peak area), is greater than $35 \%$ will be considered below the LLD and should not be identified in the reporting form. Quantitative detection will require measurement of the signal (i.e., associated peak area) to an uncertainty of less than $20 \%$. Element concentrations with a statistical uncertainty greater than $20 \%$ but less than $35 \%$ will be considered detected but not quantifiable.

\subsection{Data Validation and Verification}

All data will be reviewed and verified by a second analyst from the participant organization responsible for the performance test, assay results, and participant's report. This activity shall be performed before the participants submit the participant reporting form. Any DQOs that are not met or variations in the requested reporting of results will be identified by participants in the participant's report. The participants shall document any methods that they used for the performance test project.

\subsection{Data Reporting}

Data collected during participation in the performance test of the surrogate samples will be evaluated, peer reviewed, and documented by the participant on the reporting form (Appendix C). 


\section{QUALITY ASSURANCE AND QUALITY CONTROL METHODS}

Participants will document on the participant reporting form the quality control measures that the participants used during the analysis performance test with the surrogate samples.

Participants will maintain quality control by establishing that the equipment is working properly before and during the test. Methods will be used by each participant to measure and verify that (1) the analytical instrumentation is operating correctly, (2) the analysis routines measure the gain and zero intercept, and (3) the PGNAA or other systems are calibrated for the elemental assay of cadmium, mercury, and lead from $\sim 20,000 \mathrm{ppm}$ down to $\sim 300 \mathrm{ppm}$. Changes in key instrumentation will be identified as such in the log book. Copies of the participants' log book shall be made available to the PI upon request. 


\section{EQUIPMENT AND INSTRUMENTS}

Each participant shall document on the reporting form a complete list of the pieces of equipment and instruments that the participant used during the performance test at a level of detail useful for the performance test project without infringing upon any intellectual property of the participant. 


\section{SUPPLIES, UTILITIES, AND FACILITIES}

Each participant shall document on the reporting form the supplies, utilities, and special facilities that the participant used during the performance test. 


\section{HEALTH AND SAFETY}

The participants shall perform all measurements for the performance test in a safe manner and within all applicable federal and state regulations. 


\section{RESIDUALS MANAGEMENT}

There will be no residuals to manage by any of the participants because the custodianship of the surrogate samples will remain with Rust Geotech, Grand Junction, Colorado. Upon completion of a performance test, the participant shall return the surrogate drums to Rust Geotech. When the useful life of the surrogate samples has been served, they either will be disposed of by Rust Geotech or their custody will be transferred to the LMITCO for the INEEL for use as surrogates in trial burns or other follow-on activities. Disposal or future use of any calibration samples prepared by the participant to calibrate or test instrumentation will remain the property and responsibility of the participant. 


\section{REFERENCES}

ANSI N42.14-1991, "Calibration and Use of Germanium Spectrometers for the Measurement of Gamma-Ray Emission Rates of Radionuclides," American National Standards Institute, October 30, 1991.

Bostick,W. D., et al., 1994, Surrogate Formulations for Thermal Treatment of Low-Level Mixed Waste, Part II: Selected Mixed Waste Treatment Project Waste Streams, Report DOE/MWIP-16, January.

Chiang, J. M., et al., 1994, Surrogate Formulations for Thermal Treatment of Low-Level Mixed Waste, Part III: Plasma Hearth Process Testing, Report DOE/MWIP-17, January.

L. A. Currie, 1968, "Limits for Quantitative Detection and Quantitative Determination," Analytical Chemistry, Vol.40, p. 586.

SAIC, 1995, Feed Material Handling and Waste Disposition Plan for the Radioactive Bench-Scale Plasma Hearth Process System, Report No. SAIC-94/1159, Science Applications International Corporation, May.

Taylor, B. N., and C. E. Kuyatt, 1993, Guidelines for Evaluating and Expressing the Uncertainty of NIST Measurement Results, NIST Technical Note 1297, U.S. Department of Commerce, Technology Administration, National Institute of Standards and Technology, January.

40 CFR 264, Code of Federal Regulations, Subpart B, Title 40, "Protection of the Environment," Part 264, "Standards for Owners and Operators of hazardous Waste Treatment, Storage, and Disposal Facilities," Subpart B, "General Facility Standards."

40 CFR 264, Code of Federal Regulations, Subpart O, Title 40, "Protection of the Environment," Part 264, "Standards for Owners and Operators of hazardous Waste Treatment, Storage, and Disposal Facilities," Subpart O, "Incinerators." 
Appendix A

Preliminary Report on the Preparation of Simulated Waste Drums

20 


\title{
Appendix A
}

\section{Preliminary Report on the Preparation of Simulated Waste Drums}

\author{
Mark Hollenbach, Rust Geotech, Inc., Grand Junction, Colorado
}

\section{INTRODUCTION}

Rust Geotech (Rust) was contracted by the Lockheed Martin Idaho Technologies Company (LMTTCO) to prepare 42 drums of simulated solidified waste containing various amounts of lead, cadmium, and mercury. The drums will be shipped to laboratories to evaluate the sensitivity and accuracy of commercially developed prompt gamma neutron activation analysis systems for measuring Resource Conservation and Recovery Act (RCRA) metals. LMITCO communicated instructions for preparing the drums to Rust in a Statement of Work and through subsequent phone conversations between the LMITCO technical contact and Rust.

Rust was to develop a recipe for preparing the solidified waste spiked with lead, cadmium, and mercury so that the final product would not be classified as toxic according to the toxicity characterization leaching procedure (TCLP) test. The decision was made to add the metals as sulfides because of the relative insolubility of these compounds.

\section{DEVELOPMENT OF SIMULATED WASTE RECIPE}

Rust personnel experimented with various proportions of water, sand, $\mathrm{NaNO}_{3}$, and Portland cement to develop a suitable mixture. The recipe for a $250 \mathrm{~g}$ batch was $40 \mathrm{~g}$ of water, $91.2 \mathrm{~g}$ of silica sand, $13.8 \mathrm{~g}$ of $\mathrm{NaNO}_{3}$, and $105 \mathrm{~g}$ of cement. The sodium nitrate was dissolved in the water, and the sand and cement were mixed in with a spatule. When making simulated waste spiked with metals, the weight of the sand was reduced by the weight of the metal sulfides added.

Two batches of simulated waste were prepared containing the metals at the highest concentrations requested for the waste drums. One was prepared as above except that it contained $5.6 \mathrm{~g}$ of PbS, $2.5 \mathrm{~g}$ of $\mathrm{CDs}$, and $82.9 \mathrm{~g}$ of sand. The other was prepared as above except that it contained $5.6 \mathrm{~g}$ of $\mathrm{HgS}$ and $85.4 \mathrm{~g}$ of sand. The sulfides were ground with a mortar and pestle, if necessary, and passed through a 100-mesh screen. The mixture was allowed to solidify for 3 days and then TCLP analysis was done for lead, cadmium, and mercury. The results were well below the regulatory levels for the three elements.

The samples were weighed after preparation and again after curing to determine the amount of water lost during curing and the density of the material. This information was required to plan the preparation of the drums. 


\section{MATERIAL PROCUREMENT}

Purchase requisitions were prepared for the required quantities of Portland cement, silica sand, $\mathrm{NaNO}_{3}$, $\mathrm{PbS}, \mathrm{CDs}$, and $\mathrm{HgS}$. The cement was the typical material sold at building materials stores. The silica sand was "stawing sand" obtained from U.S. Silica Company. The $\mathrm{NaNO}_{3}$ was industrial grade, $99.4 \%$, manufactured by the Chilean Nitrate Corporation. The PbS was obtained from GFS Chemicals. No purity was specified on the label or the accompanying certificate of analysis. The $\mathrm{CDs}$ and $\mathrm{HgS}$ were obtained from Aldrich Chemical Company. The purity of the CDs was specified on the label as $98+\%$, but the purity of the HgS was not specified by the supplier. The labels of the materials were examined on receipt to verify that the materials conformed to desired specifications.

Analysis of portions of the cement, sand, and $\mathrm{NaNO}_{3}$ were initiated for aluminum, boron, calcium, potassium, sodium, cerium, lanthanum, and neodymium (see Table A-1).

Eight-gallon size steel drums were purchased to contain the simulated waste. The drums are $380 \mathrm{~mm}$ (15 in.) in diameter and $380 \mathrm{~mm}$ (15 in.) high. Four plastic trash can liners, 0.31 mills thick each, were placed in each drum before the simulated waste was added. 


\section{PREPARATION OF SIMULATED WASTE DRUMS}

Using the material proportions determined above and the metal concentrations specified in the Statement of Work, a spreadsheet was set up to calculate the required amounts of each material for each set of drums. Logsheets were prepared that listed the recipe for each batch and had a table to record the actual amount of material weighed, the balance number, and a check box to indicate that the material was added. The logsheets also had a table to record drum tare and gross weights and space to record any comments.

Batch 1 did not contain any added metals. It was prepared first to gain experience with the process. As a result of the lessons learned by preparing Batch 1, the order of adding materials was changed for all subsequent batches.

\section{Batch 1}

The cement and sand were added to a $0.25-\mathrm{yd}^{3}$ cement mixer and mixed for several minutes. The $\mathrm{NaNO}_{3}$ was dissolved in the water and added to the mixer and mixed. The water did not mix well with the solid materials. It was necessary to reach into the mixer and scrape the solids off of the bottom of the mixer. The materials eventually mixed. The concrete was poured into three drums. The amounts of material in the drums was redistributed as necessary so that the net weights of the drums were within $5 \%$ of each other.

\section{Batches 2 Through 13}

The $\mathrm{PbS}$ and $\mathrm{HgS}$ were ground to a particle size of approximately 100 mesh using a ceramic plate grinder. The CDs was already a fine powder and was not ground.

The $\mathrm{NaNO}_{3}$ was dissolved in the water and added to the mixer. The sand was then added to the mixer and mixed briefly. The cement was added slowly while mixing. The metal sulfides were added after approximately two-thirds of the cement was added. The remaining cement was added and the materials were mixed for several minutes until the mixture was smooth. The cement was poured into the three drums, and the weights were adjusted as above.

The drums containing the lead and cadmium were prepared first, and then the drums containing mercury were prepared. In all cases, the order of preparation was from lower concentration to higher concentration. The mixer was cleaned and rinsed with water between batches.

A sample was collected from each batch and submitted for TCLP analysis for the added metals. The results for all analyses were well below the RCRA maximum contaminant levels for defining toxic waste. 


\section{CALCULATION OF LEAD, CADMIUM, AND MERCURY CONCENTRATIONS}

The concentrations of the added elements were calculated in each batch of wet simulated waste based on the known amounts of the materials used in the batch. The purity of the sulfides was assumed to be $100 \%$. The individual drums were weighed at the time of preparation, after 7 days, and again on July 16, 1996. The weight change from the second to third weighing was very small, approximately 10 to $20 \mathrm{~g}$ per drum. For a given element, the concentration in the cured simulated waste is calculated by multiplying the concentration in the wet simulated waste times the net wet weight of simulated waste in a drum divided by the net cured weight of simulated waste. The drums are approximately two-thirds full of material.

The weights of materials used, the weights of the drums, and the calculated concentrations of the added elements are listed in Table A-2. This report will be modified to include the analytical results for the starting materials when they are available. Complete copies of the analytical data packages will also be sent to the LMITCO technical contact.

Table A-1. Concentrations of selected elements in the major components used to prepare simulated waste drums.

\begin{tabular}{lccc}
\hline Concentration (mg/kg) & Sand & Concrete & $\mathrm{NaNO}_{3}$ \\
\hline Aluminum & 892 & 16,900 & $<1.2$ \\
Boron & 5.6 & 27.2 & 125 \\
Calcium & 279 & 453,000 & 23.9 \\
Cerium & 2.5 & 21.6 & $<0.02$ \\
Potassium & 295 & 4,100 & 4,900 \\
Lanthanum & 1.4 & 11.4 & 0.03 \\
Sodium & 337 & 1,510 & $270,600^{2}$ \\
Neodymium & 1.6 & 9.7 & 0.06 \\
Nitrate & & $729,400^{2}$ \\
\hline a. Concentrations of sodium and nitrate in $\mathrm{NaNO}_{3}$ were calculated based on formula weight. & \\
\hline
\end{tabular}


Table A-2. Contents of surrogate waste drums.

\begin{tabular}{|c|c|c|c|c|c|c|c|c|c|c|c|c|c|c|}
\hline Batch Number & 1 & 2 & 3 & 4 & 5 & 6 & 7 & 8 & 9 & 10 & 11 & 12 & 13 & 14 \\
\hline \multicolumn{15}{|l|}{ Component (kg) } \\
\hline Water & 22.99 & 22.99 & 22.99 & 22.99 & 22.99 & 22.99 & 22.99 & 22.99 & 22.99 & 22.99 & 22.99 & 22.99 & 22.99 & 23.41 \\
\hline $\mathrm{NaNO}_{3}$ & 8.10 & 8.10 & 8.10 & 8.10 & 8.10 & 8.10 & 8.10 & 8.10 & 8.10 & 8.10 & 8.10 & 8.10 & 8.10 & 8.10 \\
\hline Cement & 60.35 & 60.35 & 60.35 & 60.35 & 60.35 & 60.35 & 60.35 & 60.35 & 60.35 & 60.35 & 60.35 & 60.35 & 60.35 & 60.35 \\
\hline Sand & 52.48 & 49.57 & 51.51 & 52.38 & 48.68 & 50.88 & 52.42 & 49.24 & 51.18 & 52.15 & 52.40 & 47.82 & 50.51 & 52.39 \\
\hline $\mathrm{PbS}$ & & & & & 2.993 & 1.463 & & & & & & 3.303 & 1.643 & \\
\hline CDs & & & & & 0.916 & 0.1487 & 0.0537 & & & & & 1.507 & 0.391 & 0.0896 \\
\hline $\mathrm{HgS}$ & & 3.008 & 0.97 & 0.097 & & & & 3.295 & 1.359 & 0.323 & 0.081 & & & \\
\hline Total wt (kg) & 143.92 & 144.02 & 143.92 & 143.92 & 144.03 & 143.93 & 143.91 & 143.98 & 143.98 & 143.91 & 143.92 & 144.07 & 143.98 & 144.34 \\
\hline \multicolumn{15}{|l|}{ Wet conc (mg/kg) } \\
\hline Lead & 0 & 0 & $\mathbf{0}$ & $\mathbf{0}$ & 18,000 & 8,802 & $\mathbf{0}$ & 0 & 0 & 0 & 0 & 19,850 & 9,882 & 0 \\
\hline Cadmium & 0 & 0 & 0 & 0 & 4,948 & 804 & 290 & 0 & 0 & 0 & 0 & 8,139 & 2,113 & 483 \\
\hline Mencury & $\mathbf{0}$ & 18,010 & 5,811 & 581 & 0 & 0 & 0 & 19,730 & 8,138 & 1,935 & 485 & 0 & 0 & 0 \\
\hline \multicolumn{15}{|l|}{ Cured conc (mg/kg) } \\
\hline Lead & 0 & 0 & $\mathbf{0}$ & 0 & 18,080 & 8,844 & 0 & 0 & 0 & 0 & 0 & 19,950 & 9,927 & 0 \\
\hline Cadmium & $\mathbf{0}$ & 0 & 0 & 0 & 4,970 & 808 & 291 & 0 & 0 & 0 & 0 & 8,181 & 2,123 & 485 \\
\hline Mercury & 0 & 18,110 & 5,835 & 583 & 0 & 0 & $\mathbf{0}$ & 19,820 & 8,177 & 1,942 & 487 & 0 & 0 & 0 \\
\hline Date prepared & $6 / 5 / 96$ & $6 / 12 / 96$ & $6 / 11 / 96$ & $6 / 11 / 96$ & $6 / 10 / 96$ & $6 / 7 / 96$ & $6 / 7 / 96$ & $6 / 12 / 96$ & $6 / 12 / 96$ & $6 / 11 / 96$ & $6 / 10 / 96$ & $6 / 10 / 96$ & $6 / 7 / 96$ & $6 / 7 / 96$ \\
\hline \multicolumn{15}{|l|}{ Drum 1 (kg) } \\
\hline Tare wt & 3.88 & 3.91 & 4.02 & 3.97 & 4.03 & 4.00 & 3.87 & 3.96 & 3.86 & 3.86 & 3.92 & 3.99 & 3.81 & 3.95 \\
\hline Initial gross wt & 47.82 & 47.49 & 48.21 & 46.96 & 46.70 & 48.71 & 47.76 & 47.91 & 47.41 & 48.03 & 48.30 & 46.78 & 48.33 & 50.14 \\
\hline Initial net wt & 43.94 & 43.58 & 44.19 & 42.99 & 42.67 & 44.71 & 43.89 & 43.95 & 43.55 & 44.17 & 44.38 & 42.79 & 44.52 & 46.19 \\
\hline Final gross wt & 47.62 & 47.26 & 48.03 & 46.79 & 46.51 & 48.50 & 47.54 & 47.71 & 47.20 & 47.88 & 48.10 & 46.56 & 48.13 & 49.98 \\
\hline Final net wt & 43.74 & 43.35 & 44.01 & 42.82 & 42.48 & 44.50 & 43.67 & 43.75 & 43.34 & 44.02 & 44.18 & 42.57 & 44.32 & 46.03 \\
\hline \multicolumn{15}{|l|}{ Drum 2 (kg) } \\
\hline Tare wt & 3.90 & 4.04 & 3.94 & 4.02 & 3.90 & 3.84 & 3.95 & 4.01 & 3.96 & 3.88 & 4.10 & 3.87 & 3.84 & 3.93 \\
\hline Initial gross wt & 47.86 & 47.17 & 49.14 & 47.57 & 46.57 & 47.85 & 47.85 & 47.50 & 47.17 & 49.72 & 48.63 & 46.80 & 48.20 & 50.09 \\
\hline Initial net wt & 43.96 & 43.13 & 45.20 & 43.55 & 42.67 & 44.01 & 43.90 & 43.49 & 43.21 & 45.84 & 44.53 & 42.93 & 44.36 & 46.16 \\
\hline Final gross wt & 47.64 & 46.98 & 48.96 & 47.41 & 46.37 & 47.63 & 47.58 & 47.27 & 46.99 & 49.53 & 48.44 & 46.60 & 47.91 & 49.92 \\
\hline Final net wt & 43.74 & 42.94 & 45.02 & 43.39 & 42.47 & 43.79 & 43.63 & 43.26 & 43.03 & 45.65 & 44.34 & 42.73 & 44.07 & 45.99 \\
\hline \multicolumn{15}{|l|}{ Drum 3 (kg) } \\
\hline Tare wt & 4.06 & 3.79 & 3.87 & 3.95 & 3.87 & 3.89 & 3.98 & 3.94 & 3.87 & 3.90 & 3.94 & 4.06 & 3.89 & 3.84 \\
\hline Initial gross wt & 47.07 & 48.26 & 48.76 & 47.73 & 46.71 & 48.85 & 47.64 & 48.30 & 47.53 & 49.07 & 48.38 & 47.37 & 48.31 & 50.04 \\
\hline Initial net wt & 43.01 & 44.47 & 44.89 & 43.78 & 42.84 & 44.96 & 43.66 & 44.36 & 43.66 & 45.17 & 44.44 & 43.31 & 44.42 & 46.20 \\
\hline Final gross wt & 46.81 & 48.12 & 48.56 & 47.55 & 46.51 & 48.63 & 47.34 & 48.13 & 47.34 & 48.88 & 48.19 & 47.20 & 48.08 & 49.89 \\
\hline Final net wt & 42.75 & 44.33 & 44.69 & 43.60 & 42.64 & 44.74 & 43.36 & 44.19 & 43.47 & 44.98 & 44.25 & 43.14 & 44.19 & 46.05 \\
\hline
\end{tabular}


Appendix B

Reporting Form 


\section{Appendix B}

\section{Reporting Form}

1. Name of company and analyst:

2. Date of assay:

3. Assay laboratory:

4. Address of assay laboratory:

5. Contact person:

6. Phone (FAX) of contact person:

7. List of equipment/instrumentation used for measurements and analysis:

Radiation detector type:

Signal processing electronics:

Computer:

Description sketches or photos of experimental layout: 
Experimental Configuration

\begin{tabular}{|l|l|l|l|l||}
\hline Module & $\begin{array}{l}\text { Setting } \\
\text { (parameter } \\
\text { and value) }\end{array}$ & $\begin{array}{l}\text { Setting } \\
\text { (parameter } \\
\text { and value) }\end{array}$ & $\begin{array}{l}\text { Setting } \\
\text { (parameter } \\
\text { and value) }\end{array}$ & $\begin{array}{l}\text { Setting } \\
\text { (parameter } \\
\text { and value) }\end{array}$ \\
\hline & & & & \\
\hline & & & & \\
\hline & & & & \\
\hline
\end{tabular}

8. Floor dimensions (footprint) for entire assay system (include photos or drawings):

9. Required utilities to operate assay system:

10. Cost estimate of the entire prototype system as configured for tests excluding shielding: 
11. Cost estimate of the entire prototype system as configured for tests inclusive of shielding:

12. If equipment sold, specify minimum training requirements for operator:

13. Viable options for use of analysis system:

Sell equipment and train operators:

Provide on site analytical service:

14. Method of assay (e.g., prompt gamma neutron activation analysis):

15. Method of generation of interrogating particle or wave (e.g., ${ }^{252} \mathrm{Cf}$, neutron generator):

16. If generator used, list key instrument specifications:

17. Assay dependent on what nuclear reactions or interactions:

18. Intensity of interrogating particle or wave beam (e.g., $5 \mu \mathrm{g}$

${ }^{252} \mathrm{Cn}$ : 
19. Estimated lower limit of detection in parts per million (ppm)for a 600-s and for a 2,000-s real-time count for a surrogate drum of waste with the RCRA metal homogeneously distributed and no interfering elements present using L. A. Currie's definition of LLD (Currie 1968):

$$
\text { 600-s count 2,000-s count }
$$

Cd: Hg: Pb:

Cd Hg $\mathbf{P b}$

Are estimated LLDs measured or modeled?

20. Provide, as a separate attachment, a copy of the counting and analysis procedures used to assay the surrogate drums.

21. Provide the calibration method and resulting function for determining elemental concentrations in analytic or graphic format. Reference the protocol used to measure or calculate the calibration functions.

22. Give the assay results for the blank drum for each waste type. Provide a labeled plot of the spectrum for each assayed blank drum showing the detected elements above the LLD for each count time used to acquire data.

23. Give the assay results for replicate counts of each blind sample for each surrogate waste type. Provide a labeled plot of the spectrum for each assayed surrogate drum showing the detected elements above the LLD.

24. Were elements detected on-line (within computer processing time of $<3$ minutes) or were they determined by postanalysis?

online:

postprocessing: 
25. Were elemental concentrations measured online (within computer processing time of $<3$ minutes) or were they determined by postanalysis?

online: postprocessing:

26. In your opinion, could the present system with or without modification, assay waste under treatment plant conditions of an environment of high radio frequency and acoustic noise?

27. Estimate the fractional loss in elemental concentration sensitivity under treatment plant conditions as stated in questions 25 and 26 ?

28. Identify those data quality objectives in Section 3.2 that do not appear to have been met and give reason for not meeting them.

29. Statement of verification of reported results.

I verify that the results including reported uncertainties have been measured and calculated following approved procedures and the calculations have been checked by a second analyst.

Signed

Signed 
Drum II) No. Count ID Date Counting Time

\begin{tabular}{|l|l|l|l|l|}
\hline Element & $\begin{array}{l}\text { gamma-ray energy } \\
(\mathrm{keV})\end{array}$ & $\begin{array}{l}\text { percent } \\
\text { concentration }\end{array}$ & $\begin{array}{l}\text { statistical } \\
\text { uncertainty }\end{array}$ & total uncertaintyc \\
\hline & & & & \\
\hline & & & & \\
\hline & & & & \\
\hline & & & & \\
\hline
\end{tabular}

a. An element should be considered not detected if the signal is below that for the lower-limit of detection (LID) as defined by L. A. Curric (1968). An element should be considered detected if the signal is above the LLD and the uncertainty is <35\% but $>20 \%$.

b. This is the estimated standard deviation in $\gamma$-ray peak area or in fit of peak area. A value with an uncertainty $>35 \%$ will be considered undetected. A value with an uncertainty between 20 and $35 \%$ will be considered detected but not quantifiable. Only values with a statistical cotimated standard deviation of $<20 \%$ will be considered quantifiable.

c. Combined uncertainty with all identified components combined in the standard manner. List each uncertainty, excluding the statistical counting uncertainty, and its source (ANSI N42.14-1991 and Taylor and Kuyatt 1993). 


\section{REFERENCES}

ANSI N42.14-1991, October 30, 1991, "Calibration and Use of Germanium Spectrometers for the Measurement of Gamma-Ray Emission Rates of Radionuclides," American National Standards Institute.

L. A. Currie, 1968, "Limits for Quantitative Detection and Quantitative Determination," Analytical Chemistry, Vol.40, p. 586.

Taylor, B. N., and C. E. Kuyatt, 1993, Guidelines for Evaluating and Expressing the Uncertainty of NIST Measurement Results, NIST Technical Note 1297, U.S. Department of Commerce, Technology Administration, National Institute of Standards and Technology, January. 


\section{Appendix C}

Instructions to Participants 


\section{Appendix C}

\section{Instructions to Participants}

The method of determining the calibration function to convert the gamma-ray peak areas to element concentrations (by weight) shall be described on the participant reporting form. The calibration function shall be verified to function correctly by recounting one of the calibration drums with a known Resource Conservation and Recovery Act (RCRA) element concentration to verify that the correct result within its uncertainty is obtained. Each blind drum shall be assayed three times with the drum removed from the counting position between individual assays. Two count times of the individual surrogates shall be made: one for 2,000-second real time and one for 600-second real time. Each participant will be allowed about 6 weeks to receive and assay the blind surrogate drums (specific instructions and the address to ship the drums will be given when the participant has finished his analysis of the drums). The completed reporting form for the assay results shall be transmitted to the principal investigator (PI) for the performance test project, R. J. Gehrke, at Lockheed Martin Idaho Technologies Company, P.O. Box 1625, Idaho Falls, Idaho 83415-2114 no later than 3 weeks after completing the assay.

For an elemental concentration to be considered detected the primary signal for a given element assay shall have an estimated standard deviation of less than $35 \%$ for the combined uncertainty in the counting statistics and the peak fitting uncertainty. A value with this degree of uncertainty should be equivalent to a lower limit of detection as defined by L. A. Currie (1968). The goal is detection in a 600-second count of all RCRA metals present at the lowest concentrations in a blind sample with an uncertainty less than $35 \%$ (one estimated standard deviation for the statistical component). It is to be determined from this performance test what is the lowest concentration level that can be successfully detected and quantified with present state-of-the-art noninvasive assay systems.

For an elemental concentration to be considered quantified, the primary signal shall have an estimated standard deviation for the counting (statistical) uncertainty component of less than $20 \%$. The total uncertainty for a quantified measurement should be less than $25 \%$ with the estimated standard deviations combined in the normal statistical manner (i.e., in quadrature).

The experimental geometry shall be reproducible and recorded with the help of a set of pictures, drawings, or sketches. The uncertainty component because of the nonreproducibility in the experimental geometry shall not be greater than $5 \%$. (Verification can be demonstrated through sequential assays of a surrogate sample.) 


\section{PREPARATION OF CALIBRATION DRUMS}

Any drums prepared for calibration by the participant should be made using the recipes provided in Appendix A. The participant is encouraged to prepare drums that meet the toxicity characterization leaching procedure (TCLP) leach test so that the drums can be disposed of at a landfill. The participant is responsible for the disposal of any drums he/she prepares to calibrate or check the operation in his/her analysis system. The drums to be used in preparing these samples should be of the same dimensions and gauge thickness as the blind surrogate (contact the PI for these dimensions and a commercial source).

\section{SELECTION CRITERIA FOR “BEST” ASSAY SYSTEM}

The following selection criteria will be used to grade the results. The total number of points possible will not be known until the surrogates are prepared; however, it will exceed 100.

1. Five points will be awarded for each element correctly identified for each blind surrogate.

2. Ten points weighted by the cube root of the percent concentration (e.g., a $0.1 \%$ surrogate drum of lead correctly identified would be $10 /(0.1) \%=21.5$ points) will be awarded for each correctly reported quantitative measurement of an element present in a surrogate drum that is within $10 \%$ of the "true" concentration.

3. Five points weighted by the cube root of the percent concentration will be awarded for each correctly reported quantitative measurement of an element present in a surrogate drum that is within $20 \%$ of the "true" concentration.

4. Ten points weighted by the cube root of the percent concentration will be subtracted from the participant's score for each incorrectly reported quantitative measurement of an element present in a surrogate drum that differs from the "true" concentration by more than $50 \%$. For quantitative results differing from 20 to $50 \%$ of the "true" concentration, there will be no awarded or subtracted points.

5. Noncompliance with the "Instructions to the Participants" without written permission of the P.I. may result in a reduction in points or in disqualification of the participant from the performance test.

Because many features of each RCRA metals assay system cannot be evaluated at the present time, the "best" assiay system will be judged primarily on the grading system specified above. 


\section{REFERENCE}

L. A. Currie, 1968, "Limits for Quantitative Detection and Quantitative Determination," Analytical Chemistry, Vol.40, p. 586. 


\section{PART 2}

\section{Participants' Reports}


Report of Analytical Results

Westinghouse Science and Technology Center 


\section{APPENDIX B}

\section{Reporting Form}

1. Name of company and analyst:

Westinghouse Science \& Technology Center (WSTC)

2. Date of assay:

$8 / 20 / 96$ to $9 / 30 / 96$

3. Assay laboratory: WSTC Nuclear Laboratory

4. Address of assay lab: 1310 Beulah Road, Pittsburgh, PA 15235-5098

5. Contact person:

Dr. Abdul R. Dulloo

412 - 256-2140 (Phone)

6. Phone (FAX) of contact person: $412-256-1222$ (Fax)

7. List of equipment/instrumentation used for measurements and analysis:

Radiation detector type: $\quad$ HPGe

Signal processing electronics: Preamplifier, Amplifier, ADC, MCA and Generator Computer: $\operatorname{VAX} 4000$ Workstation

Description sketches or photos of experimental layout:

Please see Attachment I 


\section{Experimental Configuration}

\begin{tabular}{|c|c|c|c|c|}
\hline Module & $\begin{array}{l}\text { setting } \\
\text { (parameter } \\
\text { \& value) }\end{array}$ & $\begin{array}{l}\text { setting } \\
\text { (parameter } \\
\text { \& value) }\end{array}$ & $\begin{array}{l}\text { setting } \\
\text { (parameter } \\
\text { \& value) }\end{array}$ & $\begin{array}{l}\text { setting } \\
\text { (parameter } \\
\text { \& value) }\end{array}$ \\
\hline HPGe & $\begin{array}{l}\text { Bias Voltage - } \\
3000 \mathrm{~V}\end{array}$ & $\begin{array}{l}\text { Temperature - } \\
77 \mathrm{~K}\end{array}$ & & \\
\hline Amplifier & Gain - 23.1 & $\begin{array}{l}\text { Shaping Time - } \\
0.5 \mu \mathrm{s}\end{array}$ & $\begin{array}{l}\text { Pile-up } \\
\text { Rejection On }\end{array}$ & \\
\hline$A D C$ & Gain - 8K & & & \\
\hline $\mathrm{MCA}$ & $\begin{array}{l}\text { 4-Group } \\
\text { Acquisition }\end{array}$ & $\begin{array}{l}8192 \text { Channels } \\
\text { per Group }\end{array}$ & & \\
\hline AIM & $\begin{array}{l}\text { 4-Group } \\
\text { Acquisition }\end{array}$ & & & \\
\hline & & & & \\
\hline
\end{tabular}

8. Floor dimensions (foot print) for entire assay system (include photos or drawings): $30^{\prime \prime} \times 30^{\prime \prime}$, including detector support stand

9. Required utilities to operate assay system:

Electrical power (can be self-powered using a diesel generator

for stand-alone operation)

10. Cost estimate of the entire prototype system as configured for tests excluding shielding: $\$ 200,000$ 
11. Cost estimate of the entire prototype system as configured for tests inclusive of shielding: $\$ 210,000$

12. If equipment sold, specify minimum training requirements for operator: Not intended for sale

13. Viable options for use of analysis system:

Sell equipment and train operators:

Provide on site analytical service:

$$
\mathrm{x}
$$

14. Method of assay (e.g., prompt gamma neutron activation analysis): Prompt and decay gamma neutron activation analysis

15. Method of generation of interrogating particle or wave (e.g., ${ }^{252} \mathrm{Cf}$, neutron generator): Deuterium-tritium (D-T) neutron generator

16. If generator used, list key instrument specifications:

MF Physics Model A320 Pulsed-mode operation

17. Assay dependent on what nuclear reactions or interactions:

Please see Attachment I

18. Intensity of interrogating particle or wave beam (e.g., $5 \mu \mathrm{g}$ ${ }^{252} \mathrm{Cf}$ ): $\quad 10^{7} \mathrm{n} \mathrm{s}^{-1}$ (nomina1) 
19. Estimated lower limit of detection in parts per million (ppm)for a $600 \mathrm{~s}$ and for a $2000 \mathrm{~s}$ real-time count for a surrogate drum of waste with the RCRA metal homogeneously distributed and no interfering elements present using $L$. A. Currie's definition of LLD (see Ref. 4 of text):

$$
600 \text { s count }
$$

2000 s count

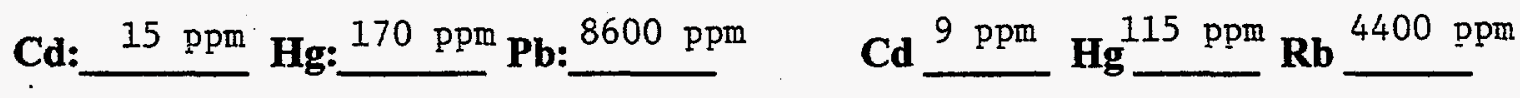
Are estimated LLD's measured or modeled? Modeled - see Attachment I

20. Provide, as a separate attachment, a copy of the counting and analysis procedures used to assay the surrogate drums. Please see Attachment I

21. Provide the calibration method and resulting function for determining elemental concentrations in analytic or graphic format. Reference the protocol used to measure or calculate the calibration functions. See Attachment I

22. Give the assay results for the blank drum for each waste type. Provide a labeled plot of the spectrum for each assayed blank drum showing the detected elements above the LLD for each count time used to acquire data. See Attachment I

23. Give the assay results for replicate counts of each blind sample for each surrogate waste type. Provide a labeled plot of the spectrum for each assayed surrogate drum showing the detected elements above the LLD. See Attachment I

24. Were elements detected on-line (within computer processing time of $<3$ minutes) or were they determined by post analysis?

on-line: 
25. Were elemental concentrations measured on-line (within computer processing time of $<3$ minutes) or were they determined by post analysis?

on-line: post processing: $\mathrm{X}$

26. In your opinion, could the present system with or without modification, assay waste under treatment plant conditions of an environment of high radio frequency and acoustic noise? Yes

27. Estimate the fractional loss in elemental concentration sensitivity under treatment plant conditions as stated in questions 25 and 26 ?

We believe that the fractional loss in sensitivity

will be $<5 \%$ with the incorporation of protective

features to the system

28. Identify those data quality objectives in Section 3.2 that do not appear to have been met and give reason for not meeting them.

None

$\therefore:$

$\div \quad$

$\therefore$

29. Statement of verification of reported results.

I verify that the results including reported uncertainties have been measured and calculated following approved procedures and the calculations have been checked by a second analyst.

Signed

Signed

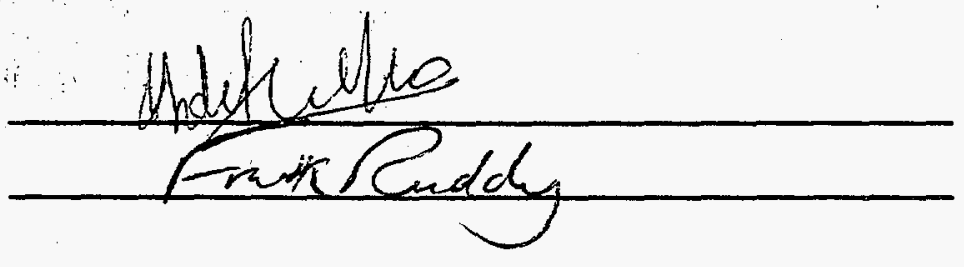




\title{
Attachment I
}

\author{
Executive Summary \\ Description of Experimental Setup
}

(Question 7)

Counting and Analysis Procedures for Calibration Drum Assays

(Questions 20 and 21)

Blank Drum Assay Results

(Question 22)

Blind Drum Assay Results

(Question 23)

Lower Limit of Detection

(Question 19) 


\section{Executive Summary}

The concentrations of mercury, cadmium and lead in surrogate waste drums were measured using the WSTC PGNAA drum assay system as part of a program to evaluate the performance of noninvasive assay systems. The results are summarized below.

Measured Concentrations of $\mathrm{Hg}, \mathrm{Cd}$ and $\mathrm{Pb}$ in Blind Surrogate Waste Drums

\begin{tabular}{|c|c|c|c|}
\hline \multirow{2}{*}{ Drum No. } & \multicolumn{3}{|c|}{ Concentration, ppm $^{2}$} \\
& Mercury & Cadmium & Lead \\
\hline 2 & $18191 \pm 14.3 \%$ & not detected & not detected \\
\hline 3 & $7031 \pm 14.1 \%$ & not detected & not detected \\
\hline 4 & $691 \pm 14.6 \%$ & not detected & not detected \\
\hline 5 & not detected & $3613 \pm 10.6 \%$ & $18814 \pm 19.3 \%$ \\
\hline 6 & not detected & $821 \pm 10.2 \%$ & $10416 \pm 21.0 \%$ \\
\hline 7 & not detected & $321 \pm 10.5 \%$ & not detected \\
\hline
\end{tabular}

${ }^{a}$ Reported uncertainty is the total uncertainty of the measurement. 


\section{Description of Experimental Setup}

The drum assay system, illustrated in Figure 1a, consists of a polyethylene interrogation chamber, a high-purity germanium (HPGe) detector, and a deuterium-tritium (D-T) accelerator neutron source. The chamber's outer dimensions are 22 inches by 22 inches by 26 inches, and its interior is designed to hold an 8-gallon drum positioned on its side, as depicted in Figure 1a. A channel built in the chamber floor prevents the drum from rolling once positioned in the chamber, and ensures that the vertical midplane of the surrogate waste sample inside the drum is approximately aligned with the detector centerline.

A 20\%, N-type HPGe detector (Canberra) was used when assaying the drums for $\mathrm{Cd}$ and $\mathrm{Hg}$. This detector was housed in a thin-walled aluminum jacket filled with natural lithium fluoride in order to minimize thermal neutron capture in the detector materials. A $106 \%$, P-type HPGe detector was substituted in the system when assaying the drums for lead. This detector was shielded by graphite slabs instead of $\mathrm{LiF}$ to protect against fast neutron damage. The detector signal in either case was sent to a signal-processing chain consisting of a preamplifier (Canberra Model 2005), a fast spectroscopy amplifier (Canberra Model 2024), an analog-to-digital counter (Canberra Model 2024)) and a multichannel analyzer based on a VAX 4000 workstation. Gamma spectrum analysis is performed with a Canberra peak search software program. Energy calibration is checked with known spectral peaks, and the gain and zero intercept values are recorded for each spectrum.

Gamma spectrum acquisition is time-correlated with neutron pulsing during an assay. A four-group spectrum is normally acquired in a run, as illustrated in Figure 1b. Group 1 typically contains prompt gammas from fast neutron-induced inelastic scattering reactions, while group 2 consists mainly of prompt gammas from thermal neutron capture reactions. Both thermal neutron-induced prompt gammas and decay gammas from longlived activation products are found in group 3, whereas group 4 consists chiefly of the decay gammas. The time duration of a group can be adjusted to emphasize data collection of the gamma signals from fast, thermal or activation reactions. 
The D-T accelerator (MF Physics Model A320) is positioned near the upper section of the drum with its accelerator target located in the vertical midplane of the sample in the drum. While the generator was set to give neutron output of $10^{7} \mathrm{n} \mathrm{s}^{-1}$ in every run, past experience had revealed that variations in the actual generator neutron output occurred from run to run. Consequently, the neutron output of each run was monitored by introducing bismuth rods around the HPGe detector. The reaction of interest is the fast neutron-induced ( $n, 2 n$ ) reaction in ${ }^{209} \mathrm{Bi}$, which leads to the formation of ${ }^{208 \mathrm{~m}} \mathrm{Bi}$ (half life $=2.6 \mathrm{~ms}$ ). A $921-\mathrm{keV}$ gamma ray accompanies the decay of this isomer, and the peak area of this gamma line in the spectrum acquired from a run is used as a measure of the generator neutron output during the run. This method cannot be utilized to monitor neutron output during lead assay runs as the neutron-irradiation of bismuth also produces gamma lines at 569- and 1063-keV, which interfere with gamma lines of the same energies that are emitted during the decay of ${ }^{207 \mathrm{~m}} \mathrm{~Pb}$ produced from lead. As will be discussed in a later section, these gamma lines are used to detect the presence of $\mathrm{Pb}$ in a drum, and bismuth must be absent from the system when performing lead assays. Instead, the peak area of the $6129-\mathrm{keV}$ gamma line from the decay of ${ }^{16} \mathrm{~N}$ is used to monitor the neutron output during a lead assay run. ${ }^{16} \mathrm{~N}$ (half life $=7.13 \mathrm{~s}$ ) is produced from the fast neutron-induced $(n, p)$ reaction in ${ }^{16} \mathrm{O}$, and the peak area of its decay gamma can provide a measure of the neutron output assuming that the oxygen content of the drum assay system, including the drum, remains unchanged from run to run.

\section{Counting and Analysis Procedures for Calibration Drum Assays}

\section{Mercury Calibration}

The $\mathrm{Hg}$ concentration of the four mercury calibration drums is given in Table 1. Since the test program requires a real-time assay of $2000 \mathrm{~s}$ for the quantification of an element in a blind drum, calibration drums were also assayed for a run time of $2000 \mathrm{~s}$. The rnain prompt gamma-ray lines that result from thermal neutron capture reactions in mercury are listed in Table 2. A spectrum collected from an assay of the 1942-ppm Hg 
calibration drum (No. 10) is given in Figure 2. It is clear from this spectrum that the $368.1-\mathrm{keV}$ line is the most prominent of the mercury peaks, and this gamma-ray is used to detect and quantify mercury in the blind drums.

A comparison of the $368.1-\mathrm{keV}$ peaks obtained from the gamma spectra of the four $\mathrm{Hg}$ calibration drums is provided in Figure 3, together with the corresponding spectral region of the blank (drum No. 1) gamma spectrum. The blank drum was assayed for $2000 \mathrm{~s}$, under identical conditions as the $\mathrm{Hg}$ calibration drums. While not apparent in Figure 3, there is a small peak observed in the blank spectrum at $366.5 \mathrm{keV}$. This peak, shown more clearly in Figure 4, is an iron prompt gamma line resulting from thermal neutron capture in the wall of the steel drum, and contributes to the peak area of the 368.1-keV Hg line. A correction for this contribution is made in the following manner: a long assay run ( $6000 \mathrm{~s}$ ) was done with the blank drum, and the ratio of the peak area of the $352.2-\mathrm{keV}$ iron line to that of the $366.5-\mathrm{keV}$ iron line (both clearly identifiable above the noise continuum) calculated from the spectral data. By dividing the peak area of the 352.2-keV Fe line observed from the gamma spectrum of a mercury-contaminated drum by this ratio, the $366.5-\mathrm{keV} \mathrm{Fe}$ peak area can be calculated and subtracted from the peak area of the $368.1-\mathrm{keV} \mathrm{Hg}$ line. It should be noted that, due to the necessity of this correction to the $\mathrm{Hg}$ peak area and to the slight difference between the energies of the $\mathrm{Hg}$ and Fe peaks ( 368.1 vs. $366.5 \mathrm{keV}$ ), the peak area of the $368.1-\mathrm{keV} \mathrm{Hg}$ line in the gamma spectra acquired from drums that contain mercury - calibration and blind-is calculated by manual integration.

A plot of $368.1-\mathrm{keV} \mathrm{Hg}$ peak area (corrected for iron interference and normalized to the generator output) versus $\mathrm{Hg}$ concentration for the calibration drums is shown in Figure 5. The non-linear increase in the peak area as a function of increasing $\mathrm{Hg}$ concentration is a result of the thermal neutron flux depression caused by the higher $\mathrm{Hg}$ concentrations. 
Table 1. Composition of Surrogate Waste Drums

\begin{tabular}{|c|c|c|c|}
\hline Drum Number & \multicolumn{3}{|c|}{ Concentration, ppm } \\
& Mercury & Cadmium & Lead \\
\hline 1 (Blank) & 0 & 0 & 0 \\
\hline 2 (Blind) & $\mathrm{U}$ & $\mathrm{U}$ & $\mathrm{U}$ \\
\hline 3 (Blind) & $\mathrm{U}$ & $\mathrm{U}$ & $\mathrm{U}$ \\
\hline 4 (Blind) & $\mathrm{U}$ & $\mathrm{U}$ & $\mathrm{U}$ \\
\hline 5 (Blind) & $\mathrm{U}$ & $\mathrm{U}$ & $\mathrm{U}$ \\
\hline 6 (Blind) & $\mathrm{U}$ & $\mathrm{U}$ & $\mathrm{U}$ \\
\hline 7 (Blind) & $\mathrm{U}$ & $\mathrm{U}$ & $\mathrm{U}$ \\
\hline 8 (Hg calib.) & 19820 & 0 & 0 \\
\hline 9 (Hg calib.) & 8177 & 0 & 0 \\
\hline 10 (Hg calib.) & 1942 & 0 & 0 \\
\hline 11 (Hg calib.) & 487 & 0 & 0 \\
\hline 12 (Cd + Pb calib.) & 0 & 8181 & 19950 \\
\hline 13 (Cd + Pb calib.) & 0 & 2123 & 9927 \\
\hline 14 (Cd calib.) & 0 & 485 & 0 \\
\hline$U=$ & & & 0 \\
\hline
\end{tabular}

$\mathrm{U}=$ unknown

Table 2. Main Prompt Gamma Lines of $\mathrm{Hg}$

\begin{tabular}{|c|c|c|}
\hline Gamma Energy, keV & Branching Ratio & Reaction \\
\hline 368.1 & 0.8135 & ${ }^{199} \mathrm{Hg}(\mathrm{n}, \gamma)^{200} \mathrm{Hg}$ \\
\hline 661.1 & 0.0447 & ${ }^{199} \mathrm{Hg}(\mathrm{n}, \gamma)^{200} \mathrm{Hg}$ \\
\hline 1263.0 & 0.0223 & ${ }^{199} \mathrm{Hg}(\mathrm{n}, \gamma)^{200} \mathrm{Hg}$ \\
\hline 1693.9 & 0.1413 & ${ }^{199} \mathrm{Hg}(\mathrm{n}, \gamma)^{200} \mathrm{Hg}$ \\
\hline 5966.2 & 0.1386 & ${ }^{199} \mathrm{Hg}(\mathrm{n}, \gamma)^{200} \mathrm{Hg}$ \\
\hline
\end{tabular}




\section{Cadmium Calibration}

The $\mathrm{Cd}$ concentration of the three cadmium calibration drums is given in Table 1. Each drum was assayed for $2000 \mathrm{~s}$. The principal prompt gamma lines that result from thermal neutron capture in cadmium are given in Table 3, while Figure 6 shows the spectrum acquired from drum No. $12(\mathrm{Cd}$ concentration $=8181 \mathrm{ppm})$. The $558.6-\mathrm{keV}$ line is clearly the most prominent peak in that spectrum, and this line is used to detect and quantify cadmium in a blind drum. A comparison of the $558.6-\mathrm{keV}$ peaks observed in the spectra of the Cd calibration drums is shown in Figure 7, together with the corresponding region of the blank gamma spectrum. No interference is observed with the $558.6-\mathrm{keV} \mathrm{Cd}$ line from gamma lines of the other elements present in the system.

A plot of 558.6-keV Cd peak area (normalized to generator output) versus $\mathrm{Cd}$ concentration is shown in Figure 8. As was noted in the case of $\mathrm{Hg}$, it is clear from this plot that the peak area tends to a plateau value with increasing $\mathrm{Cd}$ concentration. This behavior is attributed to the large cross section of cadmium ( 2450 barns) for thermal neutron absorption, which causes a thermal neutron flux depression in the inner regions of the waste matrix. Since only three calibration points are available to provide a fit to the plot of Figure 8, the experimental data were supplemented by five points obtained from a calculational model of the drum assay system containing a cadmium-contaminated waste drum. This model was generated with the Discrete Ordinates Radiation Transport (DORT) code ${ }^{1}$. The calculated results, which are shown in Figure 8, are in good agreement with the experimental data at corresponding points.

It should be noted that the leveling off of the $\mathrm{Cd}$ calibration curve with increasing concentration is expected to introduce a large uncertainty in the measured $\mathrm{Cd}$ concentration of drums with high cadmium contents.

\footnotetext{
' ORNLCCC-543, RSIC Computer Code Collection, TORT-DORT Two- and Three-Dimensional Discrete Ordinates Transport, Version 2.8.14, Oak Ridge National Laboratory, Jan. 1994
} 
Table 3. Main Prompt Gamma Lines of Cd

\begin{tabular}{|c|c|c|}
\hline Gamma Energy, keV & Branching Ratio & Reaction \\
\hline 558.6 & 0.7273 & ${ }^{113} \mathrm{Cd}(\mathrm{n}, \gamma){ }^{114} \mathrm{Cd}$ \\
\hline 651.3 & 0.139 & ${ }^{113} \mathrm{Cd}(\mathrm{n}, \gamma){ }^{114} \mathrm{Cd}$ \\
\hline 806.0 & 0.0465 & ${ }^{113} \mathrm{Cd}(\mathrm{n}, \gamma){ }^{114} \mathrm{Cd}$ \\
\hline 575.8 & 0.0231 & ${ }^{113} \mathrm{Cd}(\mathrm{n}, \gamma){ }^{114} \mathrm{Cd}$ \\
\hline 724.9 & 0.0392 & ${ }^{113} \mathrm{Cd}(\mathrm{n}, \gamma){ }^{114} \mathrm{Cd}$ \\
\hline 1209.4 & 0.0361 & ${ }^{113} \mathrm{Cd}(\mathrm{n}, \gamma){ }^{114} \mathrm{Cd}$ \\
\hline 1364.2 & 0.0495 & ${ }^{113} \mathrm{Cd}(\mathrm{n}, \gamma){ }^{114} \mathrm{Cd}$ \\
\hline
\end{tabular}

\section{Lead Calibration}

Based on results obtained from past programs, the lower limit of detection (LLD) of the current system for $\mathrm{Pb}$ using prompt gammas from thermal neutron capture in lead is estimated to be $20 \%$ by weight. Since the highest $\mathrm{Pb}$ concentration of the calibration drums is $19950 \mathrm{ppm}$, or about 2\%, the system was not expected to detect lead through therrnal neutron-induced prompt gammas. This was substantiated by the results obtained with the two cadmium calibration drums which also contain lead (Table 1). No prompt gamma lines from thermal neutron capture in lead was observed in their gamma spectra. Consequently, an alternative approach was adopted to detect lead. This approach, which uses the same physical system configuration, takes advantage of the formation of ${ }^{207 \mathrm{~m}} \mathrm{~Pb}$ by fast neutron-induced reactions in lead. The decay of this isomer, whose half life is $810 \mathrm{~ms}$, is accompanied by the emission of gamma rays whose energies and branching ratios are given in Table 4. After adjusting the timing to enhance spectral acquisition in the temporal region between neutron pulses where the ${ }^{207 \mathrm{~m}} \mathrm{~Pb}$ decay lines have the best likelihood of appearing above the noise continuum, the 569- and 1063-keV lines were detected when the $\mathrm{Pb}$ calibration drums were assayed. However, because of the high continuum existing under the $569-\mathrm{keV}$ line, only the $1063-\mathrm{keV}$ line is used to detect and quantify lead. As 
described earlier, a $106 \%$, P-type HPGe detector was utilized in the drum assay system during $\mathrm{Pb}$ assay runs in order to increase the system sensitivity.

Figure 9 shows a comparison of the $1063-\mathrm{keV}$ peaks observed in the gamma spectra of the two $\mathrm{Pb}$ calibration drums assayed for $2000 \mathrm{~s}$, as well as the corresponding region of a blank spectrum obtained under identical conditions. A plot of $1063-\mathrm{keV}$ peak area, normalized to generator output, versus $\mathrm{Pb}$ concentration is shown in Figure 10.

Table 4. Decay Gamma Lines of ${ }^{207 \mathrm{~m}} \mathrm{~Pb}$

\begin{tabular}{|c|c|c|}
\hline $\begin{array}{c}\text { Gamma Energy, } \\
\text { keV }\end{array}$ & Branching Ratio $^{\text {Main Reaction }^{\mathrm{a}}}$ \\
\cline { 1 - 2 } 569 & 0.98 & ${ }^{208} \mathrm{~Pb}(\mathrm{n}, 2 \mathrm{n}){ }^{207 \mathrm{~m}} \mathrm{~Pb}$ \\
$\mathrm{yyn}$ & 0.83 & $(\mathrm{Q}=-7.4 \mathrm{MeV})$ \\
\hline
\end{tabular}

${ }^{a}$ also produced by the ${ }^{207} \mathrm{~Pb}\left(\mathrm{n}, \mathrm{n}^{\prime}\right){ }^{207 \mathrm{~m}} \mathrm{~Pb}$ reaction

\section{Verification of Calibration Functions}

Based on the data obtained from the 2000-s calibration runs, the following calibration functions were derived for $\mathrm{Hg}, \mathrm{Cd}$ and $\mathrm{Pb}$ :

Mercury:

$\log _{10}[$ counts $]=-4.61+2.39 \log _{10}[\mathrm{Hg}$ conc. $]-0.23\left\{\log _{10}[\mathrm{Hg} \text { conc. }]\right\}^{2}$

Cadmium:

$\log _{10}[$ counts $]=1.94-1.75 \log _{10}[$ Cd conc. $]+0.22\left\{\log _{10}[\text { Cd conc. }]\right\}^{2}$

Lead:

[counts $]=0.015+3.492 \times 10^{-6}[\mathrm{~Pb}$ conc. $]$

The calibration function of each element was verified by repeating a run with one of the element's calibration drums. The concentration of the calibration drum was then 
obtained from the peak area of the primary signal measured in the run and from the calibration function. Table 5 compares the values obtained from the repeat runs of each element with the actual concentration of the calibration drum used in the run. In all cases, reasonable agreement is obtained between measured and actual drum concentrations.

Table 5. Comparison of Measured and Actual Concentrations from Repeat Calibration Runs

\begin{tabular}{|c|c|c|c|}
\hline Element & $\begin{array}{c}\text { Actual } \\
\text { Concentration, } \\
\text { ppm }\end{array}$ & $\begin{array}{c}\text { Measured } \\
\text { Concentration } \\
\mathbf{p p m}\end{array}$ & $\begin{array}{c}\text { \% Difference } \\
\text { between Actual } \\
\text { and Measured }\end{array}$ \\
\hline $\mathrm{Hg}$ & 19820 & $21360 \pm 4.5 \%$ & 7.8 \\
\hline $\mathrm{Cd}$ & 485 & $520 \pm 5.1 \%$ & 7.2 \\
\hline $\mathrm{Pb}$ & 19950 & $18814 \pm 16.0 \%$ & -5.7 \\
\hline
\end{tabular}

${ }^{2}$ Listed uncertainty is the standard deviation due to counting error only.

\section{Blank Drum Assays}

The prompt gamma spectrum collected from a 2000-s assay of the blank drum (No. 1) is given in Figure 11. The decay gamma spectrum acquired from a 2000-s assay of the blank drum is shown in Figure 12. Table 6 provides a list of the elements identified from the gamma lines present in these spectra. The 1434-keV line in the decay spectrum is tentatively attributed to the decay of ${ }^{52} \mathrm{~V}$. One possible source of ${ }^{52} \mathrm{~V}$ is the $(n, p)$ reaction in chromium $\left({ }^{52} \mathrm{Cr}\right)$, which could be present in the system if the drum is made of stainless steel. Another source is the $(n, \gamma)$ reaction in vanadium $\left({ }^{51} \mathrm{~V}\right)$, which could be present as a trace element in the concrete matrix.

In addition to the lines listed in Table 6, the $1779-\mathrm{keV}$ decay line from ${ }^{28} \mathrm{Al}$ is also observed in the blank spectrum. ${ }^{28} \mathrm{Al}$ results either from thermal neutron capture in ${ }^{27} \mathrm{Al}$ or from a fast-neutron induced $(n, p)$ reaction in ${ }^{28} \mathrm{Si}$. Similarly, ${ }^{24 \mathrm{~m}} \mathrm{Na}$, which emits the 472 - 
$\mathrm{keV}$ decay line observed in the spectrum, is created either by thermal neutron capture in ${ }^{23} \mathrm{Na}$ or from a fast-neutron induced $(\mathrm{n}, \alpha)$ reaction in ${ }^{27} \mathrm{Al}$.

Table 6. Elements Identified from Blank Drum Gamma Spectra

\begin{tabular}{|c|c|c|c|}
\hline Element & Source & $\begin{array}{c}\text { Principal Gamma } \\
\text { Line, } \mathrm{keV}\end{array}$ & Reaction \\
\hline Hydrogen & $\mathrm{H}$ in chamber walls & 2223 (prompt) & ${ }^{1} \mathrm{H}(\mathrm{n}, \gamma){ }^{2} \mathrm{H}$ \\
\hline Iron & $\mathrm{Fe}$ in drum wall & $\begin{array}{c}7631,7646,352 \\
\text { (prompt) }\end{array}$ & ${ }^{56} \mathrm{Fe}(\mathrm{n}, \gamma){ }^{57} \mathrm{Fe}$ \\
\hline Calcium & $\begin{array}{c}\text { Ca in cement } \\
\text { (sample matrix) }\end{array}$ & $\begin{array}{c}1942,6420 \\
\text { (prompt) }\end{array}$ & $\mathrm{Ca}(\mathrm{n}, \gamma)$ \\
\hline Silicon & $\begin{array}{l}\text { Si in silica sand } \\
\text { (sample matrix) }\end{array}$ & $\begin{array}{c}3539,4934 \\
\text { (prompt) }\end{array}$ & $\mathrm{Si}(\mathrm{n}, \gamma)$ \\
\hline Sodium & $\mathrm{Na}$ in sample matrix & 1633 (decay) & ${ }^{23} \mathrm{Na}(\mathrm{n}, \alpha){ }^{20} \mathrm{~F}$ \\
\hline Germanium & $\begin{array}{c}\text { Ge in HPGe } \\
\text { detector }\end{array}$ & 596 (prompt) & ${ }^{73} \mathrm{Ge}(\mathrm{n}, \gamma){ }^{74} \mathrm{Ge}$ \\
\hline Aluminum & $\begin{array}{c}\mathrm{Al} \text { in detector } \\
\text { material }\end{array}$ & 844,1014 (decay) & ${ }^{27} \mathrm{Al}(\mathrm{n}, \mathrm{p}){ }^{27} \mathrm{Mg}$ \\
\hline Oxygen & $\begin{array}{l}\text { O in silica sand } \\
\text { (sample matrix) }\end{array}$ & 6129 (decay) & ${ }^{16} \mathrm{O}(\mathrm{n}, \mathrm{p}){ }^{16} \mathrm{~N}$ \\
\hline Chromium (?) & Cr in drum wall (?) & 1434 (decay) & ${ }^{52} \mathrm{Cr}(\mathrm{n}, \mathrm{p}){ }^{52} \mathrm{~V}$ \\
\hline
\end{tabular}

\section{Blind Drum Assays}

Each blind drum was assayed three times in separate runs of $600 \mathrm{~s}$ and $2000 \mathrm{~s} \mathrm{(a}$ total of six runs per drum) for $\mathrm{Hg}$ and $\mathrm{Cd}$. A drum was completely removed from the chamber and then re-inserted in between replicate runs. The blind drum runs were identical to the $\mathrm{Hg}$ and $\mathrm{Cd}$ calibration runs described above. An additional 600-s run was 
performed on each drum with the system configured to detect lead, as described in the section on lead calibration. Lead was detected in only two of the blind drums, and these drums were then each subjected to a 2000-s run to quantify their lead content. Replicate runs of $600 \mathrm{~s}$ and $2000 \mathrm{~s}$ were also performed with the two $\mathrm{Pb}$-containing drums.

\section{Replicate Drum Assay Results}

Results from replicate runs performed with the blind drums are shown in Table 7. The uncertainty due to nonreproducible conditions in the system geometry is estimated from the data of Table 7 by assuming the following relationship:

$$
\left(\sigma_{\mathrm{m}}\right)^{2}=\left(\sigma_{\mathrm{s}}\right)^{2}+\left(\sigma_{\mathrm{r}}\right)^{2}
$$

where

$$
\begin{aligned}
& \sigma_{\mathrm{m}}=\text { standard deviation of the mean of the three replicate peak area values } \\
& \sigma_{\mathrm{s}}=\Sigma\left(\sigma_{\mathrm{i}}\right) / 3, \sigma_{\mathrm{i}} \text { being the standard deviation due to counting error only of the } \\
& \text { peak area measured in replicate run } \mathrm{i}(\mathrm{i}=1,2,3) \\
& \sigma_{\mathrm{r}}=\text { uncertainty due to nonreproducibility in system geometry }
\end{aligned}
$$

Since both $\sigma_{\mathrm{m}}$ and $\sigma_{\mathrm{s}}$ are known, $\sigma_{\mathrm{r}}$ can be calculated from the above equation. Values of $\sigma_{\mathrm{r}}$ are listed in Table 7 for each set of replicate runs. The maximum value of $\sigma_{\mathrm{r}}$ observed in the replicate measurements is $4.8 \%$. In cases where $\sigma_{\mathrm{s}}$ is greater than $\sigma_{\mathrm{m}}, \sigma_{\mathrm{r}}$ is reported as being much smaller than $5 \%$, the maximum allowable uncertainty due to nonreproducibility. 
Table 7. Replicate Assays of Blind Drums

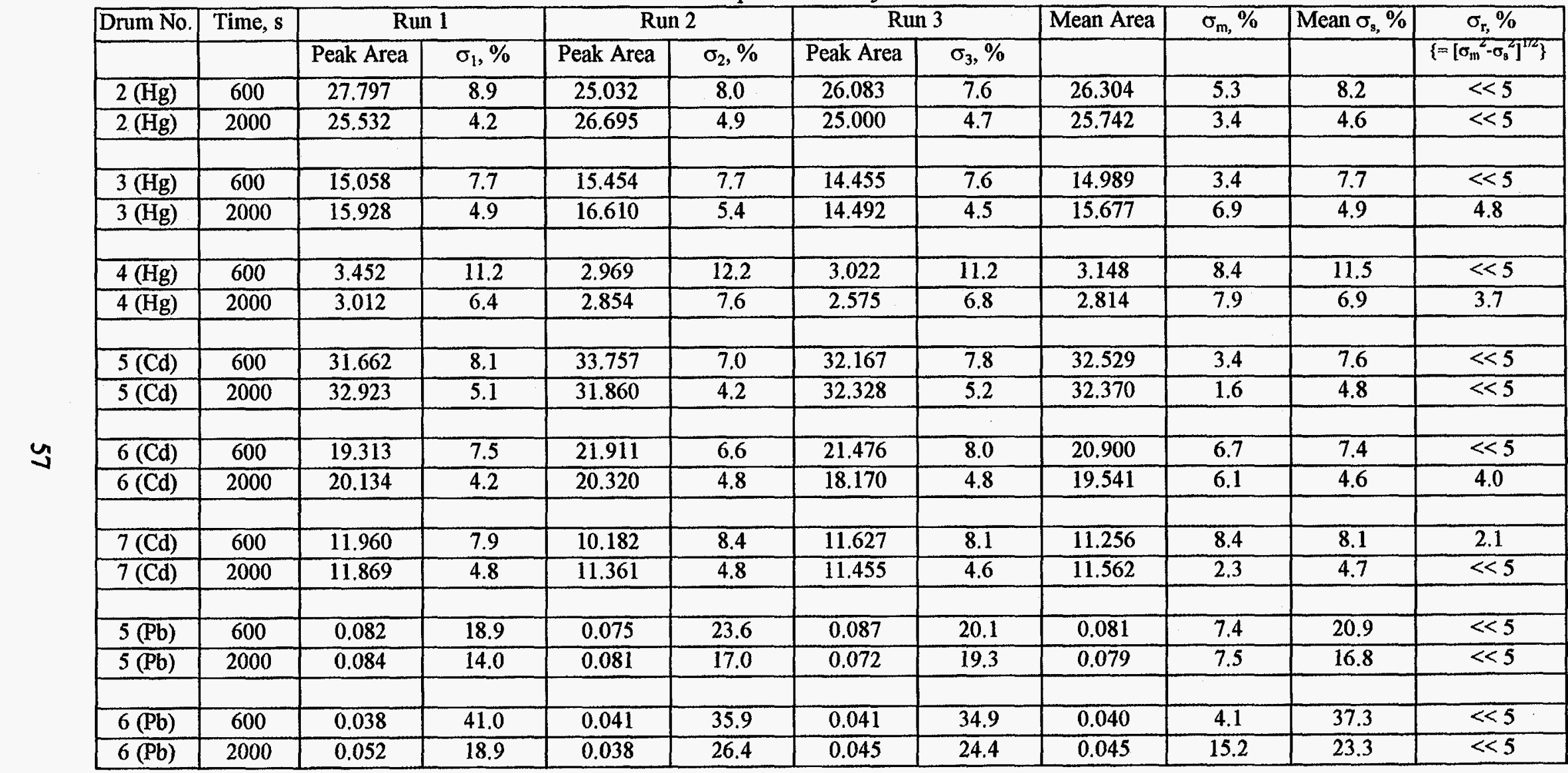




\section{Measurement Uncertainties}

Sources of uncertainty that can potentially contribute to the total uncertainty of a blind assay measurement are discussed below.

1. Primary Peak Area: The counting uncertainty in the values of the net peak area is calculated assuming that the distribution of the true value follows a normal distribution. This uncertainty (set equal to one standard deviation) includes the contribution from the error in the background area.

2. Neutron Output of D-T Source: The output of the D-T source decreased with time during the course of the measurements. Consequently, the peak areas of the primary signals have been normalized either to the intensity of $921-\mathrm{keV} \mathrm{Bi} \mathrm{line}(\mathrm{Hg}$ and $\mathrm{Cd})$ or to that of the $6129-\mathrm{keV}^{16} \mathrm{~N}$ line $(\mathrm{Pb})$. This normalization does introduce a source of random error in the measurements due to the uncertainties of the $B i$ and ${ }^{16} \mathrm{~N}$ peak areas, which are included in the combined uncertainty of the assay results. The uncertainty from the Bi normalization is of the order of $5 \%$, whereas that from the ${ }^{16} \mathrm{~N}$ normalization is of the order of $1 \%$.

3. Iron Interference with $\mathrm{Hg}$ Line: The contribution of the $366.5-\mathrm{keV}$ iron line to the peak area of the $368.1-\mathrm{keV} \mathrm{Hg}$ line would lead to an overestimation of the amount of $\mathrm{Hg}$ present in a drum if uncorrected. As described earlier, this effect can be and is accounted for in the $\mathrm{Hg}$ results. The counting errors of $352.2-\mathrm{keV}$ and $366.5-\mathrm{keV} \mathrm{Fe}$ peak areas are included in the combined uncertainty of the $\mathrm{Hg}$ assay results.

4. Source-Detector Geometry: An estimate of the nonreproducible uncertainty in the geometry is provided by the replicate assay runs performed with the blind samples. This contribution is assigned a value of $4.8 \%$, the highest value observed from the measurements (see Table 7).

5. Calibration Fit Error: The uncertainty in the calibration function was not formally calculated because of the small number of calibration points used to generate the functions. Instead, an estimate of the uncertainty was deduced from the results in Table 5. The maximum difference observed between an actual calibration concentration and one calculated using a calibration function is $7.8 \%$. Based on this 
result, an upper limit of $8 \%$ was adopted for the uncertainty of the calibration fits of all three elements, and this value was used in the calculation of the combined measurement uncertainty (Attachment II).

6. Calibration Concentrations: The error in the quoted concentration of a calibration drum is assumed to be negligible.

7. Contaminant Distribution in Sample Matrix: The sample matrix is assumed to have a uniform concentration of the unknown element. Any inhomogeneity that may exist in the sample, either through improper mixing during preparation or through stratification of the contaminant over time (ex: settling at the bottom of the drum), will introduce an error in the measurements. This error is assumed to be negligible in the present analysis.

8. Gamma Attenuation in Matrix: Gamma attenuation of the prompt signature gammarays in the matrix could lead to a systematic error, especially in samples that contain more than one unknown element. For example, the 558.6-keV line from $\mathrm{Cd}$ can be significantly attenuated if lead is present at high concentrations. Calculations show that the lead concentrations measured in the drums would have a negligible effect on the attenuation of the 558.6-keV Cd gamma line. Consequently, no correction is made for attenuation, and the error from this source is ignored in the analysis.

The combined (or total) uncertainty of the value of a measured blind concentration is obtained by summing in quadrature the contributions from each of the uncertainties listed above.

\section{Concentrations of $\mathrm{Hg}, \mathrm{Cd}$ and $\mathrm{Pb}$ in Blind Drums}

The presence of $\mathrm{Hg}, \mathrm{Cd}$ or $\mathrm{Pb}$ in a blind drum at the stated detection level (i.e. primary peak area uncertainty $\leq 35 \%$ ) is determined from the 600 -s assay of the drum. If an element is detected, then its concentration is calculated from the appropriate calibration response function using the peak area of the primary gamma line obtained in one of the 2000-s assay runs. Spectral plots from the 2000-s blind drum assays are shown in Figures 13 through 20. The measured concentrations of $\mathrm{Hg}, \mathrm{Cd}$ and $\mathrm{Pb}$ in each of the blind drums 
are reported in Table 8, together with their respective total uncertainties. Analysis sheets completed in the required format and listing individual uncertainty contributions for each measurement are provided in Attachment II.

Table 8. Measured Concentrations of $\mathrm{Hg}, \mathrm{Cd}$ and $\mathrm{Pb}$ in Blind Drums

\begin{tabular}{|c|c|c|c|}
\hline Drum No. & \multicolumn{3}{|c|}{ Concentration, ppm } \\
& Mercury & Cadmium & Lead \\
\hline 2 & $18191 \pm 14.3 \%$ & ND & ND \\
\hline 3 & $7031 \pm 14.1 \%$ & ND & ND \\
\hline 4 & $691 \pm 14.6 \%$ & ND & ND \\
\hline 5 & ND & $3613 \pm 10.6 \%$ & $18814 \pm 19.3 \%$ \\
\hline 6 & ND & $821 \pm 10.2 \%$ & $10416 \pm 21.0 \%$ \\
\hline 7 & ND & $321 \pm 10.5 \%$ & ND \\
\hline
\end{tabular}

$\mathrm{ND}=$ not detected

\section{Lower Limit of Detection (LLD)}

The results obtained from the lowest-concentration calibration drums were used to project the LLD's of the current system for mercury, cadmium and lead. These projections, shown in Table 9, are based on a detection criterion of $\pm 35 \%$ for the uncertainty in the primary signal, and have been calculated for real-time runs of $600 \mathrm{~s}$ and 2000 s. Projections of the LLD for mercury assume that the interference from the iron line is present. It should be noted that modifications and upgrades of the drum assay system may result in LLD's that are substantially better than those reported in Table 9. 
Table 9. LLD's of Current Drum Assay System

\begin{tabular}{|l|l|l|}
\hline Element & Run time, $\mathbf{s}$ & LLD, ppm \\
\hline Cadmium & 2000 & 9 \\
& 600 & 15 \\
\hline Mercury & 2000 & 115 \\
& 600 & 170 \\
\hline Lead & 2000 & 4400 \\
& 600 & 8600 \\
\hline
\end{tabular}




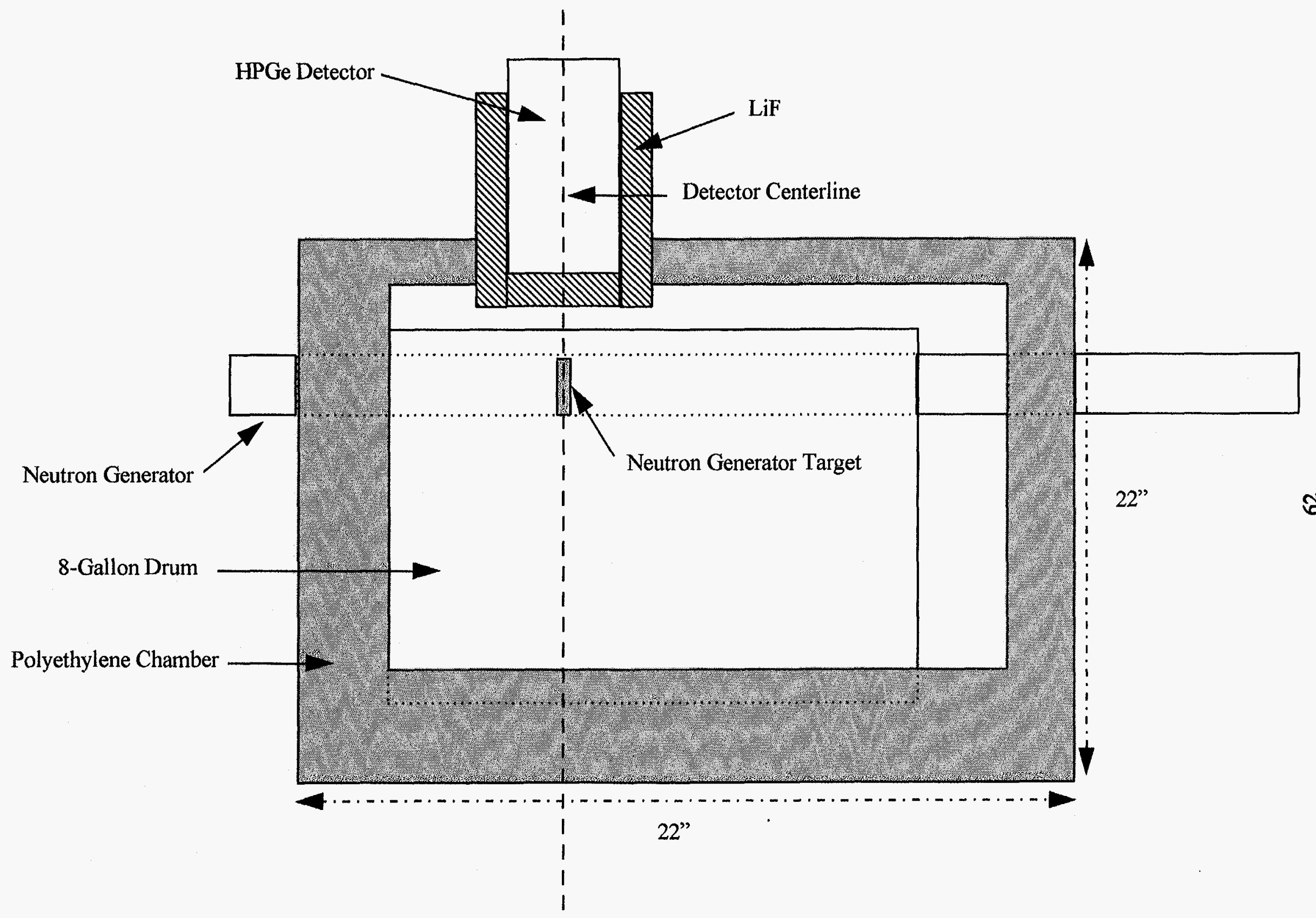

Figure 1a. Illustration of Drum Assay System 


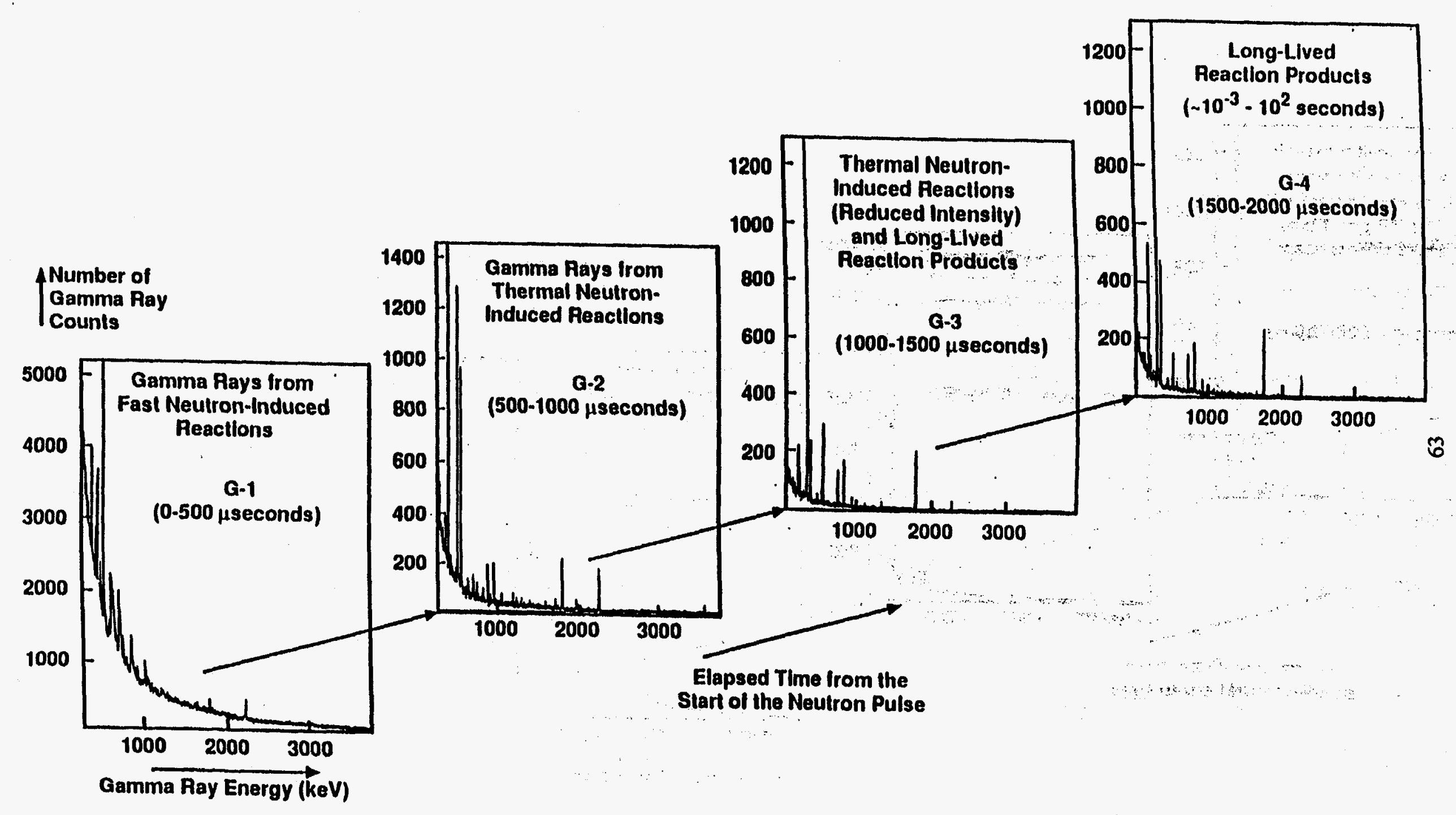

Figure 1b. Illustration of the Time-Sequenced Data Acquisition Feature of the PGNAA Drimin Assay System 

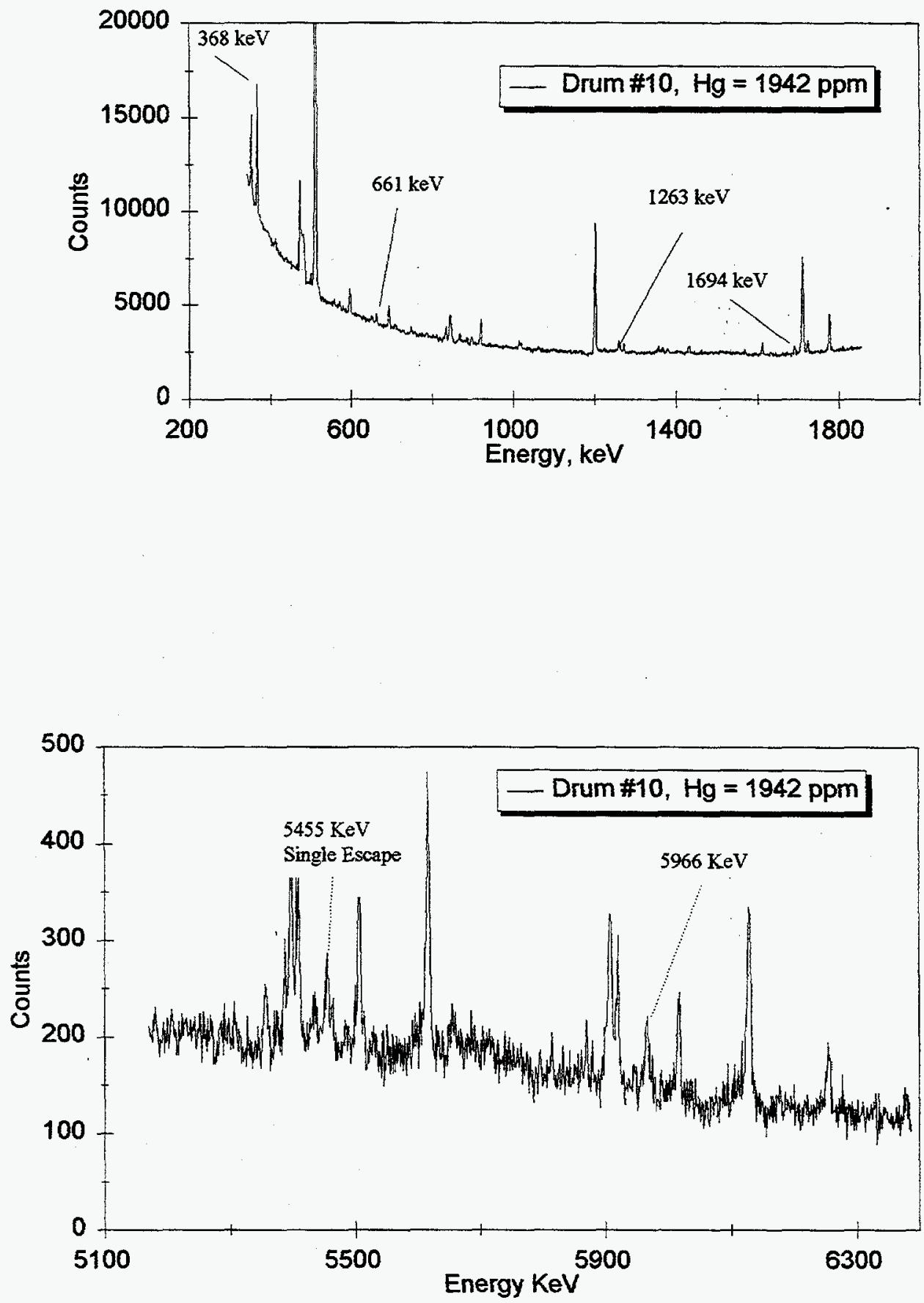

Figure 2. Prompt Gamma Spectrum of $\mathrm{Hg}$ 


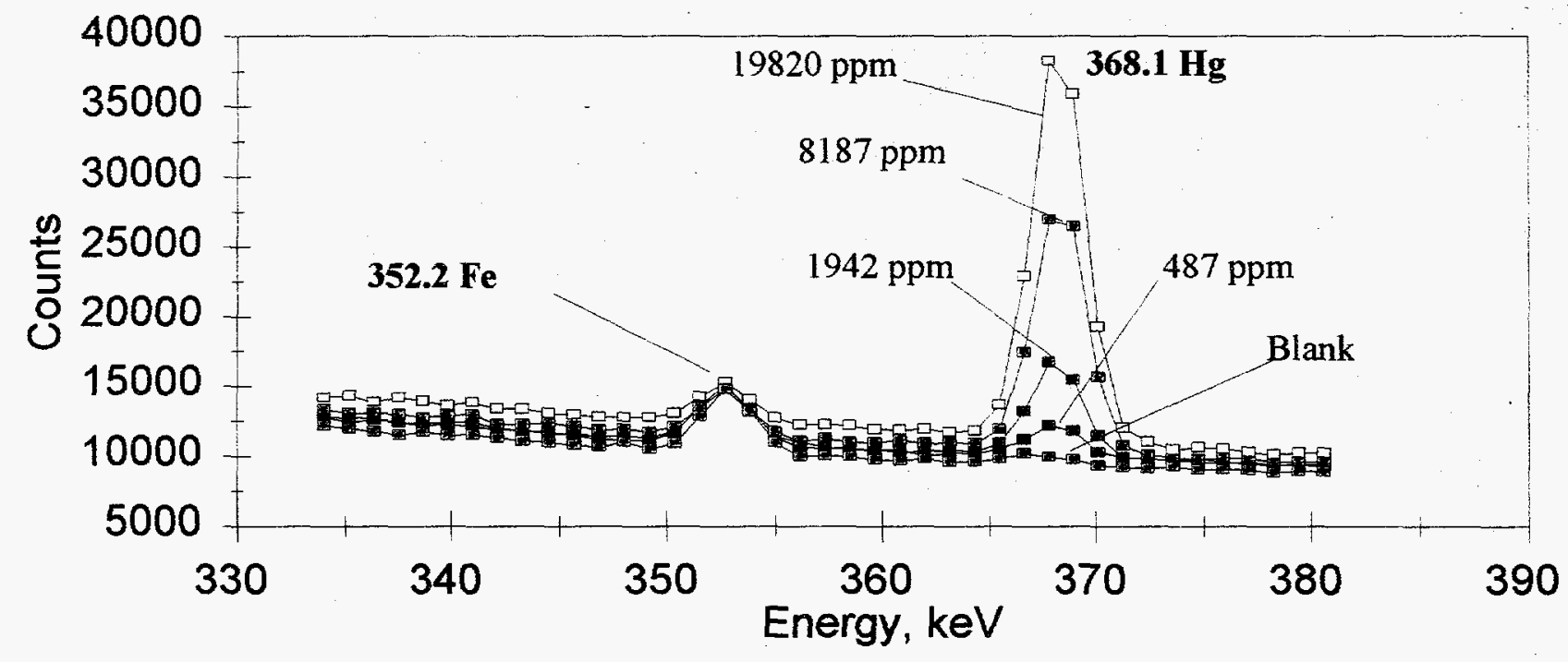

Figure 3. Comparison of 368.1-keV Peaks from Prompt Gamma Spectra of $\mathrm{Hg}$ Calibration Drums 


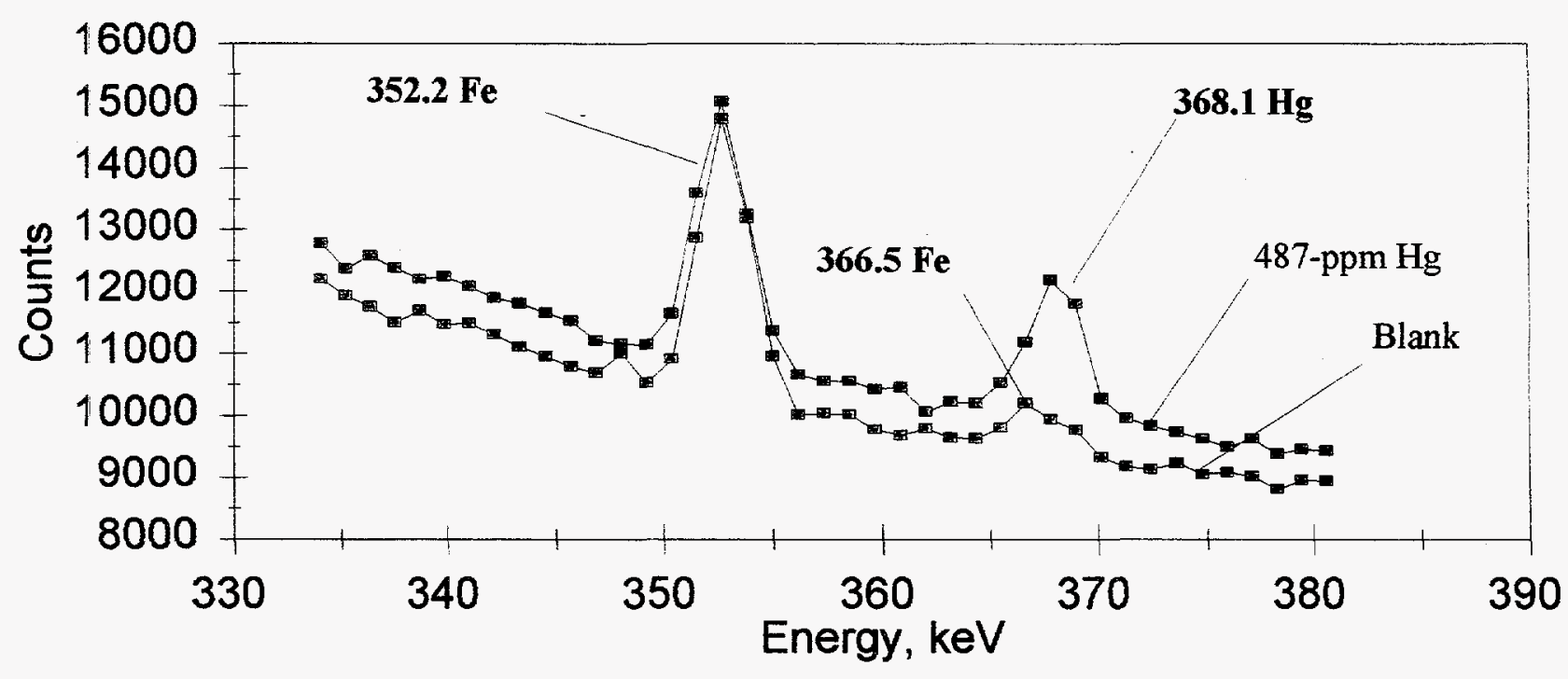

Figure 4. Comparison of Prompt Gamma Spectra from 487-ppm Hg Calibration Drum and from Blank Drum 


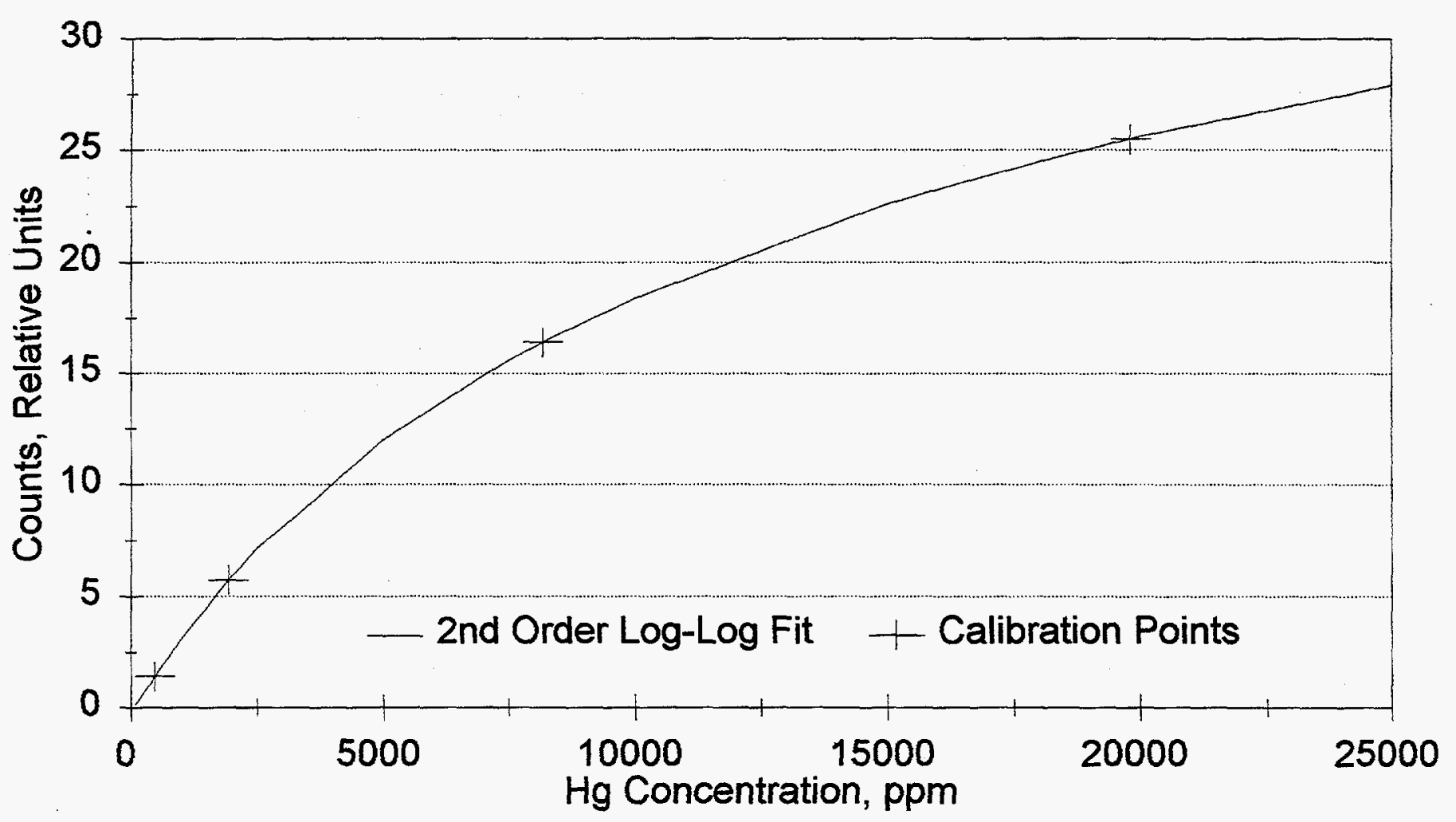

Figure 5. Calibration Response Function of $\mathbf{H g}$ 


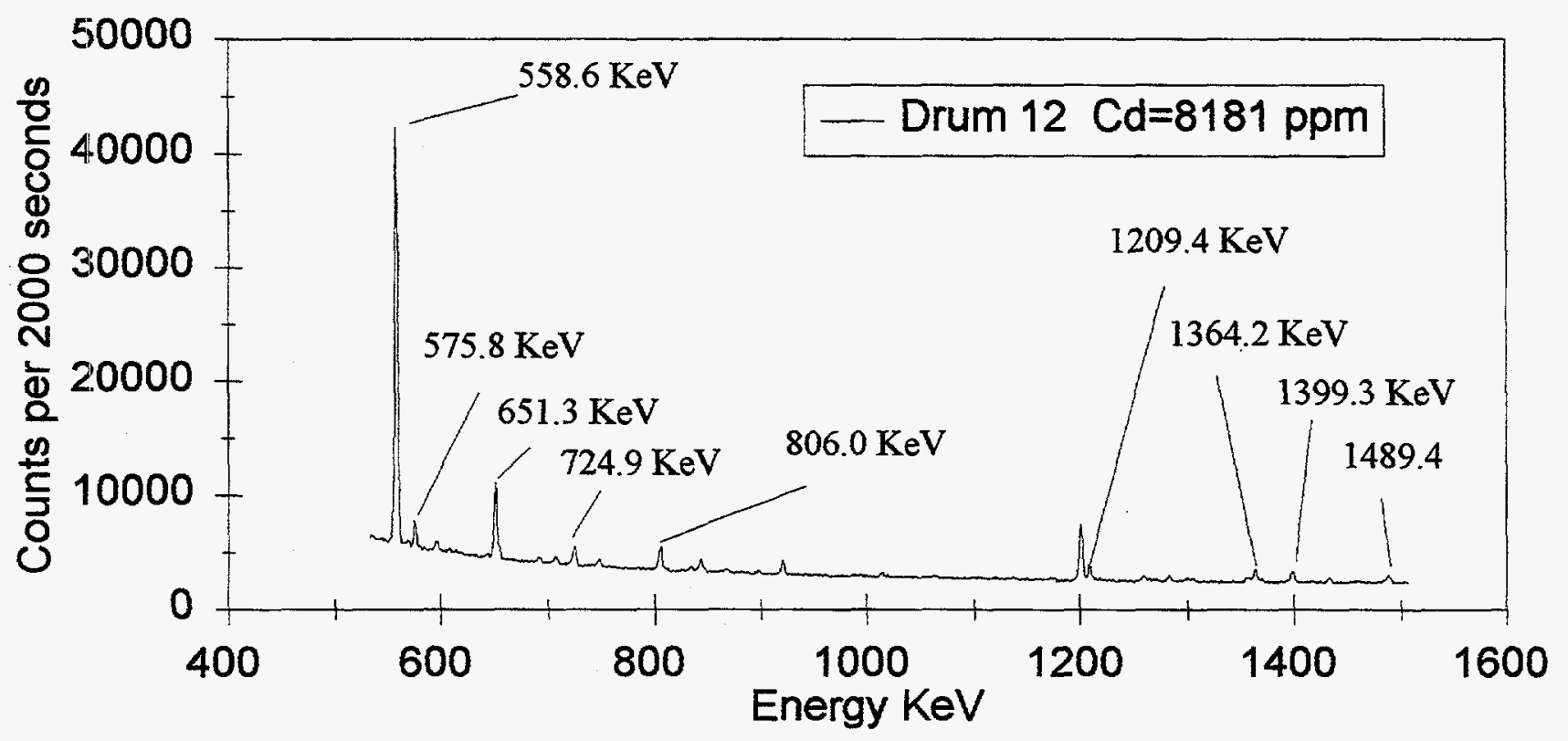

Figure 6. Prompt Gamma Spectrum of Cadmium 


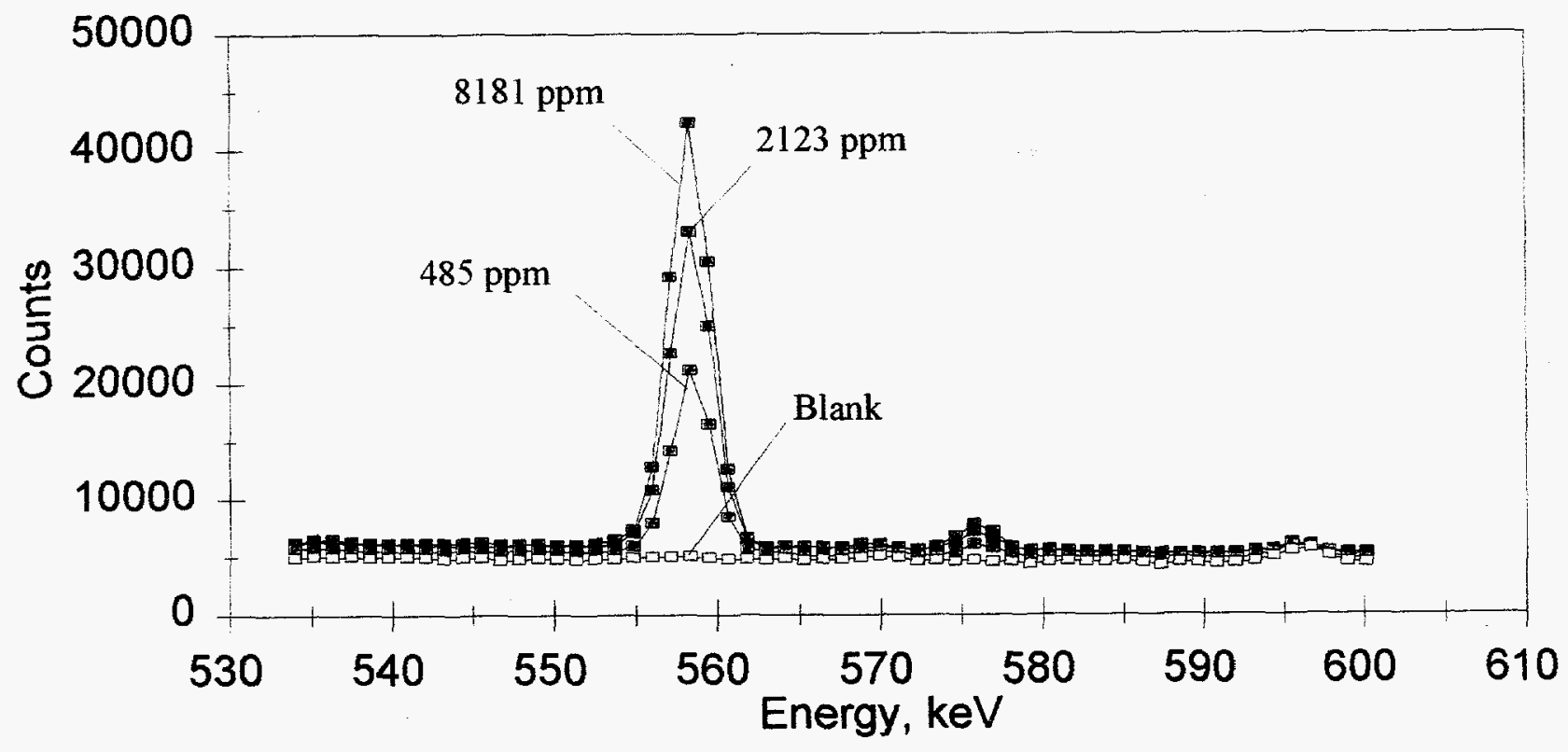

Figure 7. Comparison of 558.6-keV Peaks from Prompt Gamma Spectra of Cd Calibration Drums 


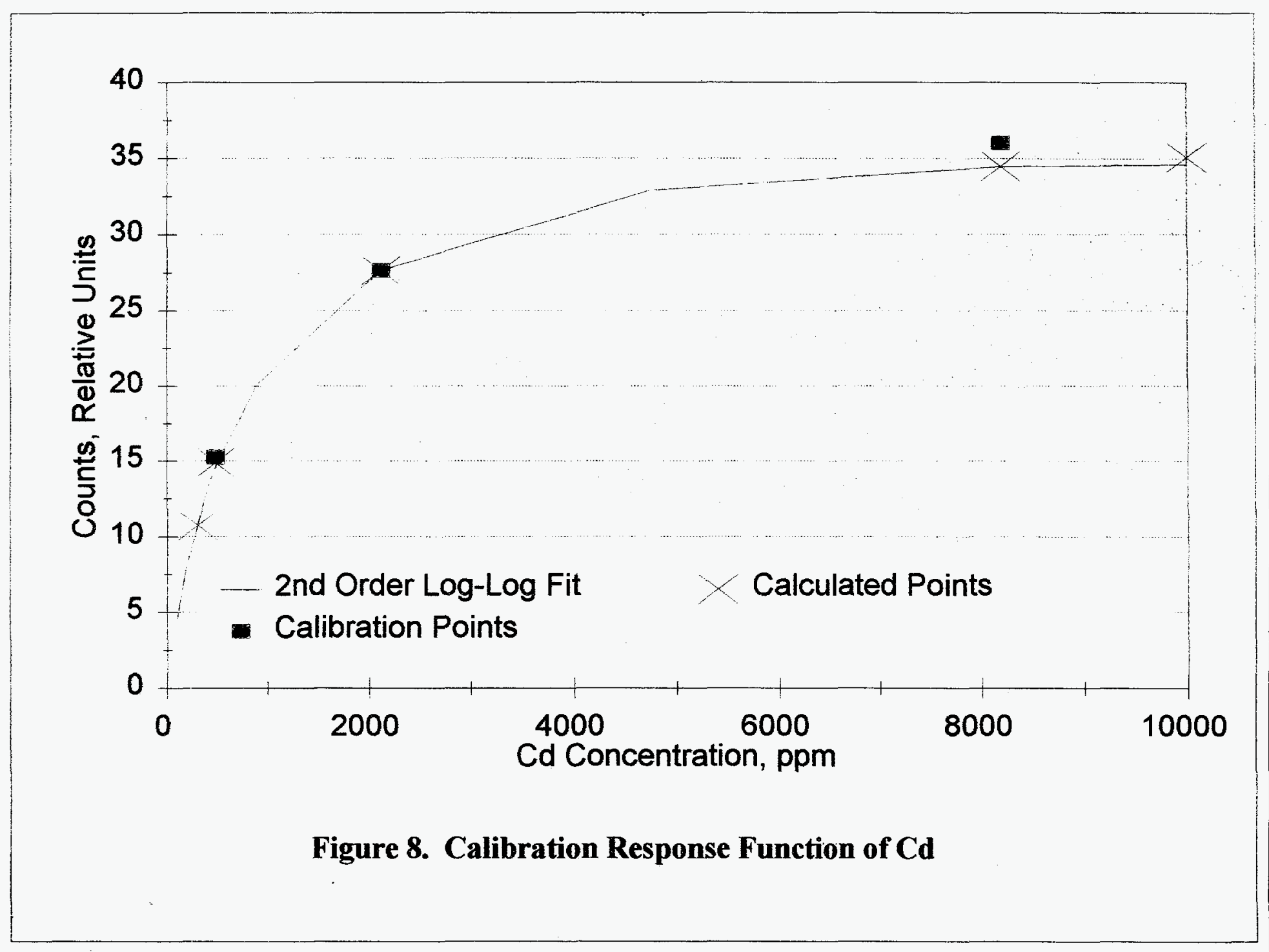




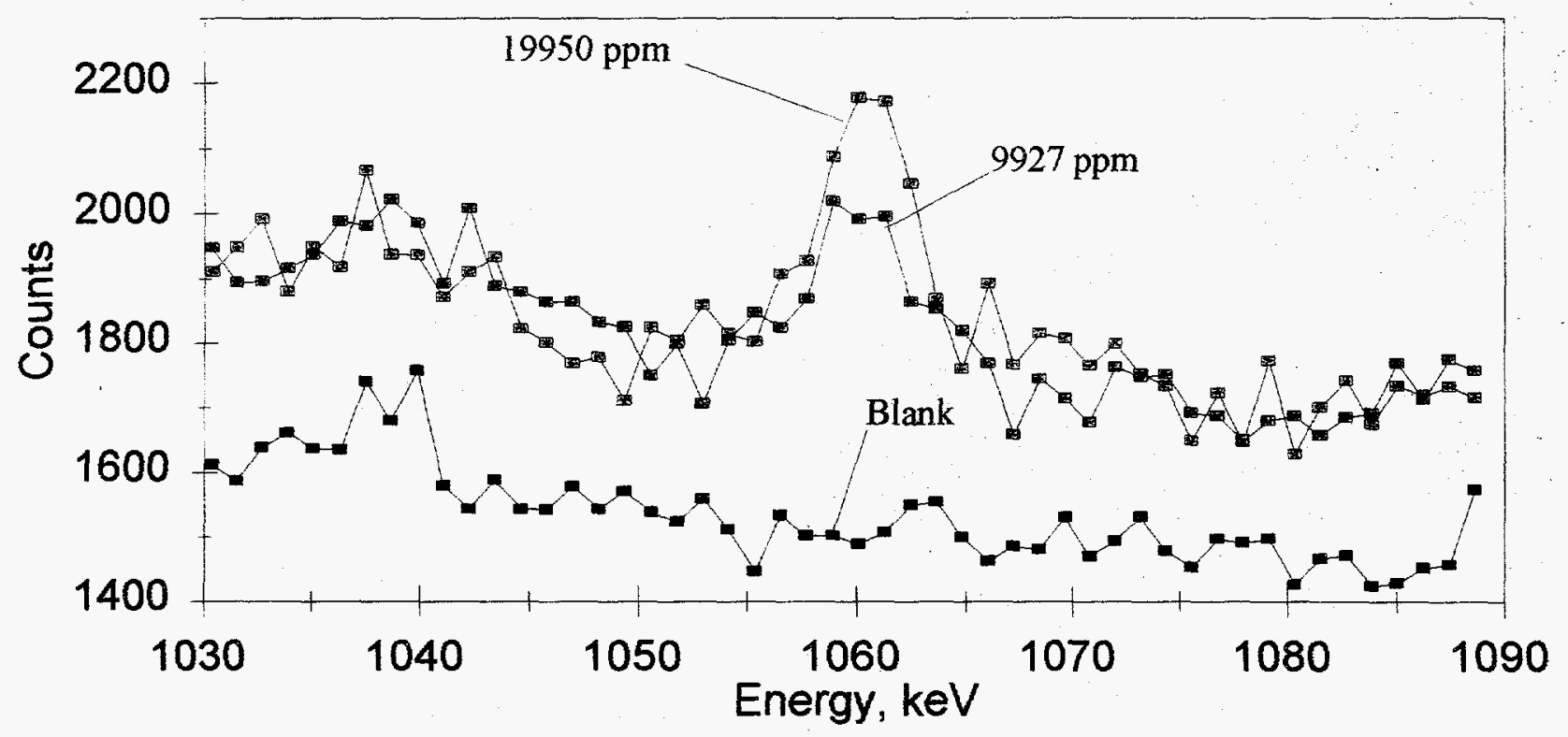

Figure 9. Comparison of 1063-keV Peaks from Decay Gamma Spectra of Pb Calibration Drums 


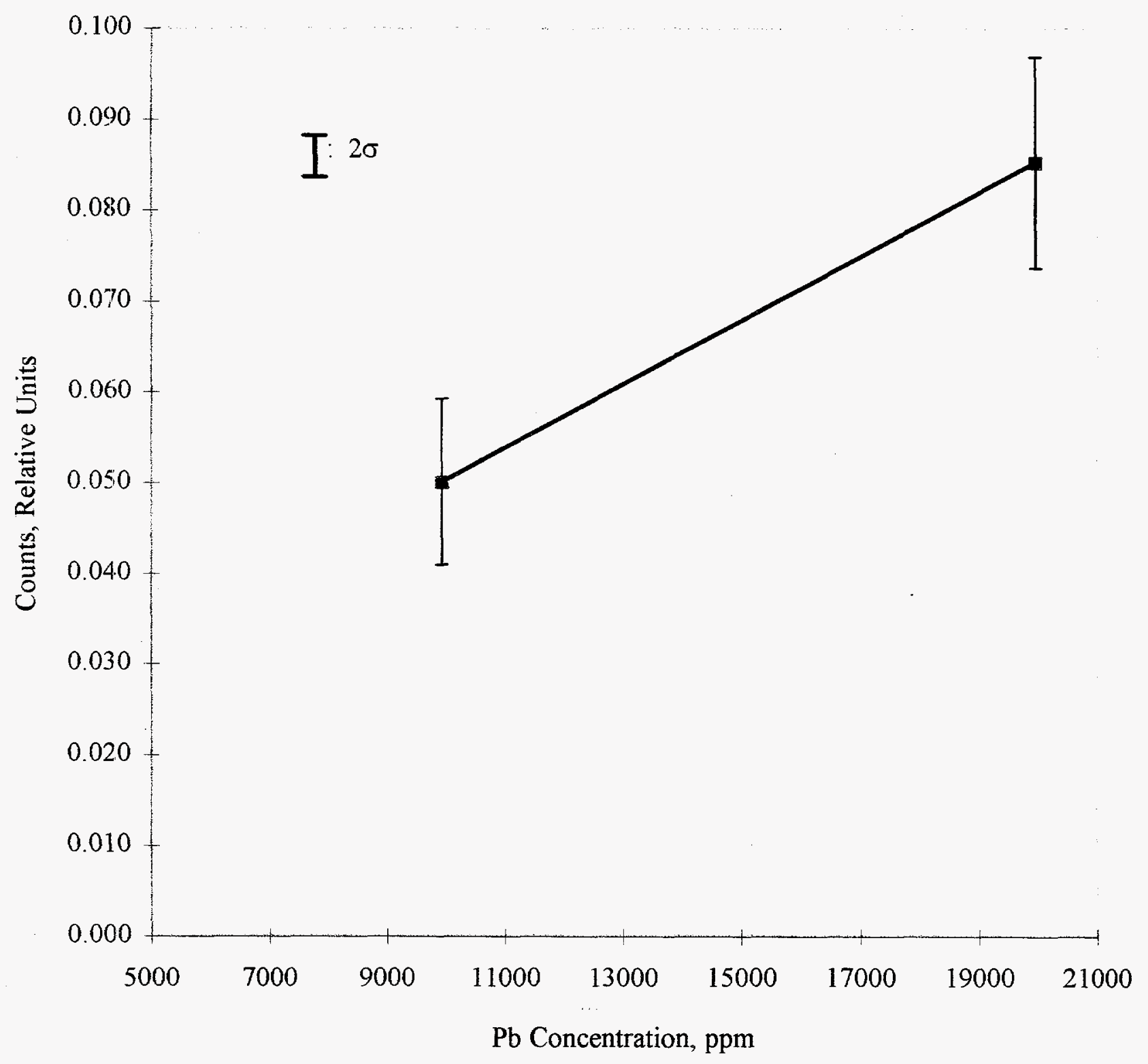

Figure 10. Calibration Response Function of $\mathbf{P b}$

72 

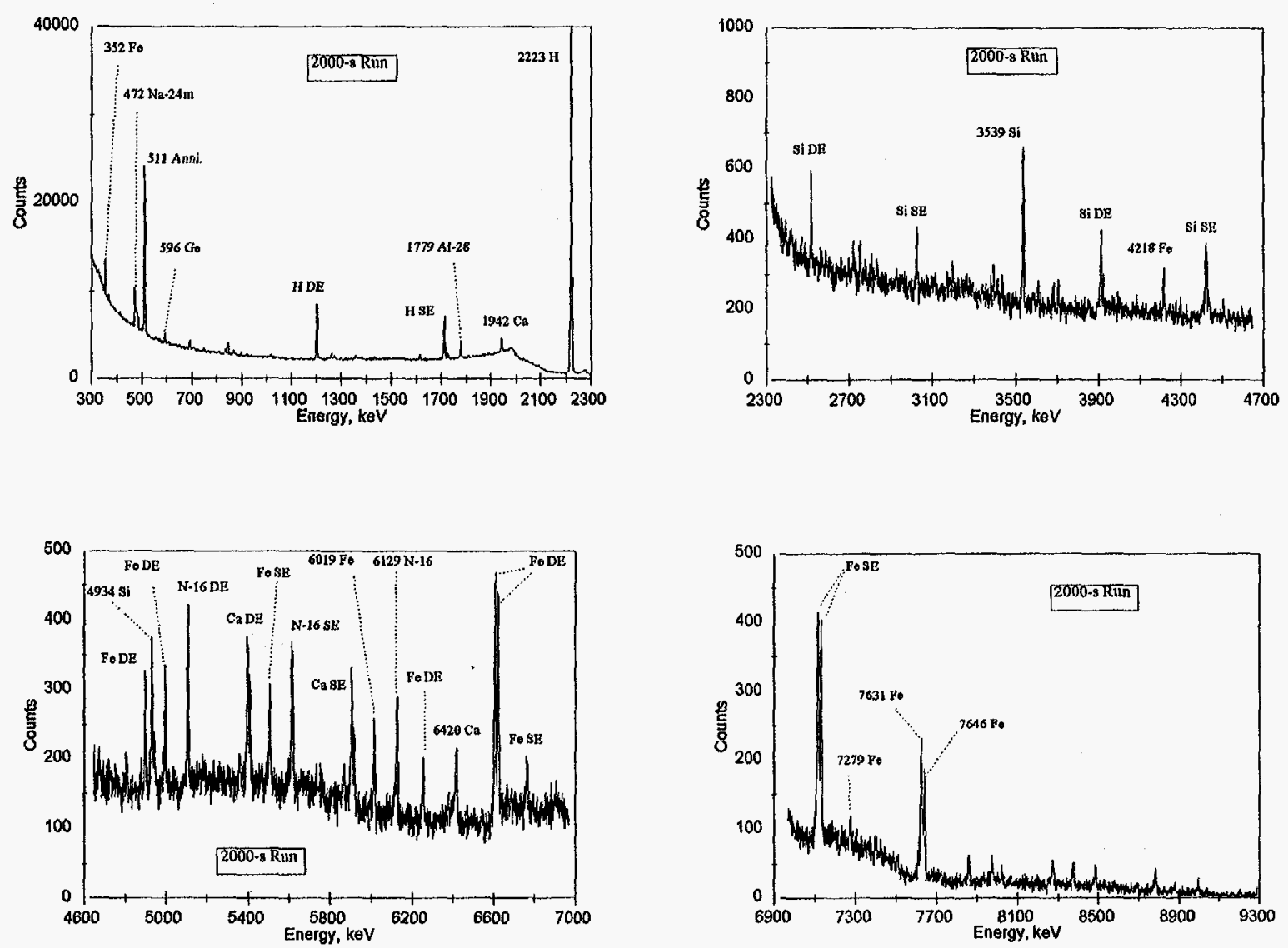

Figure 11. Prompt Gamma Spectrum of Blank Drum 


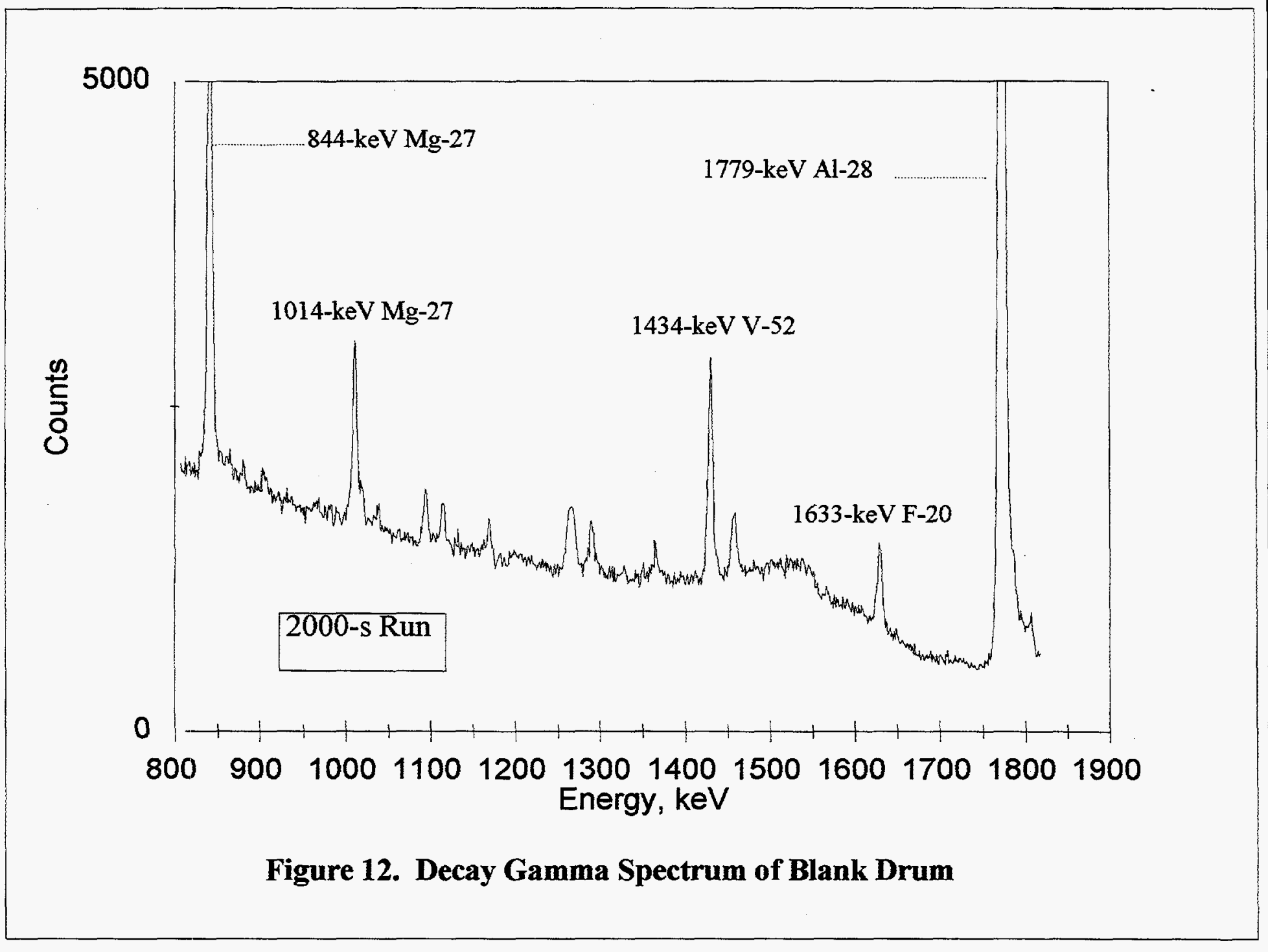




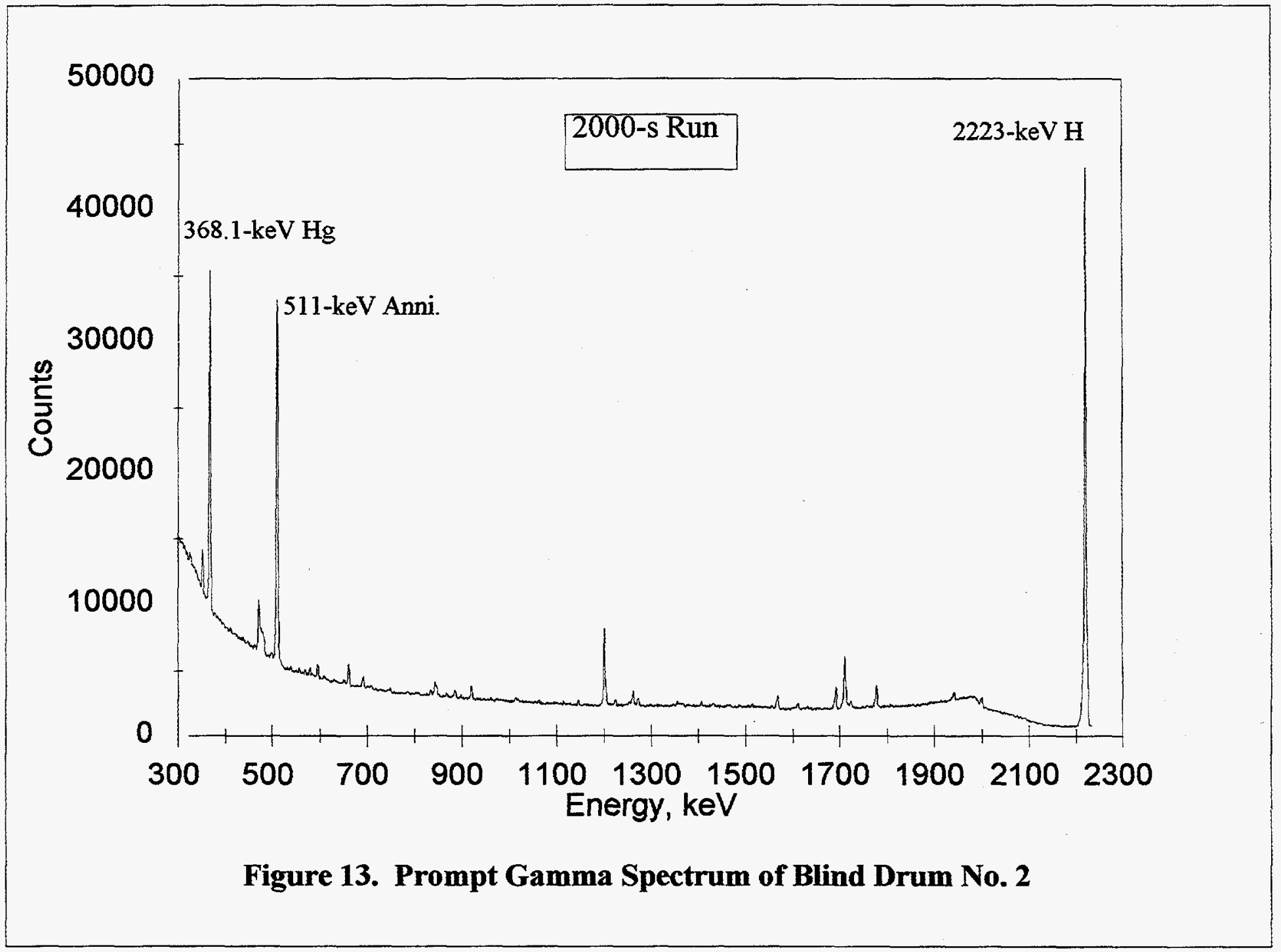




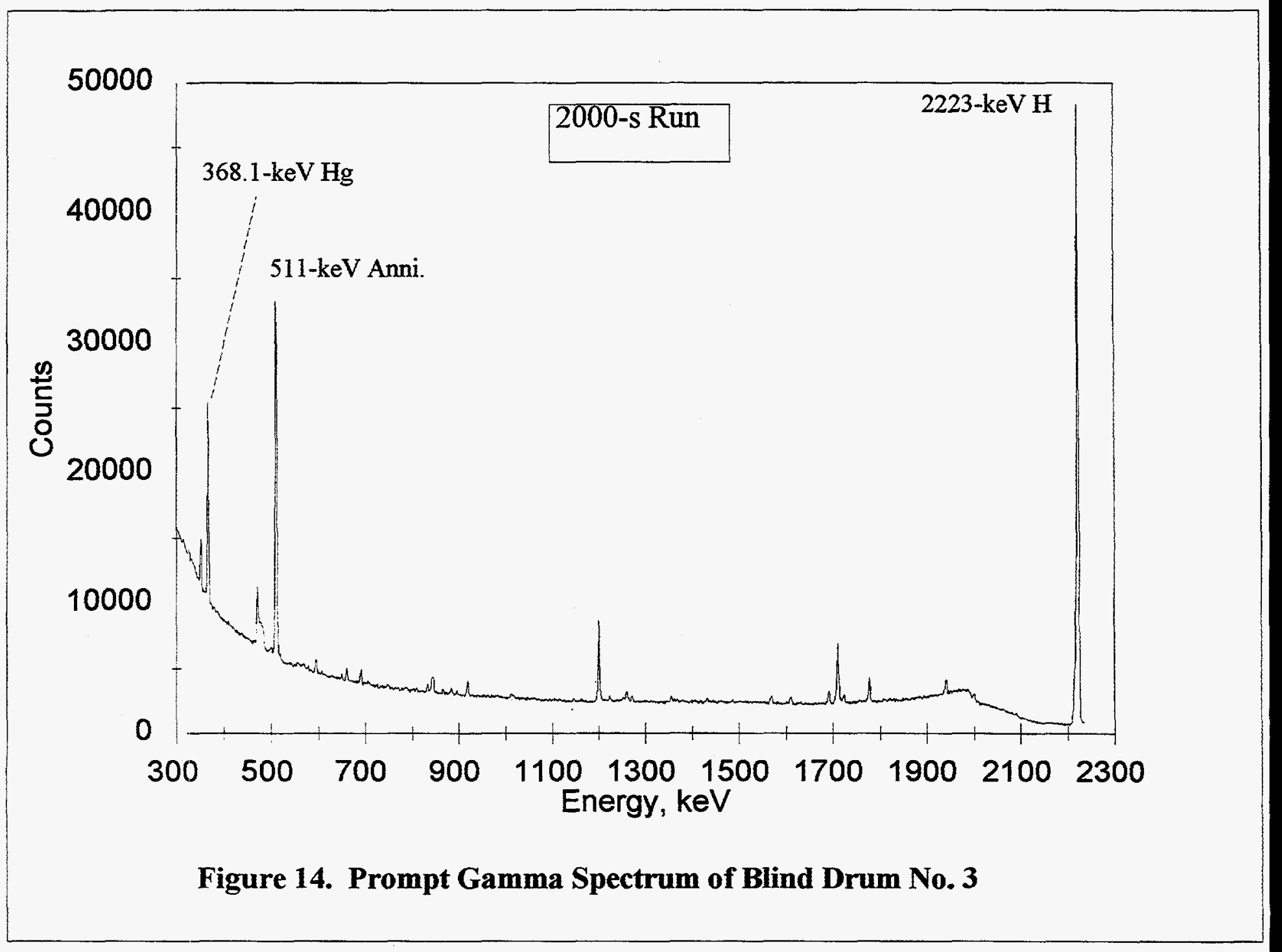



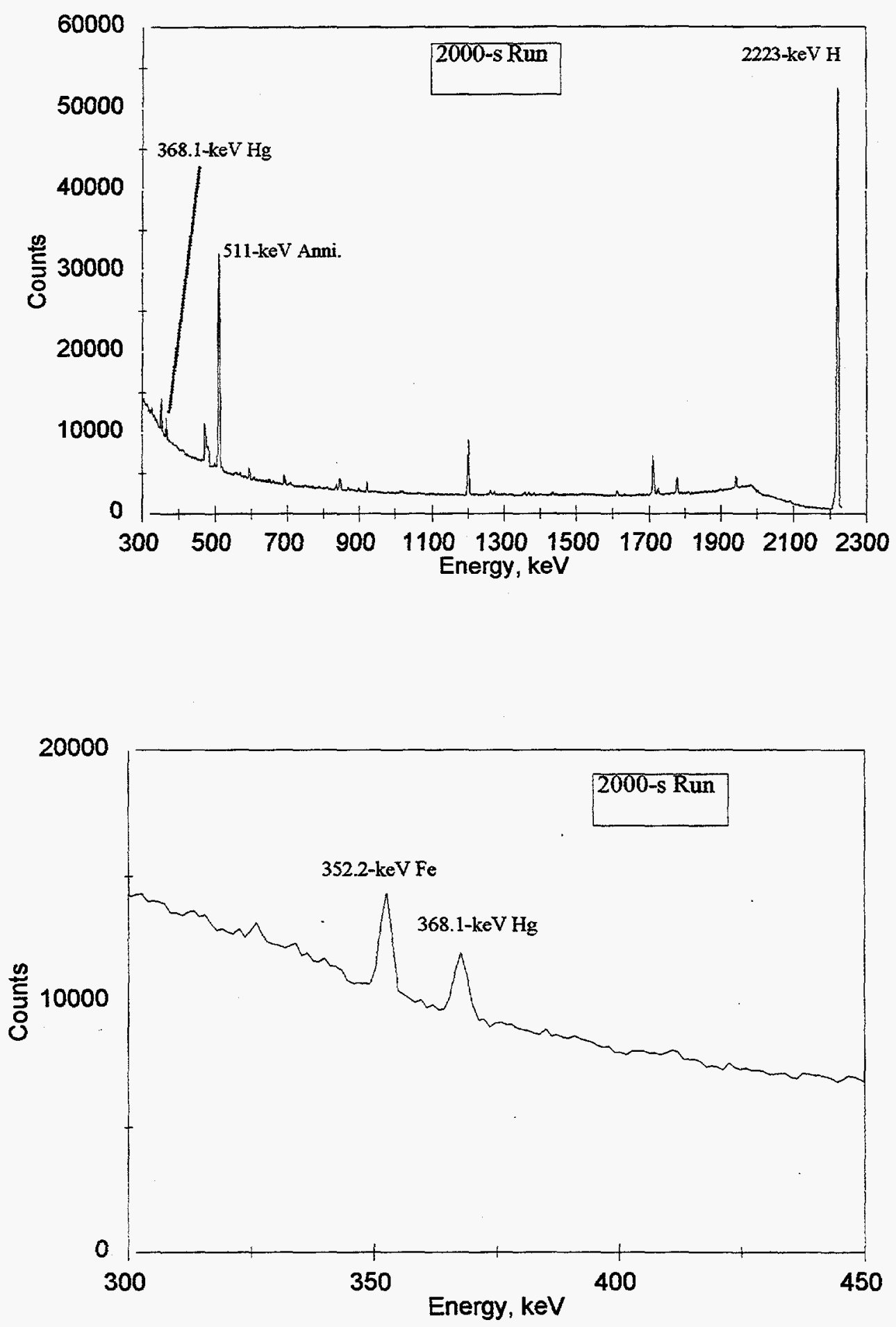

Figure 15. Prompt Gamma Spectrum of Blind Drum No. 4 


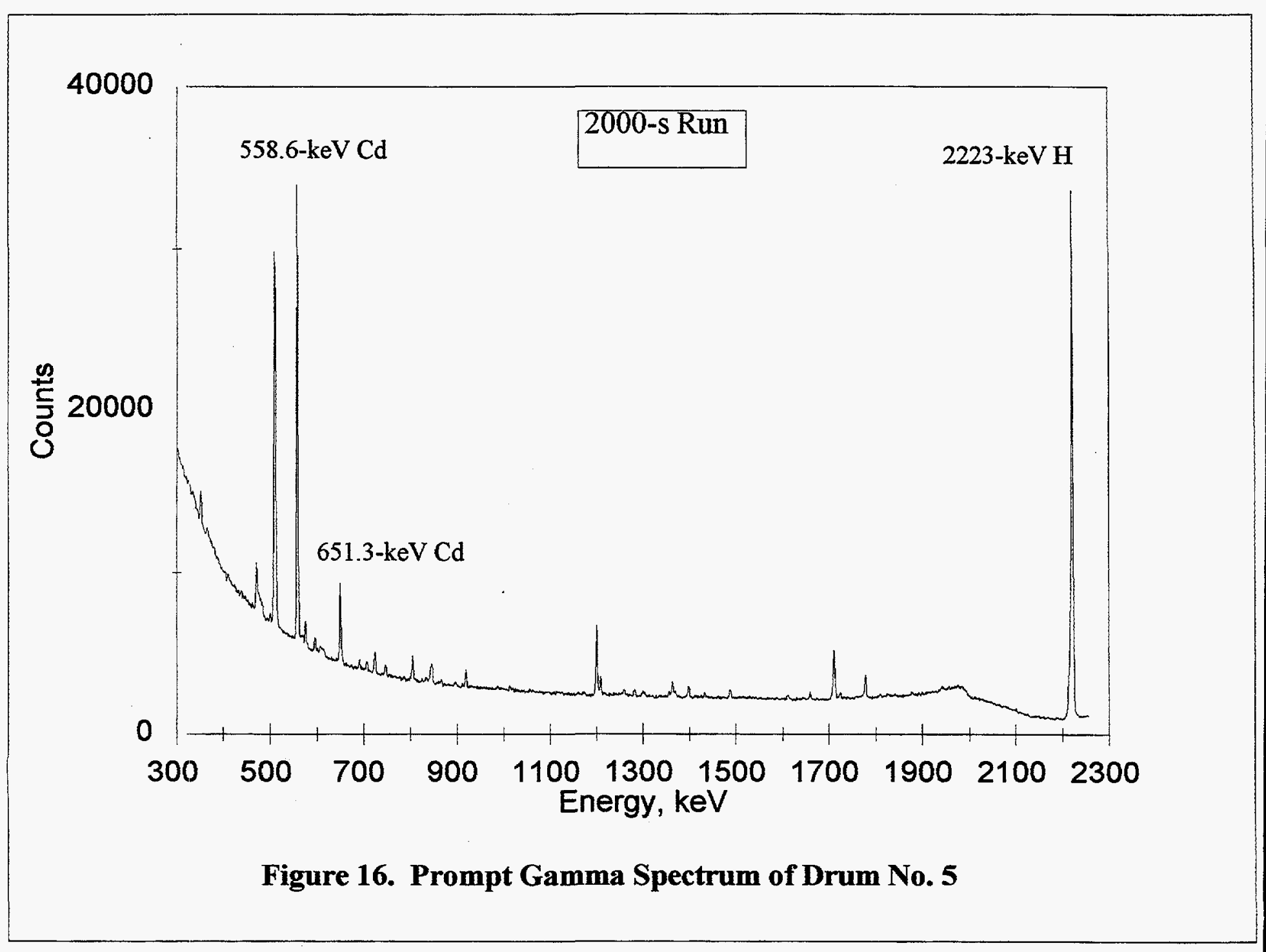




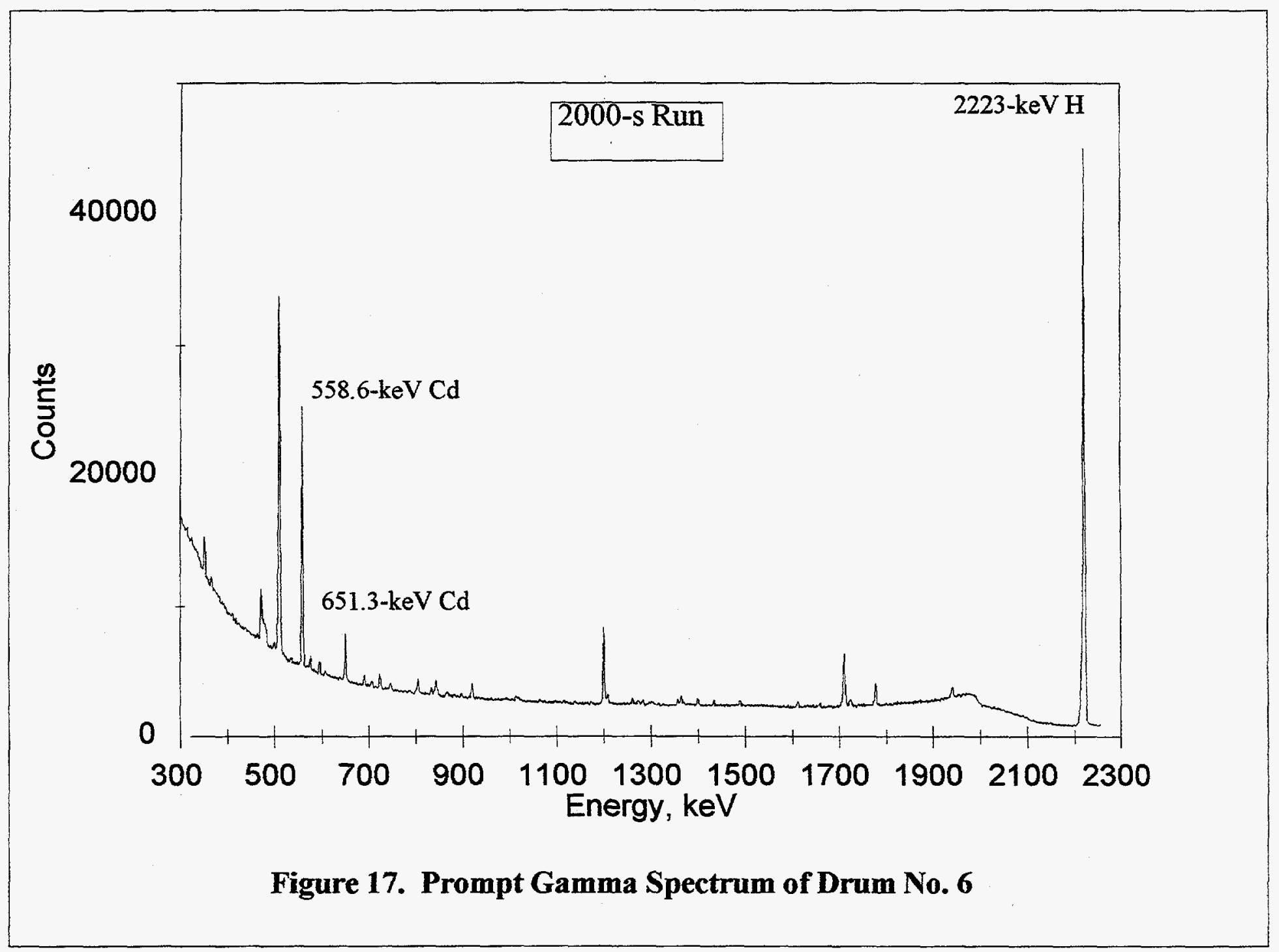




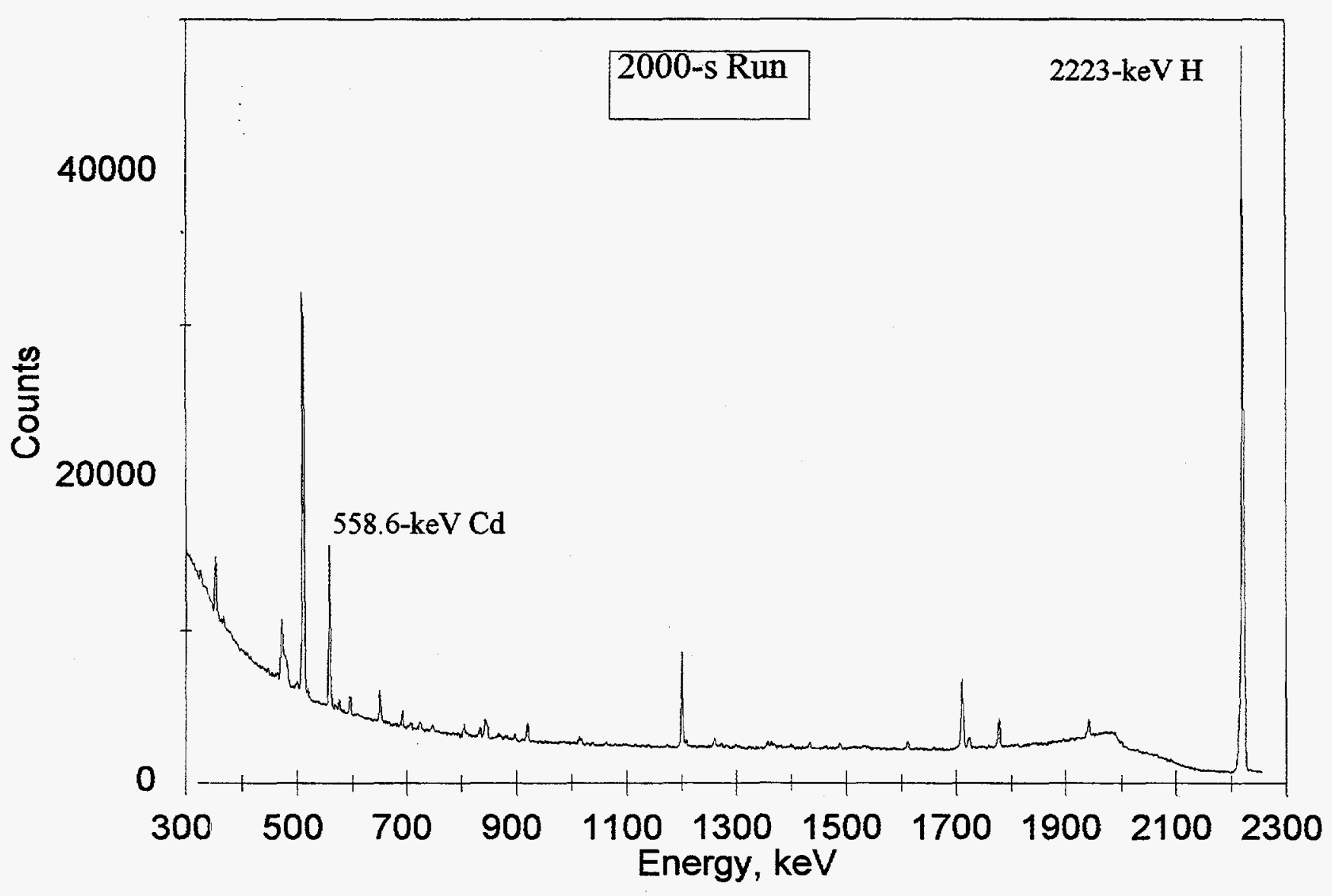

Figure 18. Prompt Gamma Spectrum of Drum No. 7 


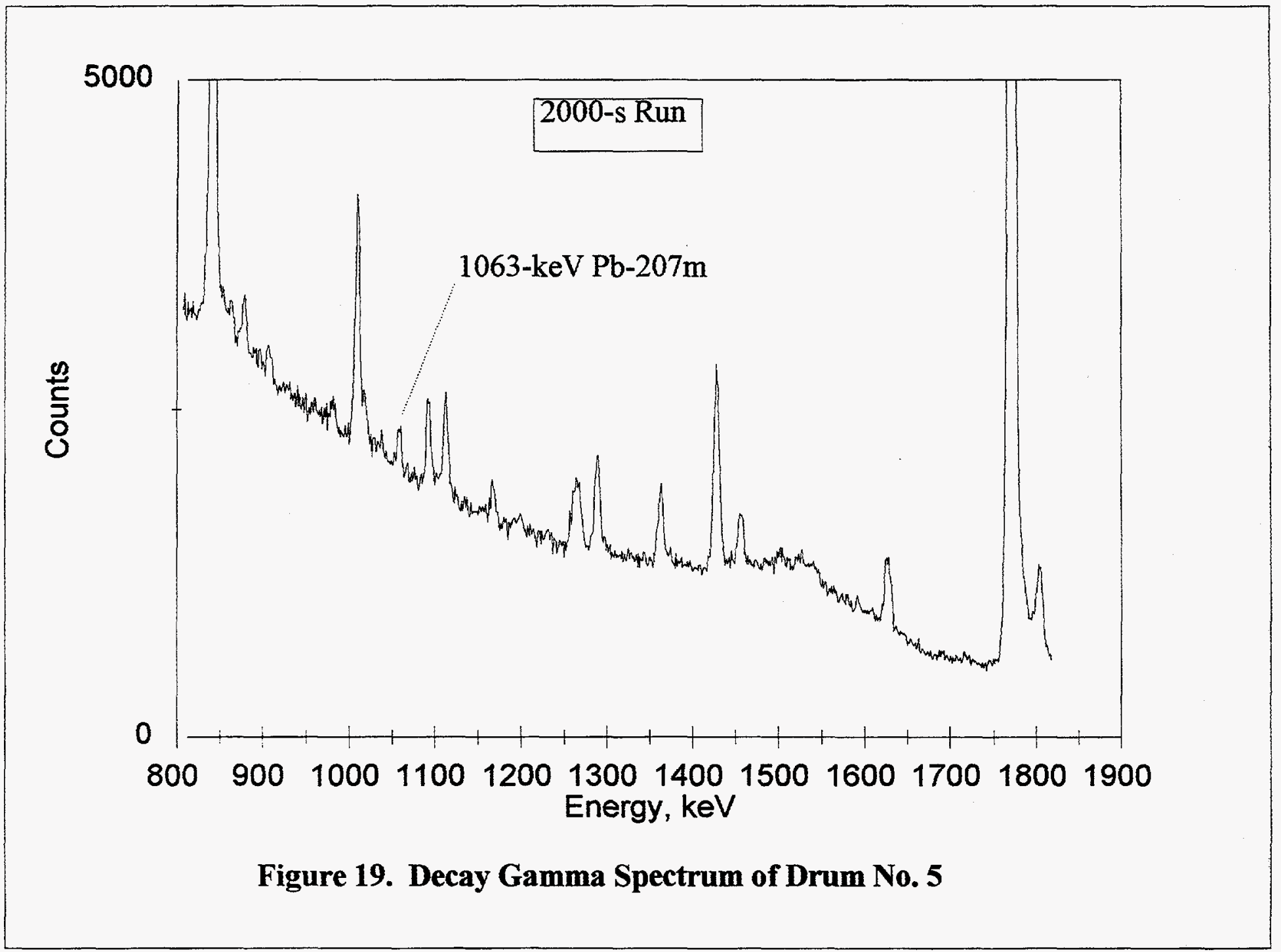




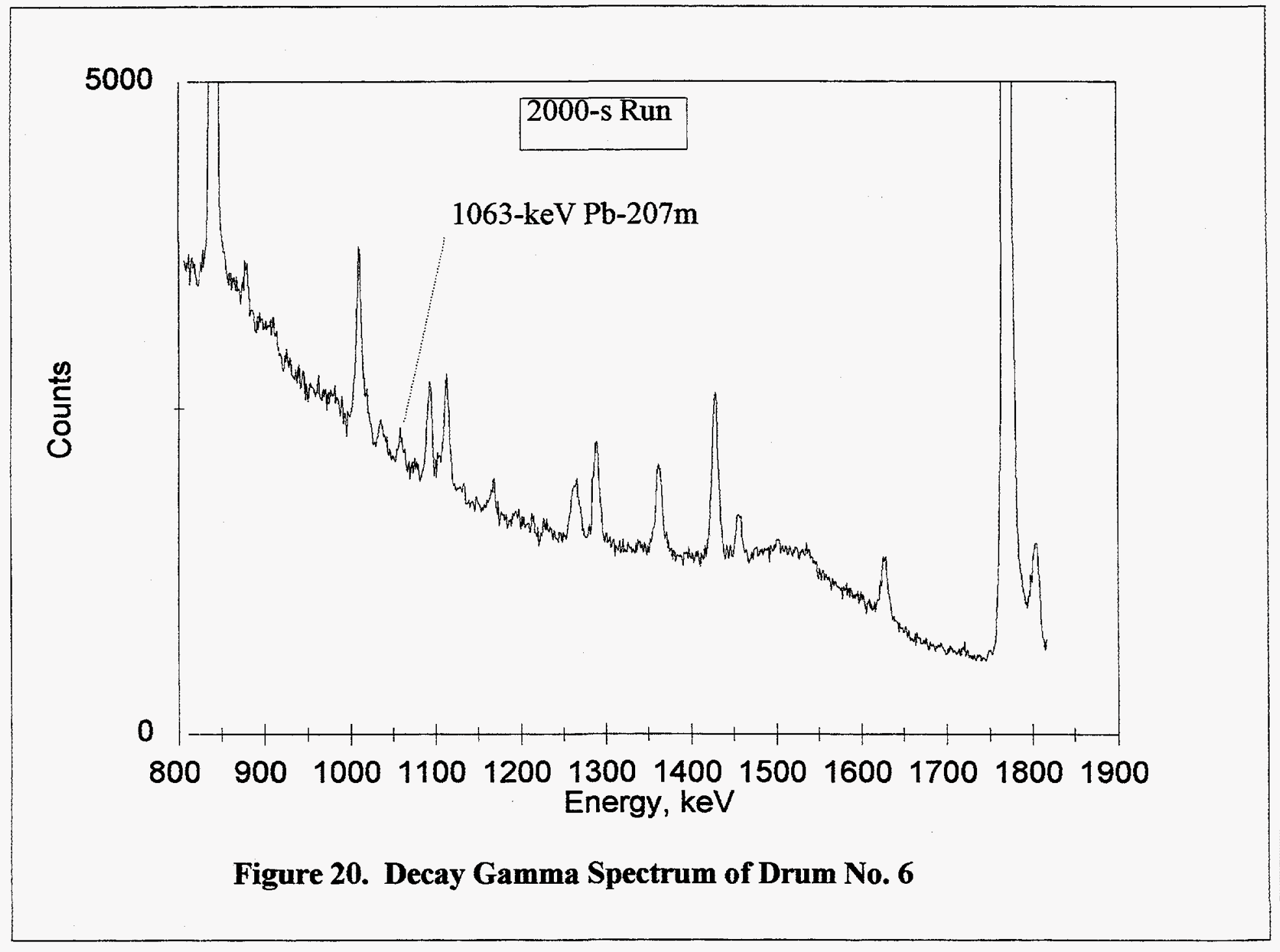




\section{Attachment II}

Analysis Sheets for Blind Surrogate Waste Drums 
Drum ID No.: 2 Count ID: G118 Date: 8/29/96 Counting Time: $2000 \mathrm{~s}$

\begin{tabular}{|l|l|l|l|l|}
\hline Elennent & $\begin{array}{l}\gamma \text {-ray energy } \\
(\mathrm{keV})\end{array}$ & $\begin{array}{l}\text { percent } \\
\text { concentration }^{\mathrm{a}}\end{array}$ & $\begin{array}{l}\text { peak area } \\
\text { statistical } \\
\text { uncertainty }\end{array}$ & $\begin{array}{l}\text { total } \\
\text { uncertainty }^{\mathrm{b}}\end{array}$ \\
\hline Mercury & 368.1 & 1.8191 & $0.8 \%$ & $14.3 \%$ \\
\hline Cadmium & 558.6 & ND & & \\
\hline Lead & 1063 & ND & & \\
\hline
\end{tabular}

a ND: not detected; DET: detected but not quantified

b Uncertainty Components:

D-T Source Output: $\quad 4.8 \%$

Fe Interference (Hg only): $\quad 9.7 \%$

System Geometry: $\quad 4.8 \%$

Calibration Fit: $\quad 8.0 \%$ 
Drum ID No: 2 Count ID: G055 Date: 8/20/96 Counting Time: $600 \mathrm{~s}$

\begin{tabular}{|l|l|l|l|l|}
\hline Element & $\begin{array}{l}\gamma \text {-ray energy } \\
(\mathrm{keV})\end{array}$ & $\begin{array}{l}\text { percent } \\
\text { concentration }^{\mathrm{a}}\end{array}$ & $\begin{array}{l}\text { peak area } \\
\text { statistical } \\
\text { uncertainty }\end{array}$ & $\begin{array}{l}\text { total } \\
\text { uncertainty }^{\mathrm{b}}\end{array}$ \\
\hline Mercury & 368.1 & DET & $1.4 \%$ & \\
\hline Cadmium & 558.6 & ND & & \\
\hline Lead & 1063 & ND & & \\
\hline
\end{tabular}

a ND: not detected; DET: detected but not quantified

b Uncertainty Components:

D-T Source Output: na

Fe Interference (Hg only): na

System Geometry: na

Calibration Fit: na 
Drum ID No.: 3 Count ID: G058

Date: $8 / 20 / 96$ Counting Time: $2000 \mathrm{~s}$

\begin{tabular}{|l|l|l|l|l|}
\hline $\begin{array}{c}\text { Element } \\
\text { Mercuis }\end{array}$ & $\begin{array}{l}\gamma \text {-ray energy } \\
(\mathrm{keV})\end{array}$ & $\begin{array}{l}\text { percent } \\
\text { concentration }^{\mathrm{a}}\end{array}$ & $\begin{array}{l}\text { peak area } \\
\text { statistical } \\
\text { uncertainty }\end{array}$ & $\begin{array}{l}\text { total } \\
\text { uncertainty }\end{array}$ \\
\hline Cadmiạm & 368.1 & 0.7031 & $1.3 \%$ & $14.1 \%$ \\
\hline Lead & 558.6 & ND & & \\
\hline
\end{tabular}

a ND: not detected; DET: detected but not quantified

b Uncertainty Components:

D-T Source Output: $\quad 4.7 \%$

Fe Interference (Hg only): $\quad 9.4 \%$

System Geometry: $\quad 4.8 \%$

Calibration Fit: $\quad 8.0 \%$ 
Drum ID No.: 3 Count ID: G057 Date: 8/20/96 Counting Time: $600 \mathrm{~s}$

\begin{tabular}{|l|l|l|l|l|}
\hline $\begin{array}{c}\text { Element } \\
\vdots\end{array}$ & $\begin{array}{l}\gamma \text {-ray energy } \\
(\mathrm{keV})\end{array}$ & $\begin{array}{l}\text { percent } \\
\text { concentration }^{\mathrm{a}}\end{array}$ & $\begin{array}{l}\text { peak area } \\
\text { statistical } \\
\text { uncertainty }\end{array}$ & $\begin{array}{l}\text { total } \\
\text { uncertainty }\end{array}$ \\
\hline Mercury & 368.1 & DET & $2.2 \%$ & \\
\hline Cadmium & 558.6 & ND & & \\
\hline Lead & 1063 & ND & & \\
\hline
\end{tabular}

a ND: not detected; DET: detected but not quantified

b Uncertainty Components:

D-T Source Output: na

Fe Interference (Hg only): na

System Geometry: na

Calibration Fit: na 
Drum $\frac{\vdots}{3}$ No.: 4 Count ID: G060

Date: $8 / 20 / 96$ Counting Time: $2000 \mathrm{~s}$

\begin{tabular}{|l|l|l|l|l|}
\hline $\begin{array}{l}\text { Element } \\
\vdots\end{array}$ & $\begin{array}{l}\gamma \text {-ray energy } \\
(\mathrm{keV})\end{array}$ & $\begin{array}{l}\text { percent } \\
\text { concentration }\end{array}$ & $\begin{array}{l}\text { peak area } \\
\text { statistical } \\
\text { uncertainty }\end{array}$ & $\begin{array}{l}\text { total } \\
\text { uncertainty }^{\mathrm{b}}\end{array}$ \\
\hline Mercury & 368.1 & 0.0691 & $4.8 \%$ & $14.6 \%$ \\
\hline Cadmium & 558.6 & ND & & \\
\hline Lead & 1063 & ND & & \\
\hline
\end{tabular}

a ND: not detected; DET: detected but not quantified

b Uncertainty Components:

D-T Source Output: $\quad 4.2 \%$

Fe Interference ( $\mathrm{Hg}$ only): $\quad 9.3 \%$

System Geometry: $\quad 4.8 \%$

Calibration Fit: $\quad 8.0 \%$ 
Drum ID No.: 4 Count ID: G059 Date: 8/20/96 Counting Time: $600 \mathrm{~s}$

\begin{tabular}{|l|l|l|l|l|}
\hline $\begin{array}{l}\text { Element } \\
\text { Mercuk }\end{array}$ & $\begin{array}{l}\gamma \text {-ray energy } \\
(\mathrm{keV})\end{array}$ & $\begin{array}{l}\text { percent } \\
\text { concentration }^{\mathrm{a}}\end{array}$ & $\begin{array}{l}\text { peak area } \\
\text { statistical } \\
\text { uncertainty }\end{array}$ & $\begin{array}{l}\text { total } \\
\text { uncertainty }\end{array}$ \\
\hline Cadmiüm & 368.1 & DET & $7.7 \%$ & \\
\hline Lead & 558.6 & ND & & \\
\hline
\end{tabular}

a ND: not detected; DET: detected but not quantified

b Uncertainty Components:

D-T Source Output: na

Fe Interference (Hg only): na

System Geometry: na

Calibration Fit: na 
Drum ID No.: 5 Count ID: G062 (Cd) Date: 8/20/96 Counting Time: $2000 \mathrm{~s}$ $\mathrm{G} 148(\mathrm{~Pb})$

\begin{tabular}{|l|l|l|l|l|}
\hline $\begin{array}{l}\text { Element } \\
\vdots\end{array}$ & $\begin{array}{l}\gamma \text {-ray energy } \\
(\mathrm{keV})\end{array}$ & $\begin{array}{l}\text { percent } \\
\text { concentration }^{\mathrm{a}}\end{array}$ & $\begin{array}{l}\text { peak area } \\
\text { statistical } \\
\text { uncertainty }\end{array}$ & $\begin{array}{l}\text { total } \\
\text { uncertainty }\end{array}$ \\
\hline Mercury & 368.1 & ND & & \\
\hline Cadmium & 558.6 & 0.3613 & $0.6 \%$ & $10.6 \%$ \\
\hline Lead & 1063 & 1.8814 & $16.9 \%$ & $19.3 \%$ \\
\hline
\end{tabular}

a ND: not detected; DET: detected but not quantified

b

Uncertainty Components:

Cadmium:

D-T Source Output: $\quad 5.1 \%$

Fe Interference (Hg only): na

System Geometry: $\quad 4.8 \%$

Calibration Fit: $\quad 8.0 \%$

Lead:

D-T Source Output: $\quad 1.1 \%$

Fe Interference (Hg only): na

System Geometry: $\quad 4.8 \%$

Calibration Fit: $\quad 8.0 \%$ 


Drum No.: 5 Count ID: G061 (Cd) Date: 8/20/96 Counting Time: $600 \mathrm{~s}$
G145 (Pb)

a ND: not detected; DET: detected but not quantified

b Uncertainty Components:

Cadmium:

D-T Source Output: na

Fe Interference (Hg only): na

System Geometry: na

Calibration Fit: na

Lead:

D-T Source Output: na

Fe Interference ( $\mathrm{Hg}$ only): na

System Geometry: na

Calibration Fit: na 


\begin{tabular}{|c|c|c|c|c|}
\hline Drum ID No.: 6 & Count ID: & $\begin{array}{l}(\mathrm{Cd}) \\
(\mathrm{Pb})\end{array}$ & Cou & Time: $2000 \mathrm{~s}$ \\
\hline Eleme & $\begin{array}{l}\gamma \text {-ray energy } \\
(\mathrm{keV})\end{array}$ & $\begin{array}{l}\text { percent } \\
\text { concentration }\end{array}$ & $\begin{array}{l}\text { peak area } \\
\text { statistical } \\
\text { uncertainty }\end{array}$ & $\begin{array}{l}\text { total } \\
\text { uncertainty }\end{array}$ \\
\hline Mercuiy & 368.1 & ND & & \\
\hline Cadmiüm & 558.6 & 0.0821 & $0.9 \%$ & $10.2 \%$ \\
\hline Lead & 1063 & 1.0416 & $18.8 \%$ & $21.0 \%$ \\
\hline
\end{tabular}

a ND: not detected; DET: detected but not quantified

b Uncertainty Components:

Cadmium:

D-T Source Output:

$4.1 \%$

Fe Interference (Hg only): na

System Geometry: $\quad 4.8 \%$

Calibration Fit: $\quad 8.0 \%$

Lead:

D-T Source Output: $\quad 1.4 \%$

Fe Interference (Hg only): na

System Geometry: $\quad 4.8 \%$

Calibration Fit: $\quad 8.0 \%$ 


\begin{tabular}{|c|c|c|c|c|}
\hline Drum ID No.: 6 & Count ID: C & $\begin{array}{l}(\mathrm{Cd}) \\
(\mathrm{Pb})\end{array}$ & Cour & Time: $600 \mathrm{~s}$ \\
\hline Elemey & $\begin{array}{l}\gamma \text {-ray energy } \\
(\mathrm{keV})\end{array}$ & $\begin{array}{l}\text { percent } \\
\text { concentration }\end{array}$ & $\begin{array}{l}\text { peak area } \\
\text { statistical } \\
\text { uncertainty }\end{array}$ & $\begin{array}{l}\text { total } \\
\text { uncertainty }\end{array}$ \\
\hline Mercury & 368.1 & ND & & \\
\hline Cadmium & 558.6 & DET & $1.4 \%$ & \\
\hline Lead & 1063 & DET & $34.8 \%$ & \\
\hline
\end{tabular}

a ND: not detected; DET: detected but not quantified

b Uncertainty Components:

Cadmium:

D-T Source Output: na

Fe Interference (Hg only): na

System Geometry: na

Calibration Fit: na

Lead:

D-T Source Output: na

Fe Interference (Hg only): na

System Geometry: na

Calibration Fit: na 


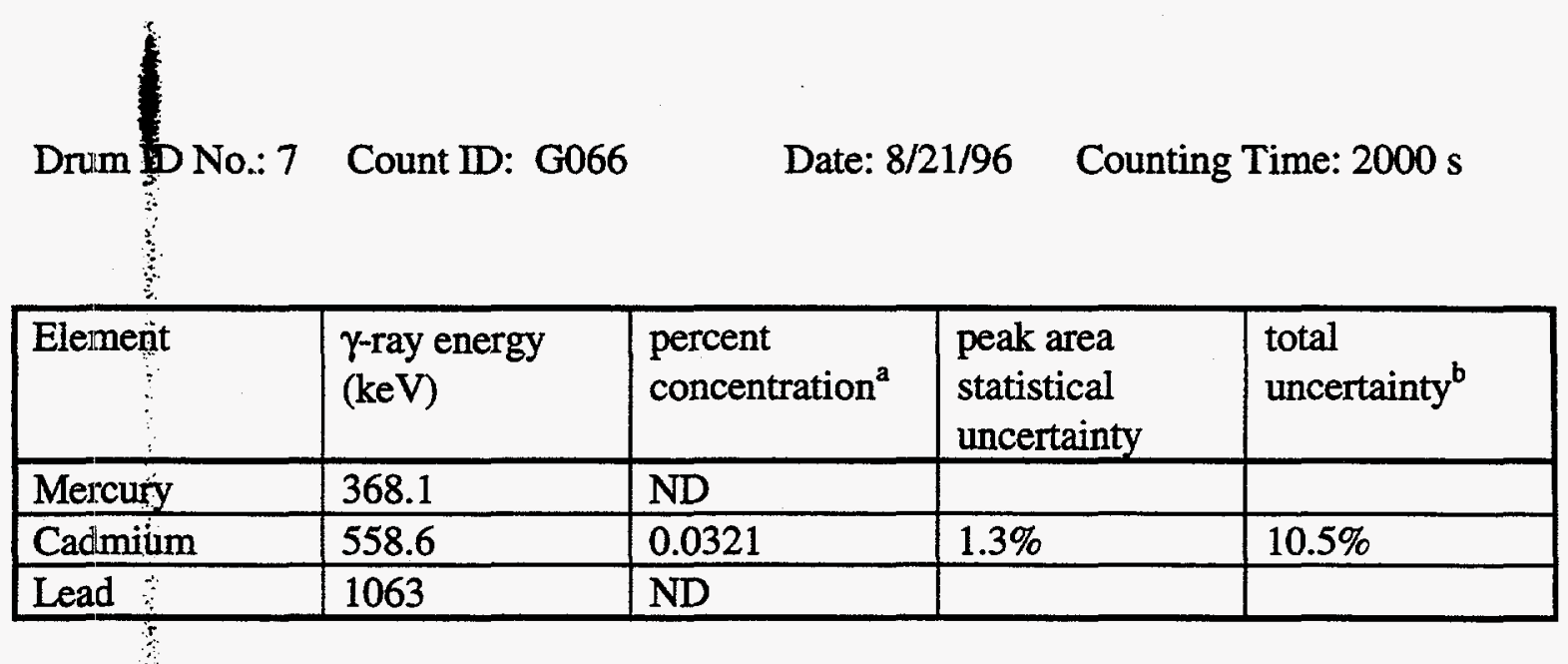

a ND: not detected; DET: detected but not quantified

b Uncertainty Components:

D-T Source Output: $\quad 4.6 \%$

Fe Interference (Hg only): na

System Geometry: $\quad 4.8 \%$

Calibration Fit: $\quad 8.0 \%$ 


\begin{tabular}{|c|c|c|c|c|}
\hline \multirow{2}{*}{ Drum No.: 7} & Count ID: G065 & \multicolumn{2}{|c|}{ Date: $8 / 21 / 96$} & Counting Time: $600 \mathrm{~s}$ \\
\hline & $\begin{array}{l}\gamma \text {-ray energy } \\
(\mathrm{keV})\end{array}$ & $\begin{array}{l}\text { percent } \\
\text { concentration }{ }^{a}\end{array}$ & $\begin{array}{l}\text { peak area } \\
\text { statistical } \\
\text { uncertainty }\end{array}$ & $\begin{array}{l}\text { total } \\
\text { uncertainty }\end{array}$ \\
\hline Mercuiy & 368.1 & ND & & . \\
\hline Cadmiự & 558.6 & DET & $2.3 \%$ & \\
\hline Lead & 1063 & ND & & \\
\hline
\end{tabular}

a ND: not detected; DET: detected but not quantified

b Uncertainty Components:

D-T Source Output: na

Fe Interference (Hg only): na

System Geometry: na

Calibration Fit: na 
Report of Analytical Results

Special Technologies Laboratory 


\section{Assay of Surrogate Waste Drums}

1. Name of company and analyst: Bechtel Nevada; James Tinsley

2. Date of assay:

December 20-31, 1996

3. Assay labớratory:

Special Technologies Laboratory

4. Address of assay lab:

5520 Ekwill St., Suite B

Santa Barbara, CA 93117

5. Contact person:

James Tinsley

6. Phone (FA) of contact person: (805) $681-2282$ (office)

(805) 681-2241 (FAX)

7. List of equipment/instrumentation used for measurements and analysis:

Radiation detector type: Sealed Tube Neutron Generator (STNG)

Signal processing electronics: Standard NIM and CAMAC modules

Computer: $\quad$ Sun (file server), 2 single-board PCs, 1 stand-alone PC

Description sketches or photos of experimental layout: see Figures 1, 2

The STNG operating parameters were as follows: $V_{\text {accel }}=75 \mathrm{kV}$

$V_{\text {focus }}=7.5 \mathrm{kV}$

$V_{\text {ion src }}=4.9 \mathrm{kV}$

All Nal detector PMTs were biased to $-2 \mathrm{kV}$.

The PSPMT (recoil alpha detector) was biased to $-1 \mathrm{kV}$.

8. Floor dimensions (foot print) for entire assay system (include photos or drawings): $\quad 13 \times 13 \mathrm{ft}$ (lab space) $+17.5 \times 7 \mathrm{ft}$ (electronics trailer). See Figures 1 and 2 for details.

Note: In the original lab system, the electronics and computers were in the same room as the STNG and detector array. The trailer system is currently in use due to preparations for field experiments. The electronics and rack-mounted computers occupy six bins (NIM bin/CAMAC crate size): they have been distributed among four racks simply for ease of access.

9. Required utilities to operate assay system: Conventional $110-120 \mathrm{~V}, 60 \mathrm{~Hz}$ electricity.

10. Cost estimate of the entire prototype system as configured for tests, excluding shielding: approximately $\$ 180,000+\$ 28,000 /$ STNG $(4-6000 \mathrm{hr}$ life) 
11. Cost estimate of the entire prototype system as configured for tests inclusive of shielding: : approximately $\$ 183,500+\$ 28,000 /$ STNG $(4-6000 \mathrm{hr}$ life).

The shielding used is quite modest because it is for the most part surrounding the neutron generator itself (see Figure 1). This reduces the radiation levels in the lab to backgkound levels, except for the conical volume where the tagged neutron flux is emitte The shielding downstream from this cone (to the right in the figure) is provid $d$ by an infrequently used room (which is secured) on the other side of the lab wall. In interlock system tied to the STNG power supply prevents the API system and the other room from being used simultaneously. The dose rate produced by the STNG is $\sim 6.5 \mathrm{mR} / \mathrm{hr}$ at $1 \mathrm{~m}$ from the center of the tube with a flux rate of $3 \times 10^{6}$ neutroins $/ \mathrm{s}$; $3 \mathrm{~m}$, this drops to $0.72 \mathrm{mR} / \mathrm{hr}$.

12. If equipment sold, specify minimum training requirements for operator: In addition to the appropriate radiation worker training and brief data analysis training, the operator must be educated about the conditioning and operation of the STNG, and how to calibrate the detection system. These last two items could be done in parallel over the course of about five days.

13. Viable options for use of analysis system: Sell equipment and train operators: yes Provide on site analytical service: yes

14. Method of assay (e.g., prompt gamma neutron activation analysis): prompt gamima neutron activation analysis

15. Method of generation of interrogating particle or wave (e.g., ${ }^{252} \mathrm{Cf}$, neutron generator): $d-t$ neutron generator

16. If generator used, list key instrument specifications: The deuteron beam is focussed to a spot size of $<1 \mathrm{~mm}$ on the target. A fused coherent fiber window capable of withstanding one atmosphere of pressure is used to transport the scintillation light from the recoil alphas to an external position-sensitive PMT. This window is $76 \mathrm{~mm}$ in diameter and is located $100 \mathrm{~mm}$ from the center of the target (at $90^{\circ}$ to the deuteron beam), so that alphas in a cone with a $\sim 17^{\circ}$ half angle are detected. The window is coated with $\sim 3 \mathrm{mg} / \mathrm{cm}^{3}$ WL1201 phosphor and then $1 \mu \mathrm{m}$ film $\left(0.27 \mathrm{mg} / \mathrm{cm}^{3}\right)$ of aluminum. The target is set at $45^{\circ}$ wrt the beam and in infused with $2 \mathrm{Ci}$ of tritium.

17. Assay dependent on what nuclear reactions or interactions: $(n, \gamma),\left(n, n^{\prime} \gamma\right)$

18. Intensity of interrogating particle or wave beams (e.g., $5 \mu \mathrm{g} \mathrm{252Cf}$ ): $3 \times 106$ neutrons/s for maximum data rate (STNG beam current is adjustable).

19. Estimated lower limit of detection in parts per million (ppm) for a $600 \mathrm{~s}$ and for a 2000s real-time count for a surrogate drum of waste with the RCRA metal 
homogeneously distributed and no interfering elements present using L. A. Currie's definition of LLD:

600 s count $2000 \mathrm{~s}$ count

Cd: $60,000 \quad \mathrm{Hg}: \mathrm{n} / \mathrm{a} \quad \mathrm{Pb}: 33,000$ Cd: $18-20,000 \quad \mathrm{Hg}: \mathrm{n} / \mathrm{a} \quad \mathrm{Pb}: 10,000$

Are e⿳亠丷⿵冂⿱十口犬timated LLD's measured or modeled? measured

20. Provide, as a separate attachment, a copy of the counting and analysis procedures used to assay the drums.

21. Provide the calibration method and resulting function for determining elemental concetrations in analytic or graphic form. Reference the protocol used to measu $\mathrm{e}$ or calculate the calibration functions.

Due the complexity of the matrix in which the RCRA materials were dispersed and the limited resolution of our Nal detectors, it was not possible to measure specific elemental peaks on top of a smooth background. Therefore, the spectrum of the blank drum was used for a "baseline". This spectrum was subtracted from the spectrum of a calibration drum to reveal peaks from the elements of interest. These were measured and counts converted to ppm as shown below. The quantity $\alpha$ refers to the count of alpha particles (and thus tagged neutrons) detected during the run, in other words, a count of the "beam" particles emitted.

$$
\begin{aligned}
& \sigma_{i}=\sigma_{i}^{\text {spec }}-\sigma_{i}^{\text {bkgnd }} \times \frac{\alpha^{\text {spec }}}{\alpha^{\text {bkgnd }}} \\
& \delta \sigma_{i}=\sqrt{\sigma_{i}^{\text {spec }}}+\sqrt{\sigma_{i}^{\text {bkgnd }}} \times \frac{\alpha^{\text {spec }}}{\alpha^{\text {bkgnd }}} \\
& C_{i}=\frac{\sigma_{i}}{\alpha^{\text {spec }}} \times\left(\frac{p^{p p m_{i}}}{\sigma_{\text {calib }}}\right) \times \alpha^{\text {calib }}
\end{aligned}
$$

where $\sigma_{\imath}$ is the counts in a particular peak, $\sigma$ spec is the counts in the full spectrum, $\sigma^{\text {bkgnd }}$ is the counts in the background spectrum, $C_{i}$ is the concentration (in ppm) of a particular element in a particular drum, $p p m_{i}$ is the given concentration of a particular element in the calibration drum and $\alpha^{2}$ is the "beam" normalization for the various runs.

22. Give the assay results for the blank drum for each waste type. Provide a labeled plot of the spectrum for each assayed blank drum showing the detected elements above the LLD for each count time used to acquire data. See Figure 4 and Table 1. 
23. Give the assay results for replicate counts of each blind sample for each surrogate waste type. Provide a labeled plot of the spectrum for each assayed surrogate drum showing the detected elements above the LLD. \%

The background-subtracted plots for each blind surrogate drum are shown in Figures 5-10, and the analysis is summarized in Table 1. A few comments are in order. Because of the calibration process (see above) and limited time available for measurements, the uncertainties in the calibration for $\mathrm{Pb}$ is $13.6 \%$ due to statistical uncertainties; that due to uncertain placement of drums ( $\pm 0.5 \mathrm{~cm}$ out of 110$)$ should be very low $(\approx 1 \%)$ because the software corrects (to some extent) the gamma counts according to distance from the neutron source using the position information given by the technique. Since the neutron particles emitted can be counted, the "integ ated beam flux" is very well known, thus its uncertainty is orders of magnitude lower than statistical uncertainties.

From our point of view, it was unfortunate that the elements $\mathrm{Cd}, \mathrm{Hg}$ and $\mathrm{Pb}$ were all used in the form of sulfides. It happens that there are several instances where a significant sulfur peak is to be found very close to a lead peak, making the lead all the more difficult to identify. Of course, this illustrates a limitation of API for similar applications when sulfur is present. Cadmium was detectable using peaks (at 1.4-1.5 MeV) known to us from other work. However, there was too little of it in the calibration drums for us to calibrate to it very well. We have established that $14 \mathrm{MeV}$ neutrons do not excite mercury to any significant degree, and we did not attempt to measure it here.

In summary, we were not able to quantifiably measure any of the elements in question in runs corresponding to $2000 \mathrm{~s}$, using the criteria given. In several cäses, elements were detected. Specific results for the unknown drums are:

Drum 2: Too little $\mathrm{Pb}$ to detect at all. Cd was detected, but due to our poor calibration, the quantity is not well known, although we think it to be more than the $8181 \mathrm{ppm}$ given for drum 12.

Drum 3: $\mathrm{Pb}$ was detected with an overall uncertainty of $34 \%$ in the best peak (combined $0.81 \& 0.89 \mathrm{MeV}$ states), approximately $19,000 \mathrm{ppm}$. Cd not be reliably detected.

Drum 4: $\mathrm{Pb}$ was detected with an overall uncertainty of $39 \%$ in the best peak, approximately $9200 \mathrm{ppm}$. Cd not be reliably detected.

Drum 5: $\mathrm{Pb}$ was detected with an overall uncertainty of $41 \%$, approximately 9000 ppm. Cd not detected.

Drum 6: Neither $\mathrm{Pb}$ or $\mathrm{Cd}$ were detected.

Drum 7: $\mathrm{Pb}$ was barely detected with guess of approximately $7,000 \mathrm{ppm}$. Similarly, for $\mathrm{Cd}$ a guess of $\sim 12,000 \mathrm{ppm}$. 
24. Were elements detected on-line (within computer processing time of $<3$ minutes) or were they determined by post analysis? On-line

25. Were elemental concentrations measured on-line (within computer processing time ôf $<3$ minutes) or were they determined by post analysis? Post analysis

Note: would be straightforward to include quantitative processing software to the on-lin system:- The API system was built as a general development system that may be us d in a variety of different contexts. Quantitative measurements have not been a hightpriority for initial tests, and so some of the necessary software has not yet

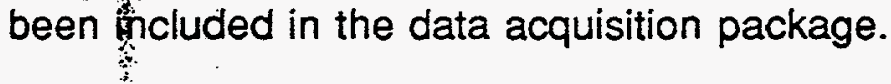

26. In yourr opinion, could the present system with or without modification, assay waste under treatment plant conditions in an environment of high radio frequency and acoustic noise? Yes. Acoustic noise should not be a factor. Sufficiently intense radio frequency electrical noise could induce noise in the signal cables. However, this can be kept in check by using the minimum length of cables and choosing a well-shielded cable. The problem is greater for the signals from the position-sensitive PMT than for the Nal signals. If transverse $(X \& Y)$ position information is determined not to be needed, the potential for problems from RF is reduced.

27. Estimate the fractional loss in elemental concentration sensitivity under treatment plant conditions as stated in questions 25 and 26? The loss in sensitivity due to induced noise in the $\mathrm{Nal}$ energy signals would probably be quite small (a few percent?) if short, well-shielded signal cables are used.

28. Identify those data quality objectives in Section 3.2 that do not appear to have been met and give reason for not meeting them.

Outside of our general inability to quantify concentrations in the time allotted (2000 s), there are several issues to address. First, we did not specifically time the runs to $2000 \mathrm{~s}$ for two reasons: 1) our last remaining STNG (a replacement is not due until February or March) is becoming depleted'in deuterium, making it difficult to maintain the $3 \times 10^{6}$ neutron/s $(5 \times 104$ tagged heutrons/s) rate that the tubes, including this one, operate at over most of their lives, and 2) due to the limited time remaining of this contract (see below), data was taken over nights and weekends at lessened neutron rates. Since we measure each neutron emitted that can lead to a count, we were able to run for an equivalent integrated beam time: $2000 \mathrm{~s} \times 5 \times 104$ neutrons $/ \mathrm{s}=108$ neutrons (or, equivalently, alpha counts). We don't believe that this compromised the results to any noticeable extent since we require prompt coincidences between neutron and gamma (within a 80 ns timing window), and believe any differences in accidental/background counts is negligible.

Second, also due to time limitations and her unavailability during the holidays, measurements were not repeated by my colleague, Laura Tunnell. The time limitation 
was caused by the failure of our high-voltage power supply. It took several weeks to fix it and we were required by budget and imposed deadlines to finish by December 31, 1996.

Third, due to the results with $2000 \mathrm{~s}$ (equivalent) exposures, $600 \mathrm{~s}$ exposures were not attempted.

General ctimments

AssociatedParticle Imaging (API) is a single-particle-counting technique in which the individual interrogation neutrons are tagged by detection of the recoil alpha from a d-t reaction. The current development apparatus was designed to test the concept of API and has not be h optimized for any of the potential uses to which it might be put. Although this present ap aratus is not quite up to the task of meeting the goals of this project, there are improveme ts that could make it more attractive.

The current system, which is geared toward field experiments, uses two "pods" of four $\mathrm{Nal}$ detectors each. The original laboratory system used four pods, doubling the acquisition rate for a given neutron rate. The electronics have the capacity to include these additional detectors already, except for one additional octal coincidence module $(<\$ 1 k)$. The additional pods would cost $\$ 70 \mathrm{k}$. Also, with perhaps more detector shielding (to keep the $\mathrm{Na}$ in the detectors from becoming activated), the pods might be placed closer to the drums with the attendant gain in collection rate.

This type of work does not require full 3-D position information. By replacing the positionsensitive PMT on the STNG with a conventional one and using passive collimation alone, $\sim \$ 23 \mathrm{k}$ could be saved. Decreasing the coincidence gate would speed up the potential neutron rate and limit the range over which events could be detected to $\sim 1 \mathrm{~m}$, plenty for the interrogation of drums. This would enable one to increase the neutron rate by several times.

The Sun computer, mentioned in item 7 , was purchased several years ago before PCs were considered sufficiently fast to do the realtime processing that our system features. In the future-as funding permits-we plan to port the software running on the Sun to a PC; this will save an additional $\sim \$ 12-13 \mathrm{k}$, and make the interface somewhat more accessable to the casual user.

HPGe detectors have much higher resolution than Nal. However, they are relatively "slow" and thus can not be used in coincidence with the alpha detector to provide adequately precise timing for $\mathrm{API}$ in general. They are much more expensive than $\mathrm{Nal}$ for the same area coverage. They also require cooling (such as liquid nitrogen), which makes them unattractive for mobile field use. For these reasons, we haveused them only to suppliment API data, especially for acquiring data not readily available in the literature. For assays of waste materials, they may be more attractive, except for the cost. Mobility would not be an issue, and the poorer timing might not be so critical. 
In other work, I am involved in developing liquid xenon detectors. These have achieved resolution of 4-5 times that of $\mathrm{Nal}$, and should be cheaper and nearly as efficient for the same size gietector. With further progress, we expect them to be available in 1-2 years. Such detectors would provide much cleaner spectra and might make an enormous difference for work such as this.

29. I verify that the results, including reported uncertainties, have been measured and calculated following approved procedures:-

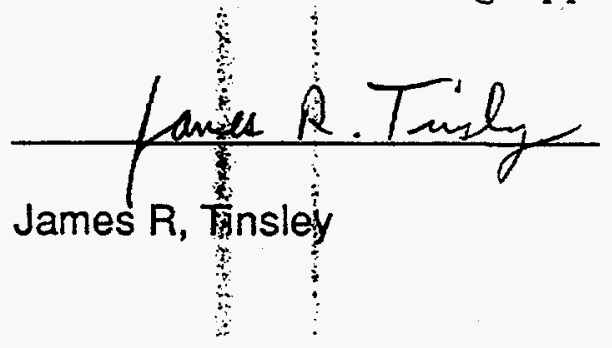




\section{Appendix: Procedures}

Before data is acquired, the $\mathrm{Nal}$ detectors are used to perform the position calibrations. This is don by placing each pod in the beam at a measured position relative to the center of the targe in the STNG tube. Data is acquired using a specialized calibration program, which tran ates the location of peaks in the spectra of various data parameters, such as time of flig and transverse horizontal or vertical detector position (as recorded with the PSPMT), it to parameter values used to calculate the physical position of an event. Then the detectofs are placed in their usual positions, and the precise locations measured and entered int the computer. This completes the position calibrations. Next, data is taken on familiar materials, such as salt and water, and well-known peaks in these data are used to caltorate the energy of each individual $\mathrm{Nal}$ detector. The energy calibrations are found to be stable over several weeks, or more, when the system is operated in the lab, due to the good temperature control in the building.

When data acquisition on a particular object comences, 2-D position spectra are used to set "windows" on the data values to eliminate data whose coordinates don't correspond to that object.

For this project, the exposures have been measured by integrated neutron flux (as described above) to correspond to a "standard" amount of exposure. For each run, the distance of the drum from the STNG target is measured and recorded; at the end of the run the scalar values (eg. "Total alpha counts") are recorded. The spectra of each drum measured was transferred to a separate PC for the extraction of the concentrations of RCRA elements (as described in item 21). Drums 1,2 and 12 were measured a second time to verify the energy calibration and the consistancy of the data. 


\section{Table 1}

\begin{tabular}{|c|c|c|c|c|c|c|c|c|c|}
\hline Drum & Alphas & $\begin{array}{c}\text { Peak Energy } \\
(\mathrm{MeV})\end{array}$ & Peak & $\begin{array}{l}\text { Counts: } \\
\text { Foregnd }\end{array}$ & Backgnd & $\begin{array}{l}\text { Peak } \\
\text { Uncert. }\end{array}$ & Elam & $\begin{array}{r}\text { Conc } \\
\text { PRAM }\end{array}$ & ration \\
\hline 1 & $258,594,278$ & $\longrightarrow$ & "Backgrour & nd" measure & nent from ble & nk drum- & & & \\
\hline & $244,164,717$ & 0.85 & 941.03 & 4414.50 & 4345.64 & 128.68 & $\mathbf{P b}$ & 19950 & given \\
\hline (calibration) & & 1.06 & 427.24 : & 3926.34 & 3939.71 & 121.93 & $\mathbf{P b}$ & 19950 & given \\
\hline & & 1.27 & 1989.60 & 14748.20 & 14146.20 & 233.74 & & & \\
\hline & & 1.45 & 316.21 & 4566.59 & 4511.71 & 131.00 & $\mathrm{Cd}$ & 8181 & given \\
\hline & & 1.75 & 787.61 & 10000.80 & 9971.20 & 194.29 & $\mathrm{~Pb}, \mathrm{~S}$ & 19950 & given \\
\hline 2 & $100,057,262$ & 0.85 & & &. & & $\mathrm{~Pb}$ & $n / a$ & \\
\hline & & 1.06 & & & & & $\mathbf{P b}$ & $\mathrm{n} / \mathrm{a}$ & \\
\hline & & 1.27 & 591.55 & 6271.46 & 14680.60 & 126.07 & & & \\
\hline & & 1.45 & 283.58 & 3168.18 & 7455.67 & 89.70 & $\mathrm{Cd}$ & 17904 & $32 \%$ \\
\hline $\overrightarrow{0}$ & & 1.75 & 245.50 & 4272.23 & 10407.70 & 104.84 & $\mathbf{P b}, \mathbf{S}$ & 15175 & $43 \%$ \\
\hline 3 & $104,290,305$ & 0.85 & 186.67 & 1344.14 & 2870.01 & 58.27 & $\mathbf{P b}$ & 9265 & $31 \%$ \\
\hline & & 1.06 & & & & & $\mathbf{P b}$ & $\mathrm{n} / \mathrm{a}$ & \\
\hline & & 1.27 & 535.10 & 6240.25 & 14146.20 & 126.96 & & & \\
\hline & & 1.45 & 105.10 & 3147.26 & 7543.16 & 91.13 & $\mathrm{Cd}$ & 6366 & $87 \%$ \\
\hline & & 1.75 & 359.92 & 4381.30 & 9971.20 & 106.46 & $\mathrm{~Pb}, \mathrm{~S}$ & 21344 & $30 \%$ \\
\hline 4 & $104,435,995$ & 0.85 & 185.07 & 1787.51 & 4178.47 & 68.38 & $\mathbf{P b}$ & 9173 & $37 \%$ \\
\hline & & 1.06 & 99.94 & 1610.82 & 3939.71 & 65.48 & $\mathbf{P b}$ & 10911 & $66 \%$ \\
\hline & & 1.27 & 411.61 & 6041.61 & 14680.60 & 126.66 & & & \\
\hline & & 1.45 & 134.71 & 2478.58 & 6111.81 & 81.36 & $\mathrm{Cd}$ & 8148 & $60 \%$ \\
\hline & & 1.75 & 158.76 & 4051.29 & 10150.00 & 104.34 & $\mathbf{P b}, \mathbf{S}$ & 9401 & $66 \%$ \\
\hline 5 & $102,209,379$ & 0.85 & 179.43 & 1847.28 & 4345.64 & 69.04 & $\mathbf{P b}$ & 9087 & $38 \%$ \\
\hline & & 1.06 & 58.93 & 1570.99 & 3939.71 & 64.44 & $\mathbf{P b}$ & 6574 & $109 \%$ \\
\hline & & 1.27 & 277.14 & 5706.44 & 14146.20 & 122.55 & & & \\
\hline & & 1.45 & & & & & Cd & $n / a$ & \\
\hline & & 1.75 & 132.87 & 3959.82 & 9971.20 & 102.40 & $\mathrm{~Pb}, \mathrm{~S}$ & 8040 & $77 \%$ \\
\hline
\end{tabular}


Table 1 (cont.)

\begin{tabular}{|c|c|c|c|c|c|c|c|c|c|}
\hline Drum & Alphas & $\begin{array}{c}\text { Peak Energy } \\
(\mathrm{MeV})\end{array}$ & Peak & $\begin{array}{l}\text { Counts: } \\
\text { Foregnd }\end{array}$ & Backgnd & $\begin{array}{l}\text { Peak } \\
\text { Uncert. }\end{array}$ & Elemen & $\begin{array}{r}\text { Conc } \\
\text { PRM }\end{array}$ & $\begin{array}{l}\text { tration } \\
\pm(\%)\end{array}$ \\
\hline \multirow[t]{5}{*}{6} & $101,185,763$ & 0.85 & 58.36 & 1758.81 & 4345.64 & 67.73 & $\mathbf{P b}$ & 2986 & $116 \%$ \\
\hline & & 1.06 & & & & & $\mathbf{P b}$ & $n / a$ & \\
\hline & & 1.27 & & & & & & & \\
\hline & & 1.45 & & & & & $\mathrm{Cd}$ & $n / a$ & \\
\hline & & 1.75 & & & & & $\mathbf{P b}, \mathbf{S}$ & $n / a$ & \\
\hline \multirow[t]{5}{*}{7} & $100,958,245$ & 0.85 & 91.06 & 1161.22 & 2748.24 & 54.54 & $\mathbf{P b}$ & 4669 & $60 \%$ \\
\hline & & 1.06 & 84.55 & 1706.68 & 4165.72 & 66.51 & $\mathbf{P b}$ & 9548 & $79 \%$ \\
\hline & & 1.27 & 349.19 & 5857.71 & 14146.20 & 122.97 & & & \\
\hline & & 1.45 & 188.37 & 3125.68 & 7543.16 & 89.82 & $\mathrm{Cd}$ & 11787 & $48 \%$ \\
\hline & & 1.75 & 253.93 & 4136.71 & 9971.20 & 103.30 & $\mathrm{~Pb}, \mathrm{~S}$ & 15555 & $41 \%$ \\
\hline
\end{tabular}




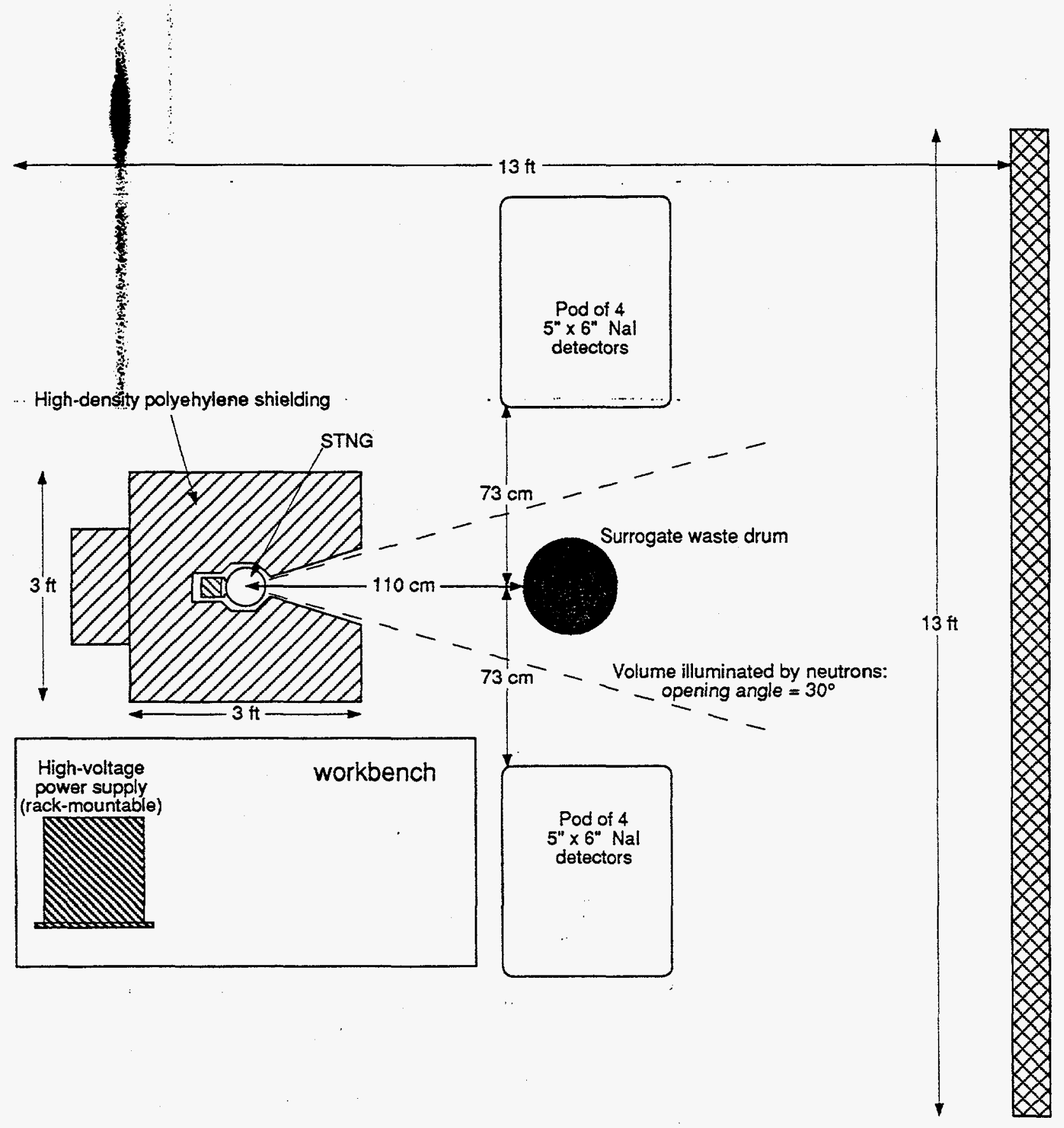

Figure 1 Configuration of API in the lab. For clairity, cables between the STNG, pods, HVPS and the trailer are not shown. The original location of the electronics and computer system was adjacent to this area, toward the bottom of the page(outside the neutron cone, the radiation is at background level). 


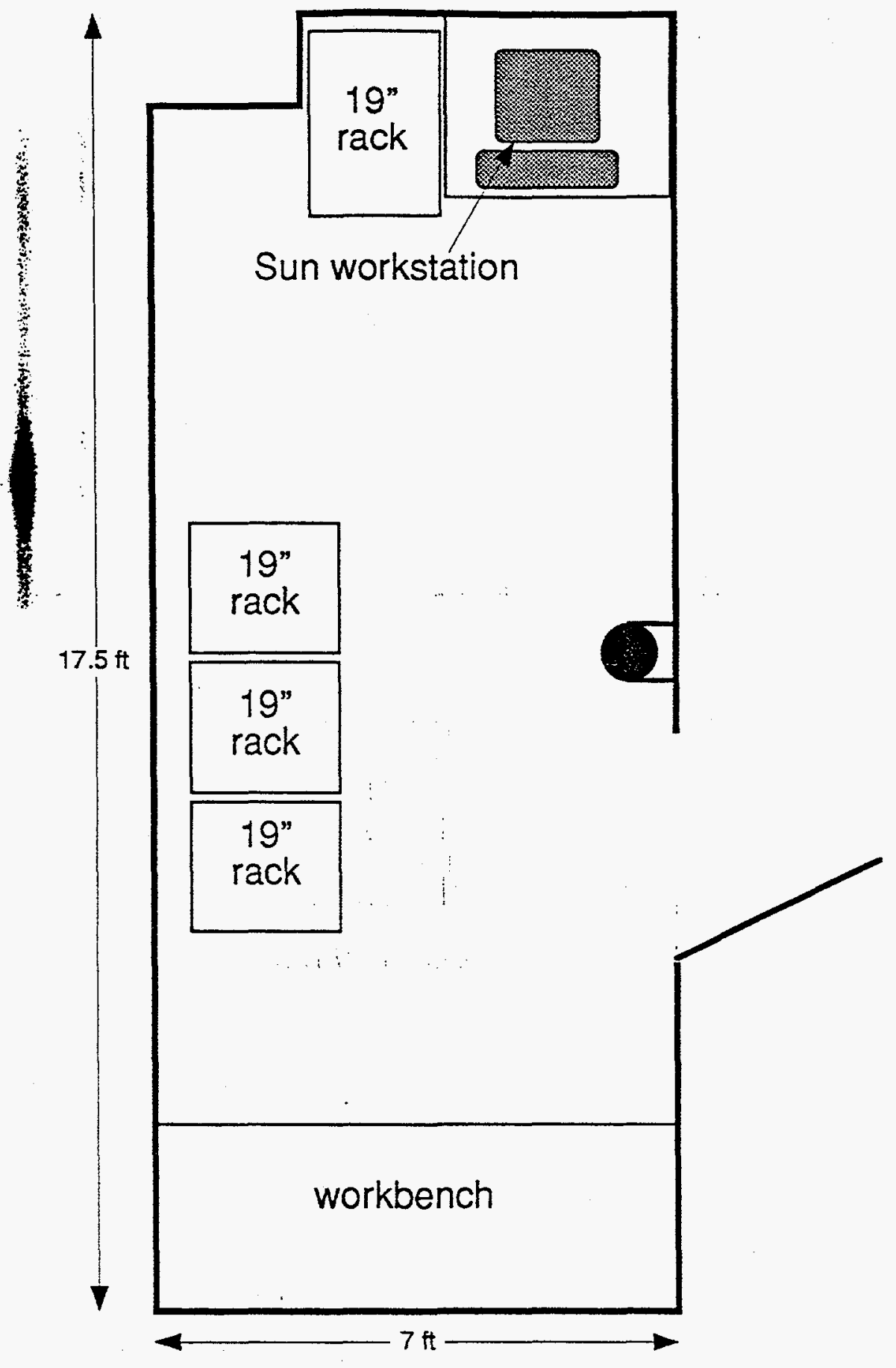

Figure 2. Electronics and computer station. This mobile station is being used in preparation for forthcoming field experiments. 
Figure 3

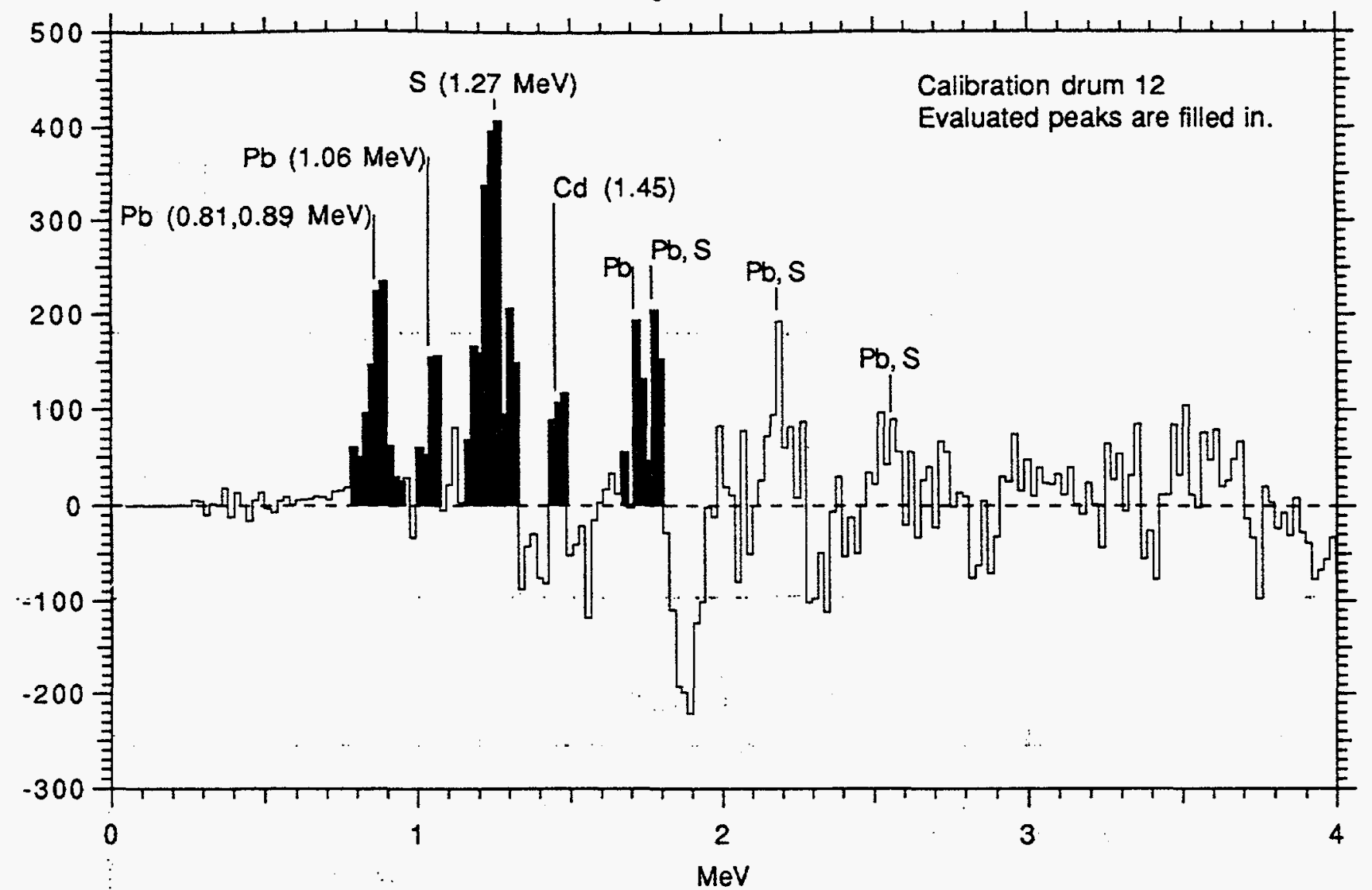

Figure 4

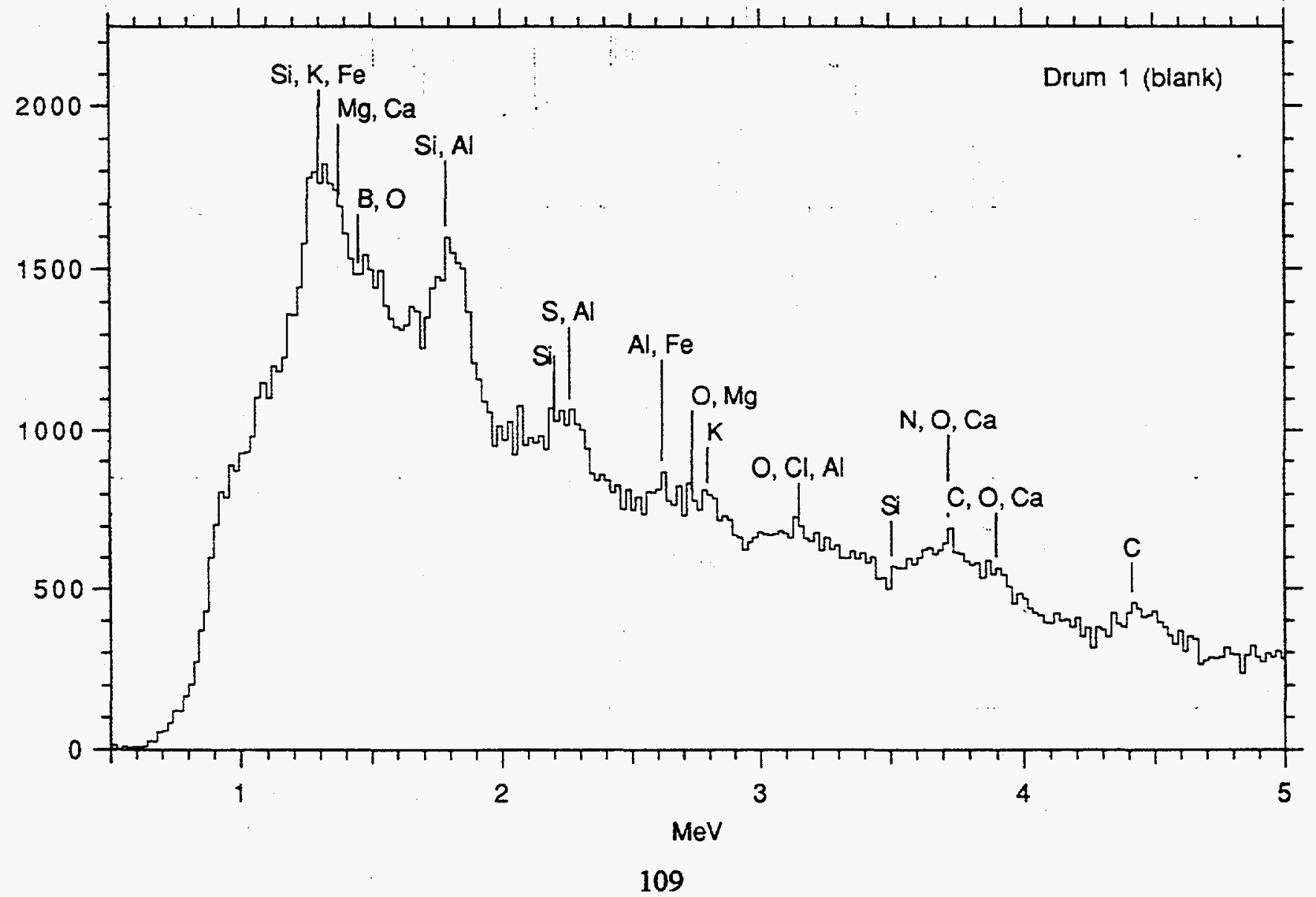


Figure 5

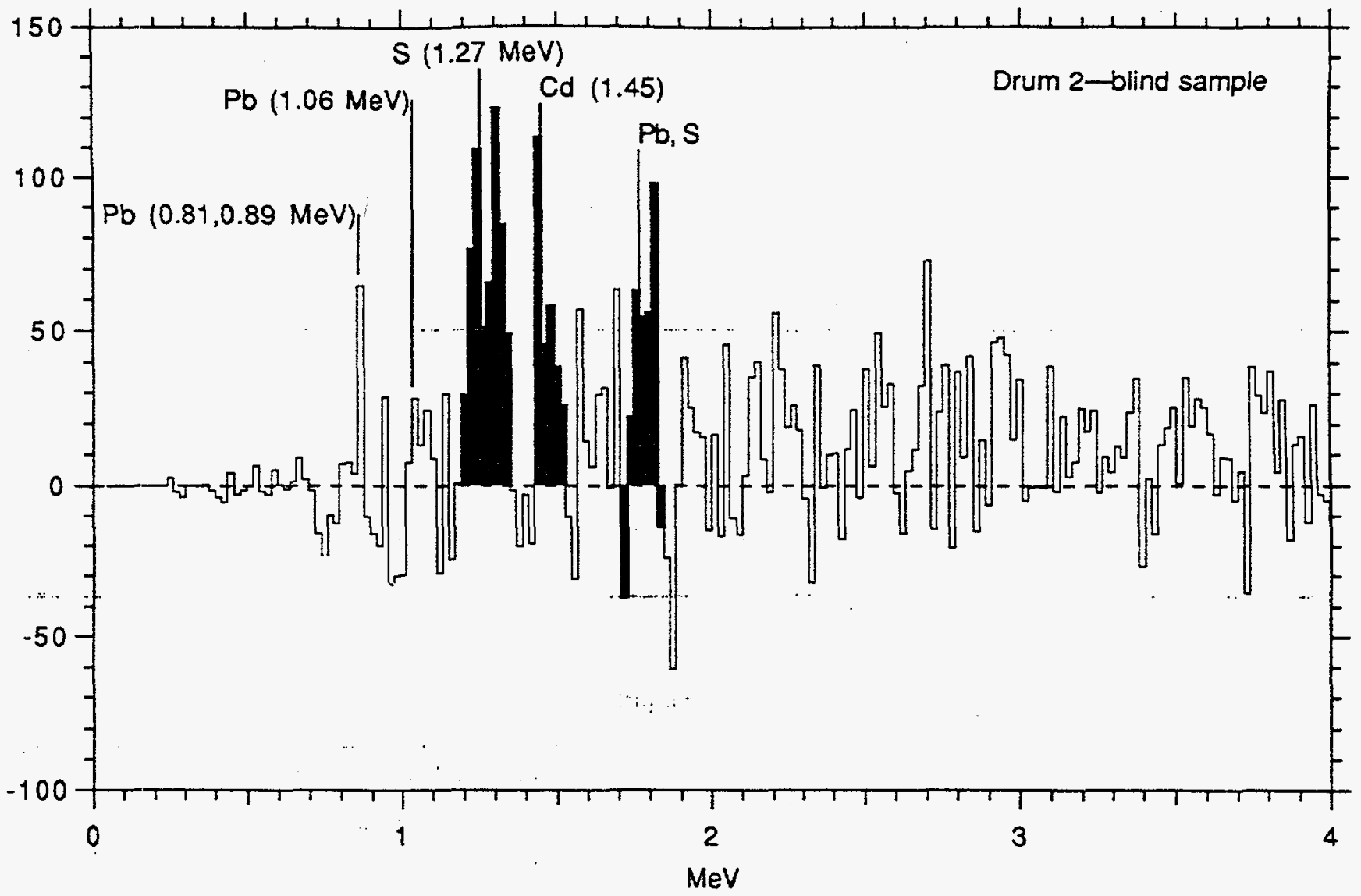

Figure 6

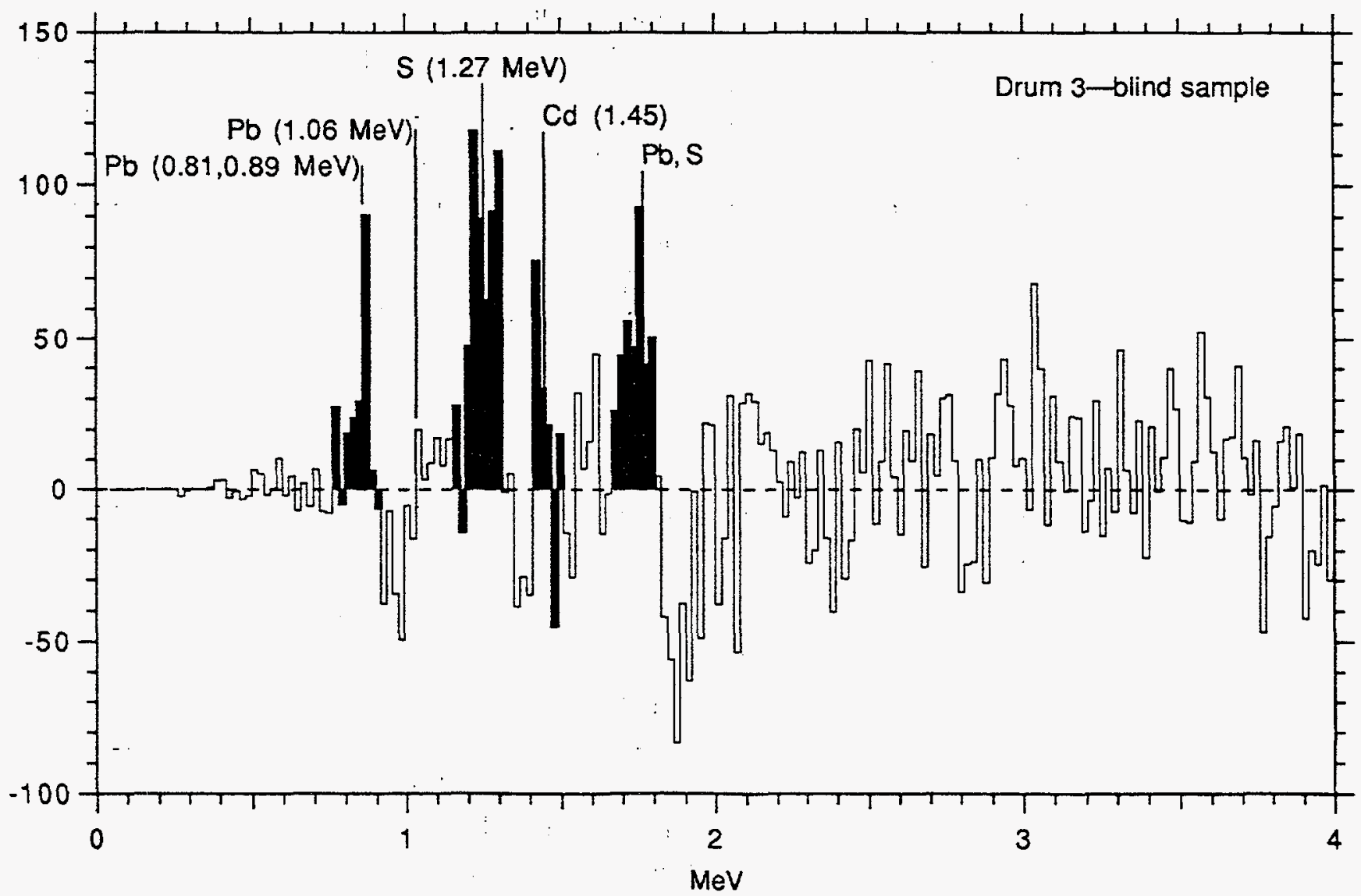


Figure 7

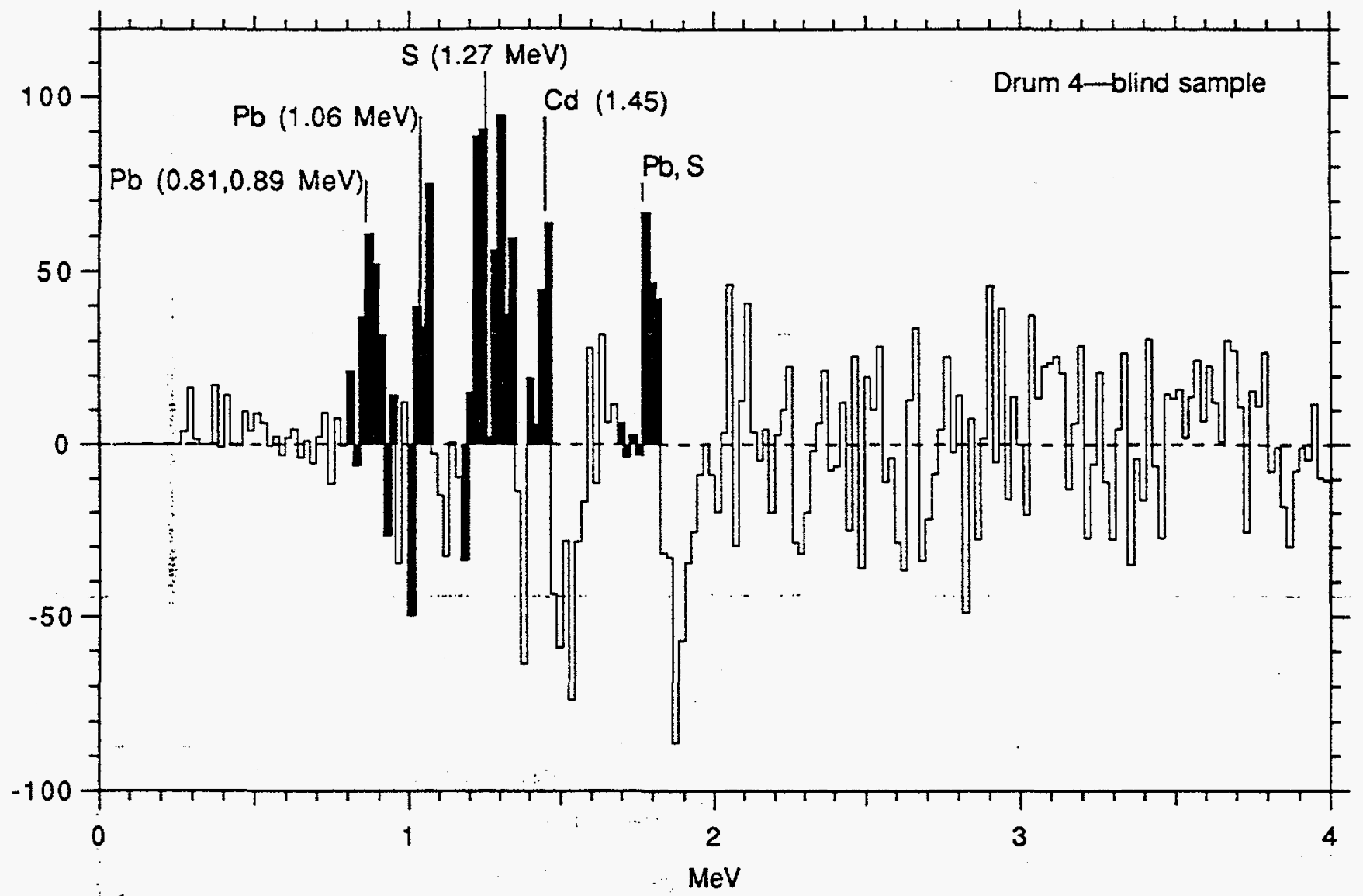

Figure 8

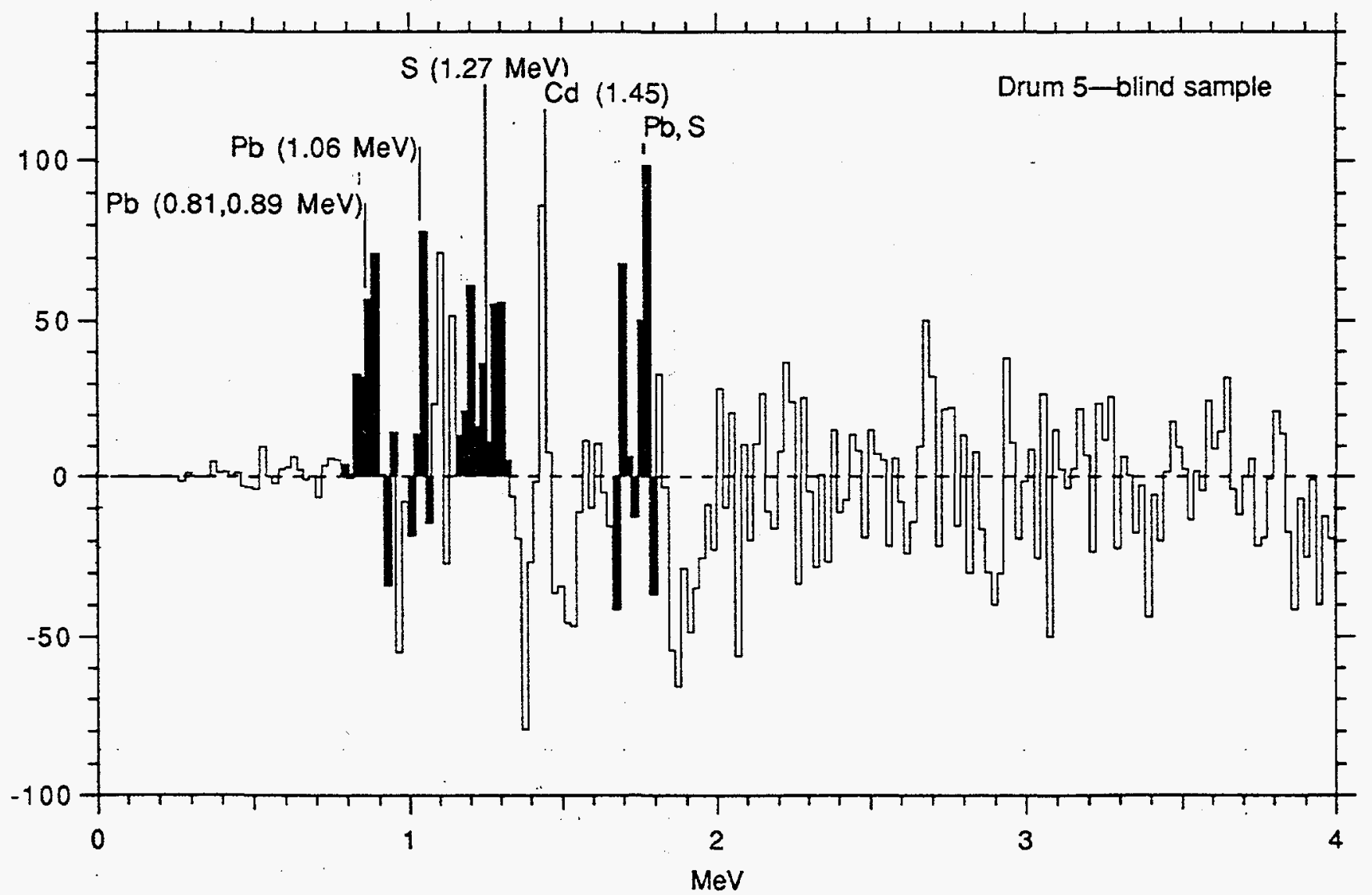


Figure 9

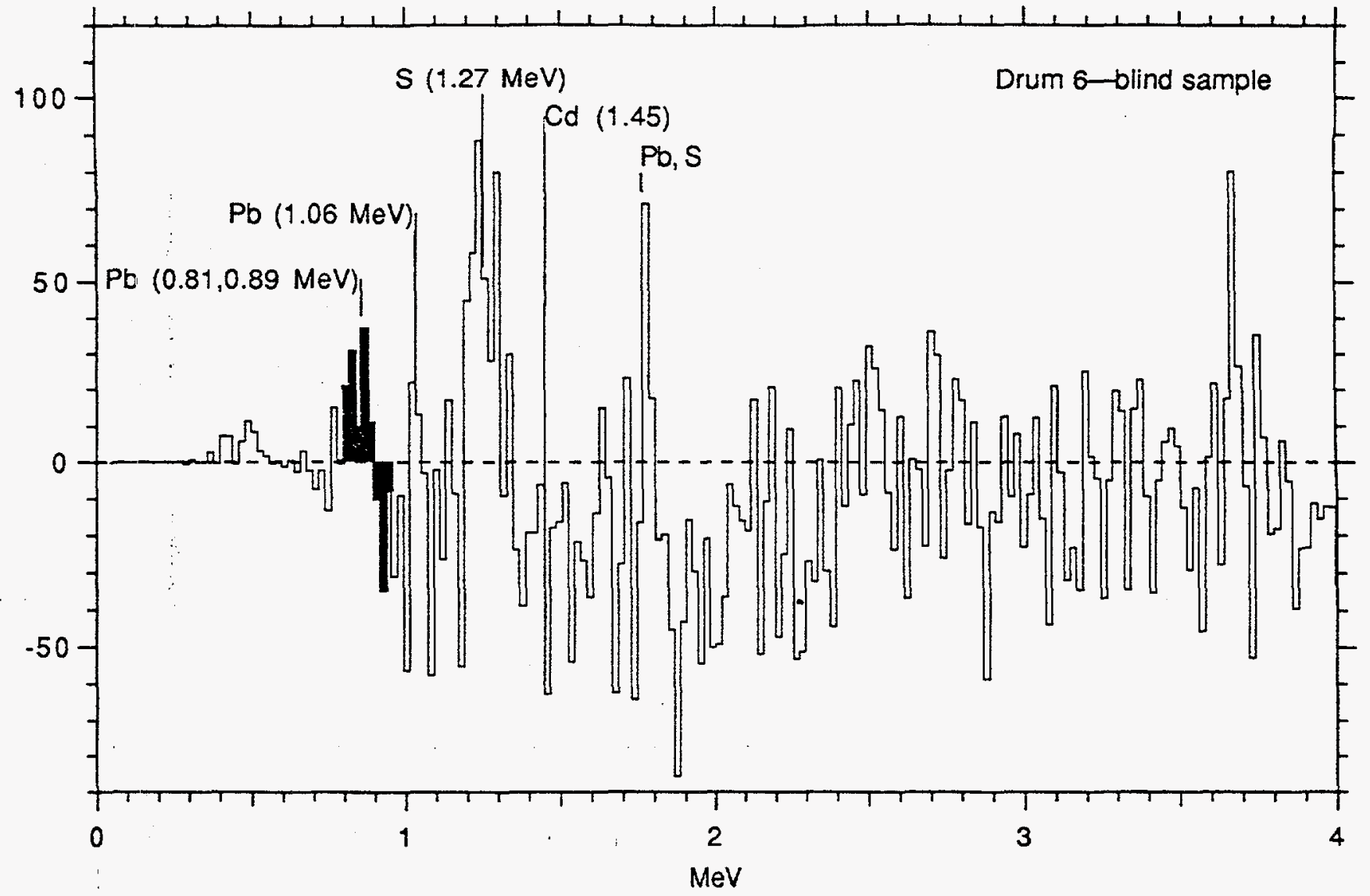

Figure 10

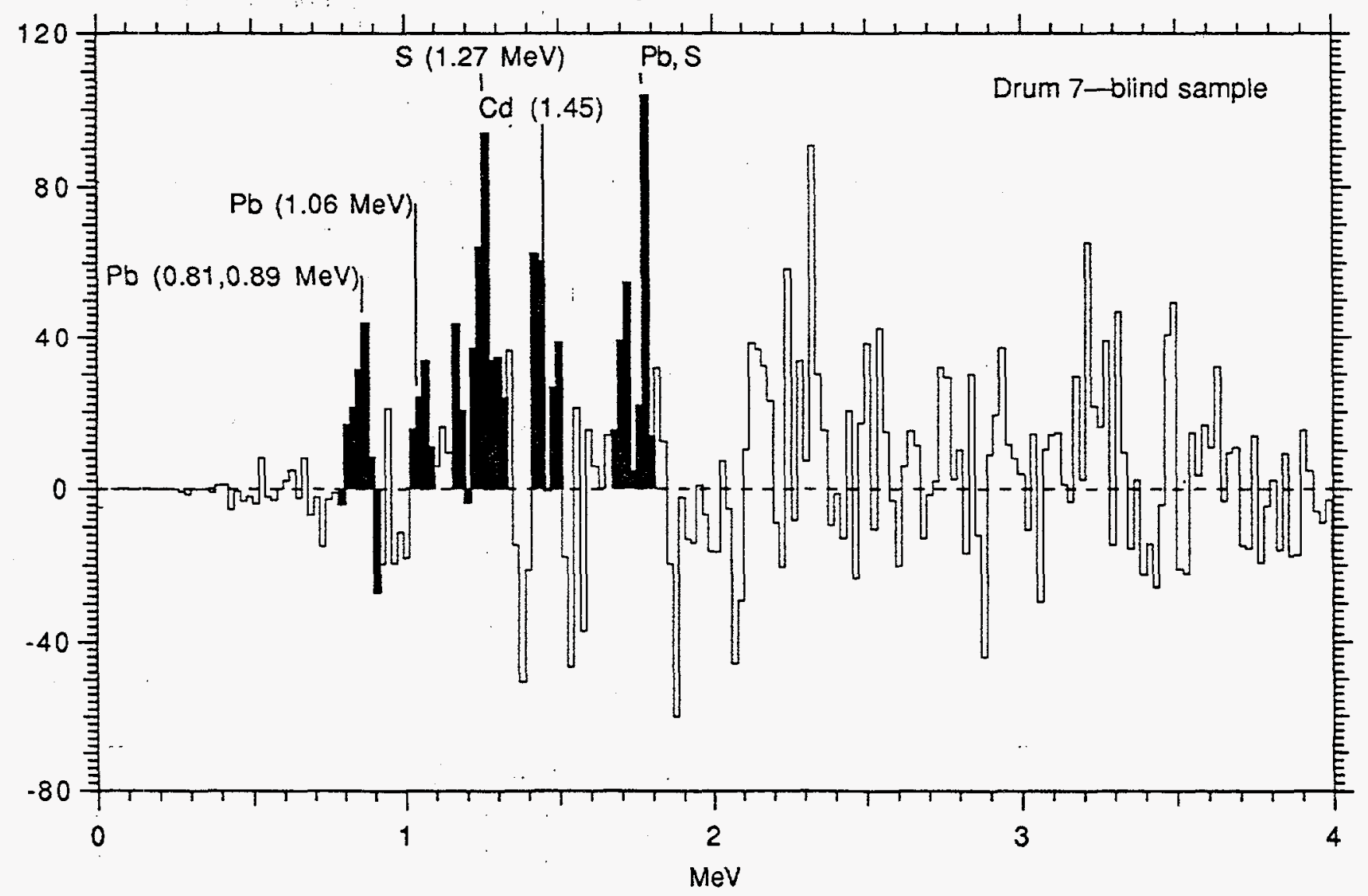




\section{Evaluation of and Comments on Participants' Results}

\section{EVALUATION OF PARTICIPANT PERFORMANCE}

The participants in the Resource Conservation and Recovery Act (RCRA) waste characterization performance test project comprised Westinghouse Science and Technology Center and Special Technology Laboratory. A fair evaluation of the performance of the participants in the project was possible because both of the participants followed the performance test instructions (see Appendix C). The data submitted from the participants were in the same format, and the results with their uncertainties were calculated by the same methods. Therefore, the reported information was compared on a uniform basis.

The method of calibration for elemental concentration in the drums was left to the participant notwithstanding that in some cases the gamma-ray emission rates would be related to the elemental concentrations based on measurements of the calibration surrogates provided with the unknown samples and in other cases the gamma-ray emission rates would be related to the elemental concentrations based on measurements combined with modeling. The unknown surrogate concentrations were determined from measurements and calibration protocol. The following measurements were requested of each participant:

1. A count of one of the calibration surrogate drums, which was to be taken and analyzed after the calibration procedure was carried out to verify that the calibration function provided elemental concentrations correctly. The uncertainty component caused by the nonreproducibility in the experimental geometry was to have been demonstrated through multiple counts not to be greater than $5 \%$.

2. Two counts of each surrogate were to be taken with the surrogate removed and put back into the counting position between counts.

3. Two counts, one for 600 seconds and one for 2,000 seconds, were to be taken of each surrogate.

4. The blank drum was to be counted and used to subtract any interference peaks present in the background. The peaks in the background spectrum and the elements associated with them were to be identified on the participant reporting form (see Appendix B).

The elemental concentrations were to be reported as follows:

1. For an elemental concentration to be considered detected, the primary signal for a given element assay was to have an estimated standard deviation of less than $35 \%$ for the combined uncertainty in the "signal" (i.e., counting statistics and the peak fitting uncertainty), which should have been equivalent to a lower limit of detection as defined by L. A. Currie (1968). The goal of the project was detection of all RCRA metals present in the surrogate samples down to the lowest 
concentration level in the blind surrogate sample when real-time counting periods are for 600 seconds or 2,000 seconds.

2. For an element concentration to be considered quantified, the primary signal from a blind surrogate sample was to have an estimated standard deviation of less than $20 \%$. The total uncertainty for a quantified measurement should have been less than $25 \%$ with the estimated standard deviations combined in the normal statistical manner (i.e., in quadrature). All RCRA metal concentrations reported as quantified were to be known to be less than $25 \%$.

3. The lower-limits of detection (LLDs) were to be estimated using the Currie $\mathrm{L}_{D}$ definition (Currie 1968).

4. The participant reporting form was used to ensure that the same information was received from the participants.

Based on the above instructions, the reported information from the participants was judged and scored as described in the following section. 


\section{SELECTION CRITERIA FOR "BEST" ASSAY SYSTEM}

The total number of points achievable (i.e., a perfect score) in the performance test was 184.9 points. The following selection criteria as stated in the test plan (Appendix $\mathbf{C}$ of Part 1) were used to grade the results.

1. Five points were awarded for each element correctly identified as present for each blind surrogate.

2. Ten points weighted by the cube root of the percent concentration (e.g., a $0.1 \%$ surrogate drum of lead correctly identified would be $10 /(0.1) \%=21.5$ points) were be awarded for each correctly reported quantitative measurement of an element present in a surrogate drum that is within $10 \%$ of the actual concentration (see Table A-2 of Appendix A in Part 1).

3. Five points weighted by the cube root of the percent concentration were awarded for each correctly reported quantitative measurement of an element present in a surrogate drum that is within $20 \%$ of the actual concentration (see Table A-2 of Appendix A in Part 1).

4. Ten points weighted by the cube root of the percent concentration were subtracted from the participant's score for each incorrectly reported quantitative measurement of an element present in a surrogate drum that differed from the actual concentration by more than $50 \%$ (see Table A-2 of Appendix A in Part 1). For quantitative results differing from 20 to $50 \%$ of the actual concentration, no points were awarded or subtracted.

5. Noncompliance with the "Instructions to the Participants" without written permission of the PI could have resulted in a reduction in points or in disqualification of the participant from the performance test.

The contents of each blind surrogate drum is given in Table A-2 of Appendix A in Part 1. This table was not included in the draft provided to the participants.

\subsection{Score of Westinghouse Science and Technology Results}

Westinghouse Science and Technology received one set of the surrogate sludge drums during the summer of 1996 and performed the measurements within the requested time. All elements were assayed and the RCRA metals of lead, cadmium, and mercury were detected in the drums to which these elements were added. Each drum was counted twice as requested and the blank drum was assayed for all detected elements. The LLDs for the elements cadmium, lead, and mercury are reported in Table 9 of the Westinghouse report (see Part 2) for both 600-second and 2,000-second counts. The measured concentrations for the blind surrogate drums are reported in Table 8 of the Westinghouse report (see Part 2). Table A-2 of Appendix A in Part 1 shows the actual elemental concentrations for each blind surrogate assayed along with their assay value.

The Westinghouse Science and Technology Center scored the highest on this performance test with a score of 142.1 points out of a possible 184.9 points. They successfully identified the presence of the RCRA elements lead, cadmium, and mercury in all of the blind samples. Further, they made no incorrect 
identification of elements not present (Drum 7 contained no lead). They also quantified these elements in all but one drum (Drum 5 for cadmium) to within $\pm 20 \%$ for a total percent score of $76.9 \%$.

\subsection{Score of Special Technology Laboratory}

Special Technology Laboratory found that the use of a NaI(TI) detector and the presence of the RCRA metals in the form of sulfides significantly hampered the laboratory's ability to identify, much less quantify, the RCRA elements of lead, cadmium, and mercury at the concentrations provided in the performance test. Sulfur has prompt gamma rays in the energy regions near several of the prompt gamma rays emitted from lead, cadmium, and mercury. Unfortunately, sulfides of lead, cadmium, and mercury are the best compounds of these elements to ensure passage of the toxicity characterization leaching procedure (TCLP) test for eventual landfill disposal of these samples. As a result, in part because of the above limitations, none of the reported results met the requirements for awarding points for assays with less than $20 \%$ deviation from the actual (see Table 2 of Appendix A in Part 1) concentration for any of the three elements. The laboratory identified the RCRA elements present incorrectly about as often as correctly.

No attempt was made by Special Technology Laboratory to measure the mercury concentrations because the $14 \mathrm{MeV}$ associated particle imaging (API) technique used by the laboratory was primarily designed to image waste and detect the presence of bulk quantities, and is severely limited in its present configuration to quantitatively assay for RCRA elements. Grading the results using Table 1 of Special Technology Laboratory's report (see Part 2) and the comments in the text of the laboratory's report is difficult because no provision was made for subtracting incorrect identifications, and about half of the reported identifications were incorrect. Only correct positive identifications were awarded points. Points were not awarded for correct identification of the absence of an element. With this in mind, the total score for Special Technologies Laboratory is 10 points with 48 points possible for correctly identifying all RCRA elements present. They received no points for quantifying any of the blind surrogate waste drums. Therefore, their total score was 10 points out of a total possible of 184.9 points. 


\section{DISCUSSION}

A performance test was conducted to determine the effectiveness of commercial prototype prompt gamma neutron activation analysis (PGNAA) systems for the quantitative assay of three RCRA elements present as a homogeneous mixture of surrogate sludge (i.e., cement matrix). The test was designed to be straightforward with no undisclosed mixtiures, and to avoid as much as possible any cross interferences between the constituents composing the matrix or in the container itself. Sludge was chosen because it tends to be more homogeneous than some other common waste types and because its high density presents more of a challenge to the assay system than low density matrixes (e.g., combustible material). The RCRA metals included in the test were lead, cadmium, and mercury in concentrations ranging from $\sim 300 \mathrm{ppm}$ to $\sim 20,000$ ppm.

Though the principal investigator for the project encouraged all commercial companies with expertise in PGNAA to participate, only two companies chose to participate. The reasons the nonparticipating companies gave for not being involved included that 1) work schedules did not permit participation, 2) the DOE market for PGNAA devices was ill defined and did not warrant the use of company funds to participate, and 3) the size of the test drums would mean reconfiguration of the company's PGNAA facility.

Despite the limited participation by commercial companies, the results reported by the Westinghouse Science and Technology Center were encouraging. The company demonstrated that the low concentrations of RCRA elements can be detected in high-density matrixes (cement) of homogeneous surrogate waste.

For example, Westinghouse achieved LLDs of 9 and 15 ppm cadmium for 2,000- and 600-second counts, respectively; LLDs of 115 and $170 \mathrm{ppm}$ mercury for 2,000- and 600-second counts, respectively; and LLDs of 4,400 and 8,600 ppm lead for 2,000- and 600-second counts, respectively. The detection limits of other RCRA elements undergoing thermal capture can be estimated from a ratio of the macroscopic cross sections, $\boldsymbol{\Sigma}$, of an above element (e.g., mercury) times its respective prompt gamma-ray emission probability, $\mathbf{P}_{\boldsymbol{\gamma}}$, to that of the element in question." These detection limits indicate that PGNAA could be used to limit the concentrations of waste being fed into a treatment facility, which would thereby prevent overwhelming off-gas cleanup systems. PGNAA also shows potential for use with the characterization of containerized waste to verify contents or the absence of RCRA metals.

Quantitative measurements of mercury and cadmium were performed at the $\sim 350$-ppm concentration level to an accuracy of less than $20 \%$. Quantitative measurements of lead were performed by the analysis of the 1063-keV gamma-ray peak from the decay of the activated 810-millisecond isomer of ${ }^{207 \mathrm{~m}} \mathrm{~Pb}$.

In its present configuration, the neutron imaging system of Special Technology Laboratory appears to be limited in its ability to perform RCRA element assays, qualitative or quantitative, at low element concentrations. Possible reasons for this limitation include the use of $\mathrm{NaI}(\mathrm{Tl})$ detectors instead of the higher energy resolution Ge detectors, the lack of a sufficient neutron-moderating environment for thermal neutron capture, and the lower neutron fluence of the neutron generator used. It seems that the preferred experimental configuration for imaging and that for elemental assay at low concentrations may be at odds.

a. The macroscopic thermal neutron capture cross section is $\Sigma=(\sigma) / A$ where $\sigma$ is the microscopic thermal capture cross section and $A$ is the atomic number. The ratio with which to scale the LLD of mercury to determine the LLD for silver, for example, is $\Sigma\left(A_{g}\right)\left(P_{A g r}\right) \mathbf{\Sigma}\left(H_{g}\right)\left(P_{H_{t r}}\right)=0.0473$. Therefore, the LLD for silver for a 2,000-second count with the Westinghouse system is deduced to be (115 ppm) $0.0473=2,428 \mathrm{ppm}$. 


\section{CONCLUSIONS AND RECOMMENDATIONS}

It should be obvious from the results of the performance test project that PGNAA provide significant advantages in the assay of RCRA elements present in bulk material and containerized waste. Westinghouse Science and Technology Center, with a score of 142.1 points out of a possible 184.9, received the highest score by a wide margin. Though analyses at free release limits were not the objective of this test and have not been achieved, quantification of RCRA metals at concentration levels useful for waste treatment, process control, and verification either has been demonstrated or shown to be within reach with improvements to the present experimental configuration and analysis methodology.

If PGNAA is to be used for waste assay during cleanup of the DOE complex, it is time for DOE to fund the building of a full-scale demonstration PGNAA facility for full-size 55-gal drums and for the assay of loose waste material. Furthermore, Westinghouse is interested in building or participating in a collaborative effort with a major manufacturer of ionizing radiation measurement instrumentation and systems to build such a facility. This facility could be used to further explore the ability to assay other waste forms and other RCRA elements, improve the sensitivity for detection, and develop advanced methods including modeling for the assay of nonhomogeneous matrixes. PGNAA has the capability to result in the savings of large sums of money by reducing or even eliminating the need for sampling and laboratory analysis. The savings could be realized throughout the waste handling, treatment, and disposal processes if PGNAA is developed to its full potential. 


\section{REFERENCE}

L. A. Currie, 1968, "Limits for Qualitative Detection and Quantitative Determination," Analytical Chemistry, Vol. 40, p. 586. 